Florida International University FIU Digital Commons

$3-27-2014$

\title{
High Pressure and Low Temperature Study of Ammonia Borane and Lithium Amidoborane
}

Shah Najiba

snaji001@fiu.edu

DOI: $10.25148 /$ etd.FI14040899

Follow this and additional works at: https://digitalcommons.fiu.edu/etd

Part of the Other Materials Science and Engineering Commons

\section{Recommended Citation}

Najiba, Shah, "High Pressure and Low Temperature Study of Ammonia Borane and Lithium Amidoborane" (2014). FIU Electronic Theses and Dissertations. 1388.

https://digitalcommons.fiu.edu/etd/1388

This work is brought to you for free and open access by the University Graduate School at FIU Digital Commons. It has been accepted for inclusion in FIU Electronic Theses and Dissertations by an authorized administrator of FIU Digital Commons. For more information, please contact dcc@fiu.edu. 


\section{FLORIDA INTERNATIONAL UNIVERSITY}

Miami, Florida

\section{HIGH PRESSURE AND LOW TEMPERATURE STUDY OF AMMONIA BORANE AND LITHIUM AMIDOBORANE}

A dissertation submitted in partial fulfillment of the requirements for the degree of DOCTOR OF PHILOSOPHY

in

MATERIALS SCIENCE AND ENGINEERING

by

Shah Najiba

2014 
To: Dean Amir Mirmiran

College of Engineering and Computing

This dissertation, written by Shah Najiba, and entitled High Pressure and Low Temperature Study of Ammonia Borane and Lithium Amidoborane, having been approved in respect to style and intellectual content, is referred to you for judgment.

We have read this dissertation and recommend that it be approved.

Wendy L. Mao

Chunlei Wang

Norman D.H. Munroe

Yen-Chih Huang

Jiuhua Chen, Major Professor

Date of Defense: March 27, 2014

The dissertation of Shah Najiba is approved.

Dean Amir Mirmiran

College of Engineering and Computing

Dean Lakshmi N. Reddi

University Graduate School

Florida International University, 2014 
C Copyright 2014 by Shah Najiba All rights reserved. 


\section{DEDICATION}

I dedicate this dissertation to my loving parents for their love, guidance and support. I also dedicate this dissertation to my newborn son Aarib for accompanying me throughout the writing phase of dissertation. I dedicate this dissertation also to my husband Saif for his enormous support and helpful discussion. I also dedicate this dissertation to my five siblings who always encouraged me towards this goal. 


\section{ACKNOWLEDGMENTS}

Firstly I would like to be very much thankful to my major professor Prof. Jiuhua Chen for his advices, support and guidance throughout the dissertation period. I greatly acknowledge him for providing me a lot of opportunities during my dissertation such as to attend many conferences and workshops and to conduct experiment in national synchrotron facilities. The gathered experiences from these opportunities have helped me to broaden my knowledge and reach my goal.

I also would like to thank my dissertation committee members, Dr. Norman D.H. Munroe, Dr. Wendy Mao, Dr. Chunlei Wang and Dr. Yen-Chih Huang, for their suggestions and encouragement at different stages of my dissertation. I also acknowledge

Dr. Surendra K. Saxena for his help and useful discussions about the research. I greatly appreciate Dr. Vadym Drozd for his guidance and help at different stages of the experiments. I thank Dr. Andriy Durygin for making me familiar with the lab instruments. I extend my thanks to all other colleagues at the Center for the Study of Matter at Extreme Conditions (CeSMEC) for their help and support during my graduate study.

I greatly acknowledge the financial support from Florida International University graduate school in the form of doctoral evidence acquisition (DEA) fellowship and dissertation year fellowship (DYF).

Part of this work was performed at HPCAT of Advanced Photon Source (APS), Argonne National Laboratory. HPCAT is supported by DOE-BES, DOE-NNSA, NSF, and the W.M. Keck Foundation. APS is supported by DOE-BES, under Contract No. DE- 
AC02-06CH11357. I also would like to thank the beam line scientist Dr. Stanislav Sinogeikin for helping with experimental setups.

I also would like to acknowledge all great teachers, who inspired me a lot for this goal. I greatly acknowledge the support of my parents. I acknowledge my loving husband Saif for his support and also for his invaluable assistance at various stages of this work. I also thank all of my friends for encouraging me during my graduate study. Lastly, I would like to thank my family members for motivating me to pursue higher studies and being supportive throughout my education. 


\section{ABSTRACT OF THE DISSERTATION \\ HIGH PRESSURE AND LOW TEMPERATURE STUDY OF AMMONIA BORANE \\ AND LITHIUM AMIDOBORANE}

by

Shah Najiba

Florida International University, 2014

Miami, Florida

Professor Jiuhua Chen, Major Professor

Hydrogen has been considered as a potentially efficient and environmentally friendly alternative energy solution. However, one of the most important scientific and technical challenges that the hydrogen economy faces is the development of safe and economically viable on-board hydrogen storage for fuel cell applications, especially to the transportation sector. Ammonia borane $\left(\mathrm{BH}_{3} \mathrm{NH}_{3}\right)$, a solid state hydrogen storage material, possesses exceptionally high hydrogen content (19.6 wt \%). However, a fairly high temperature is required to release all the hydrogen atoms, along with the emission of toxic borazine. Till now the detailed information about the bonding characteristics of $\mathrm{AB}$ is not sufficient to understand details about its phases and structures.

Elemental substitution of ammonia borane produces metal amidoboranes. Lithium amidoborane is synthesized by ball milling of ammonia borane and lithium hydride. During this dissertation, Raman spectroscopic study of lithium amidoborane has been carried out at high pressure in a diamond anvil cell. It has been identified that there is no dihydrogen bond in the lithium amidoborane structure, whereas dihydrogen bond is the characteristic bond of the parent compound ammonia borane. At high pressure up to 15 
GPa, Raman spectroscopic study indicates two phase transformations of lithium amidoborane, whereas synchrotron X-ray diffraction data indicates only one phase transformation.

Pressure and temperature has a significant effect on the structural stability of ammonia borane. This dissertation explored the phase transformation behavior of ammonia borane at high pressure and low temperature using in situ Raman spectroscopy. The P-T phase boundary between the tetragonal $(\mathrm{I} 4 \mathrm{~mm})$ and orthorhombic $\left(P m n 2_{1}\right)$ phases of ammonia borane has a positive Clapeyron slope, which indicates the transition is of exothermic in nature. Influence of nanoconfinemment on the $14 \mathrm{~mm}$ to $P m n 2_{1}$ phase transition of ammonia borane was also investigated. Mesoporus silica scaffolds, SBA-15 and MCM-41, were used to nanoconfine ammonia borane. During cooling down, the I4mm to $P m n 2_{1}$ phase transition was not observed in MCM-41 nanoconfined ammonia borane, whereas SBA-15 nanoconfined ammonia borane shows the phase transition at $\sim 195 \mathrm{~K}$. Four new phases of ammonia borane were also identified at high pressure up to $15 \mathrm{GPa}$ and low temperature down to $90 \mathrm{~K}$. 


\section{ABBREVIATIONS}

DAC

$\mathrm{AB}$

LiAB

SBA

MCM

XRD

$\mathrm{H}_{2}$

$\mathrm{NH}_{3} \mathrm{BH}_{3}$

$\mathrm{LiNH}_{2} \mathrm{BH}_{3}$

$\mathrm{P}$

$\mathrm{T}$

asym.

sym.

def.

St.

V

S

DSC

atm

CsI

$\mathrm{N}$
Diamond Anvil Cell

Ammonia Borane

Lithium Amidoborane

Santa Barbara Amorphous

Mobil Crystalline Materials

X-ray Diffraction

Hydrogen

Ammonia Borane

Lithium Amidoborane

Pressure

Temperature

Asymmetric

Symmetric

Defomation

Stretching

Volume

Entropy

Differential Scanning

Calorimetry

atmospheric

Cesium Iodide

Nitrogen 
B

$\mathrm{Li}$

$\mathrm{NH}_{4} \mathrm{BH}_{4}$

APS
Boron

Lithium

Ammonium Borohydride

Advanced Photon Source 


\section{NOMENCLATURE}

${ }^{\circ} \mathrm{C}$

K

$\mathrm{GPa}$

$\mathrm{cm}^{-1}$

$\mathrm{A}^{\mathrm{o}}$

$w t \%$

$\mathrm{MPa}$

$\mathrm{Pa}$

$\mathrm{nm}$
Celcius

Kelvin

Gigapascal

per centimeter

Angstrom

weight percentage

Megapascal

Pascal

naometer 


\section{TABLE OF CONTENTS}

CHAPTER

PAGE

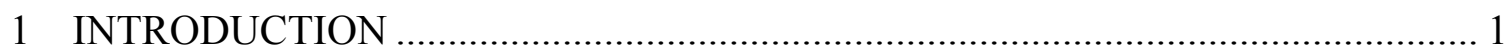

1.1 Hydrogen Energy and Hydrogen Storage Materials ............................................... 1

1.1.1 Hydrogen ............................................................................................. 1

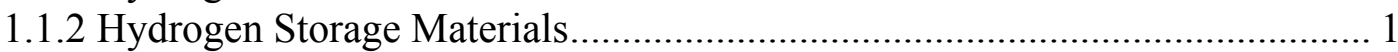

1.1.3 Ammonia Borane and its Derivatives for Hydrogen Storage ........................ 3

1.2 High Pressure Effect ...................................................................................... 4

1.3 High pressure studies of hydrogen storage materials ........................................... 5

1.4 Motivation and Structure of Dissertation......................................................... 12

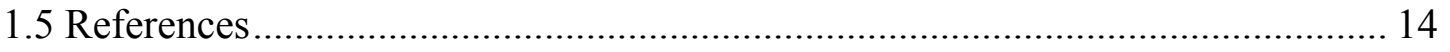

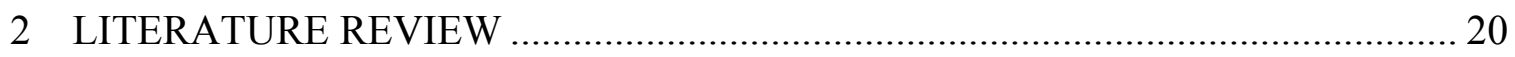

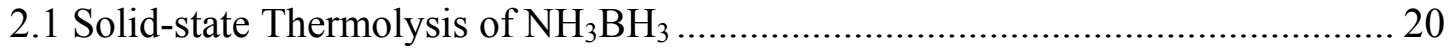

2.2 Strategies for Enhancing $\mathrm{H}_{2}$ Release from Thermolysis of $\mathrm{NH}_{3} \mathrm{BH}_{3} \ldots \ldots \ldots \ldots \ldots \ldots . .23$

2.2.1 Chemical modification of $\mathrm{NH}_{3} \mathrm{BH}_{3}$ : metal amidoboranes .......................... 23

2.2.2 Nano-confinement of $\mathrm{NH}_{3} \mathrm{BH}_{3}$ using scaffolds ........................................... 25

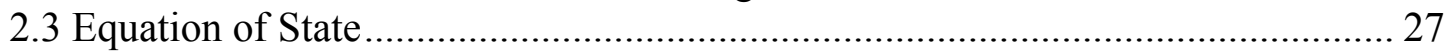

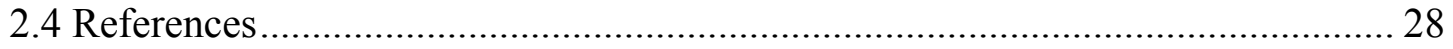

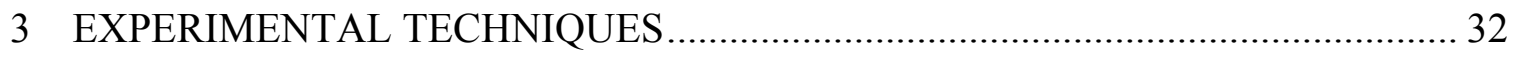

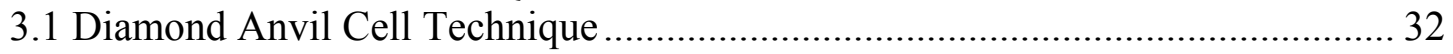

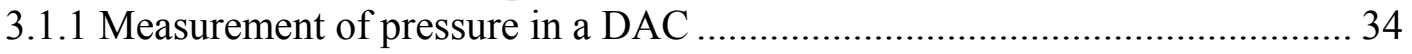

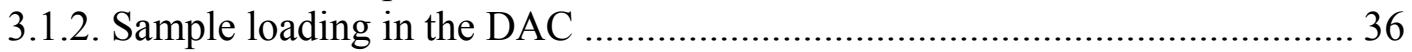

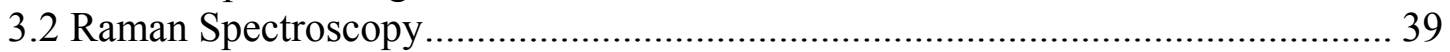

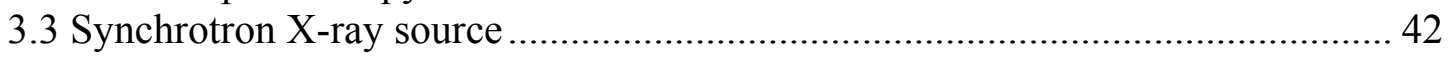

4 HIGH PRESSURE STUDY OF LITHIUM AMIDOBORANE ………………........ 47

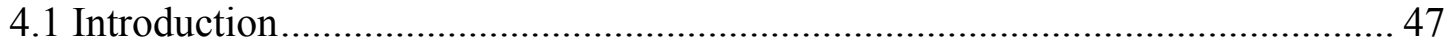

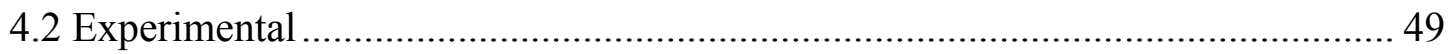

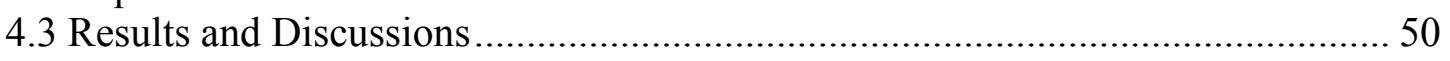

4.4 High pressure study of Lithium Amidoborane using synchrotron X-ray diffraction

.

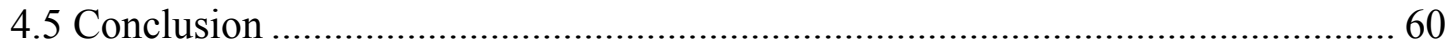

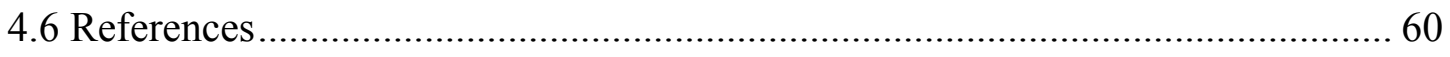

5 PRESSURE INFLUENCE ON THE LOW TEMPERATURE PHASE TRANSITION

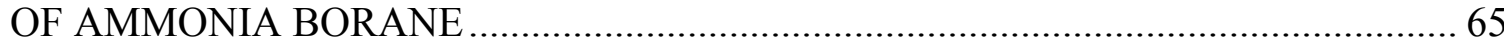

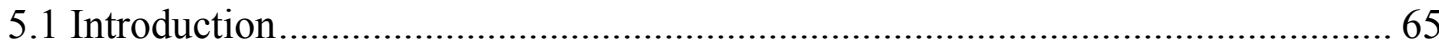

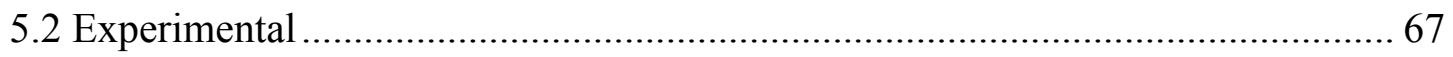

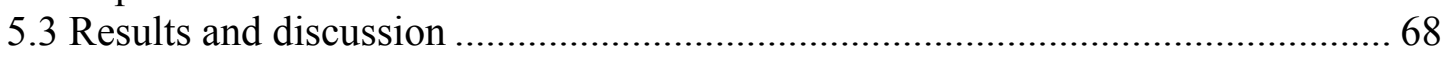

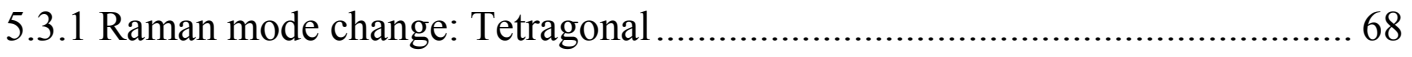

5.3.2 Raman mode change: Orthorhombic............................................................ 70 
5.3.3 Undercooling: presence of an intermediate phase ...................................... 71

5.3.4 P-T phase boundary between $I 4 m m$ and $P m n 2_{1}$ phases ............................. 76

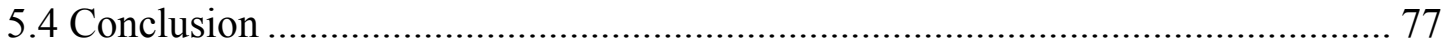

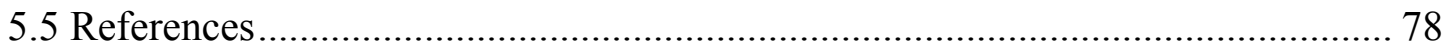

6 NANOCONFINEMENT INFLUENCE ON THE PHASE TRANSITION OF NANOCONFINED AMMONIA BORANE …………..................................................... 81

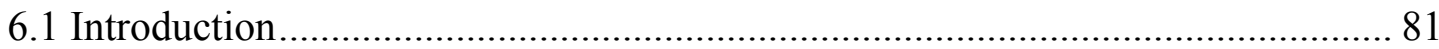

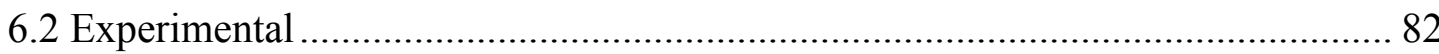

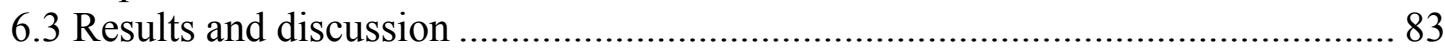

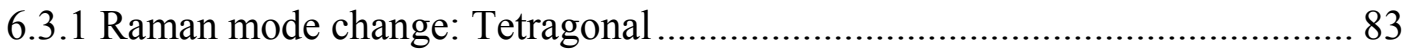

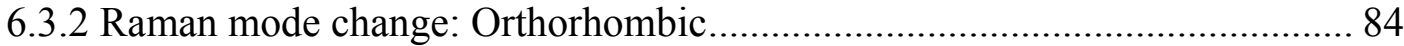

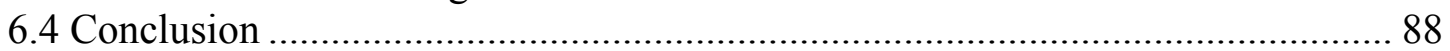

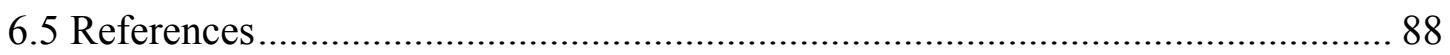

7 PHASE STABILITY OF AMMONIA BORANE AT LOW TEMPERATURE AND

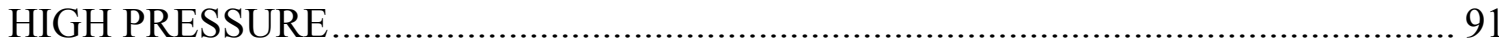

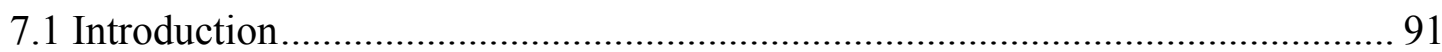

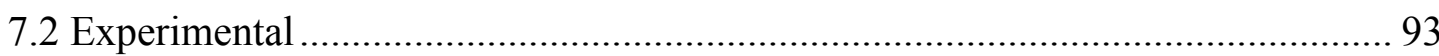

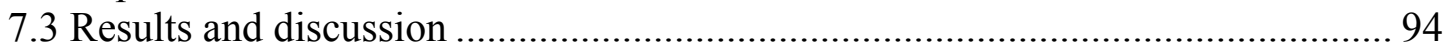

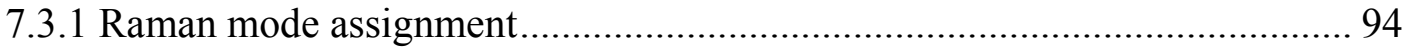

7.3.2 Pressure induced transformation at room temperature................................. 95

7.3.3 Low temperature and high pressure induced phase transitions..................... 97

7.3.3.1 Change of Raman modes during cooling down ...................................... 97

7.3.3.2 Pressure Dependence of Raman Peak Wavenumber............................... 101

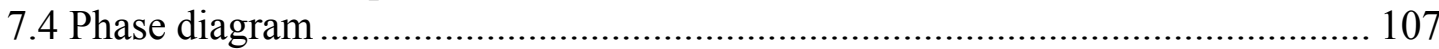

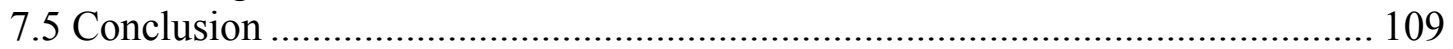

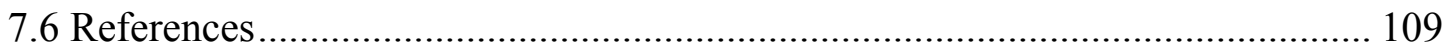

8 SUMMARY AND FUTURE WORK …........................................................ 112

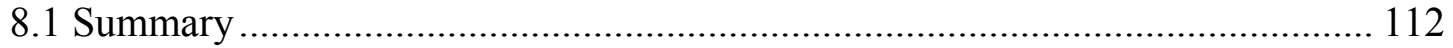

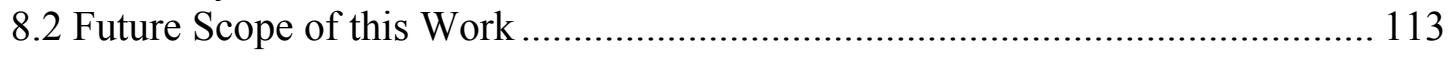

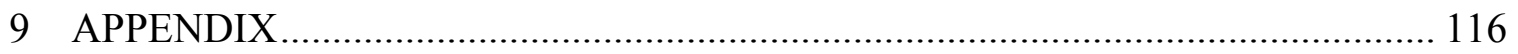

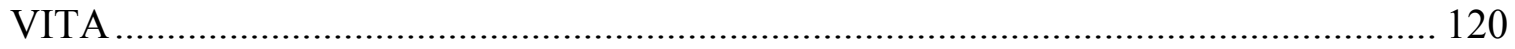




\section{LIST OF FIGURES}

FIGURE

PAGE

Figure 1.1 Gravimetric $\mathrm{H}_{2}$ density (wt\%) plotted against volumetric $\mathrm{H}_{2}$ density (kg $\mathrm{H}_{2} / \mathrm{m}^{3}$ ) for selected representative potential hydrogen storage materials. ........................ 2

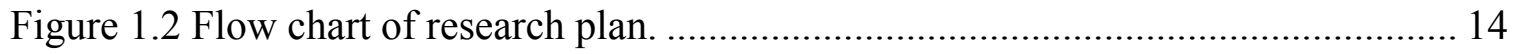

Figure 3.1 Schematic diagram of a DAC. The compressed area is shaded.................... 33

Figure 3.2 Calibration curve of the shift with pressure of the wavelength of the ruby R1

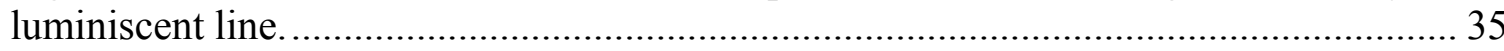

Figure 3.3 Drilling machine for drilling holes in the gaskets using spark erosion method.

Figure 3.4 Raman spectroscopy setup with in situ ruby pressure measurement system at CeSMEC.

Figure 3.5 Aerial photo of the Advanced Photon Source.......................................... 44

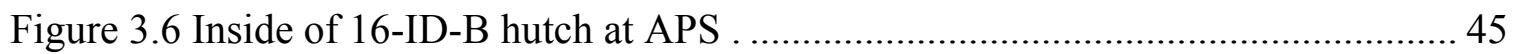

Figure 4.1 Comparison of the major Raman modes of ammonia borane (-) and lithium

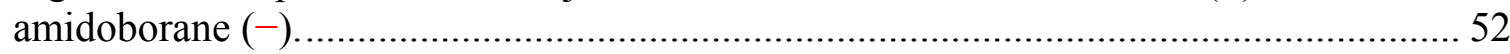

Figure 4.2 Evolution of N-H and B-H stretching modes at high pressure...................... 55

Figure 4.3 Change of photomicrograph of lithium amidoborane in gasket hole associated with the first phase transition.

Figure 4.4 Schematic structure of two molecules of $\mathrm{LiNH}_{2} \mathrm{BH}_{3}$ : (- - -) indicates the

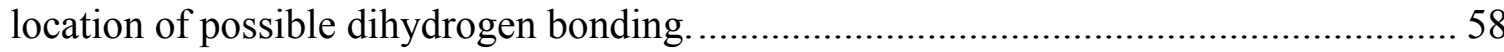

Figure 4.5 Synchrotron X-ray diffraction data of lithium amidoborane at high pressure. 59

Figure 5.1 Selected Raman spectra of $\mathrm{NH}_{3} \mathrm{BH}_{3}$ at different temperature and pressure.... 72

Figure 5.2 Effect of annealing time at the onset transition temperature: selected Raman spectra of $\mathrm{NH}_{3} \mathrm{BH}_{3}$ at different temperature and pressure.

Figure 5.3 Phase boundary between the Tetragonal (I4mm) and Orthorhombic (Pmn2 1 ) phase. 
Figure 6.1 Selected Raman spectra of $\mathrm{NH}_{3} \mathrm{BH}_{3}$ at different temperature in the spectral region of $600 \mathrm{~cm}^{-1}-3400 \mathrm{~cm}^{-1}$.

Figure 6.2 Selected Raman spectra of $\mathrm{NH}_{3} \mathrm{BH}_{3}$ at different temperature in the spectral region of $600 \mathrm{~cm}^{-1}-3400 \mathrm{~cm}^{-1}$ : nanoconfined ammonia borane in MCM-41

Figure 7.1 Raman spectra of $\mathrm{NH}_{3} \mathrm{BH}_{3}$ at different temperature and pressure in the spectral region of (i) $200-1800 \mathrm{~cm}^{-1}$ and (ii) $2260-3400 \mathrm{~cm}^{-1}$; (a) transition of mixed $\mathrm{I} 4 \mathrm{~mm}+\mathrm{Cmc} 2_{1}$ to phase $\mathrm{A}$; (b) transition of $\mathrm{Cmc} 2{ }_{1}$ to phase $\mathrm{B}$; (c) transition of Phase III to phase $\mathrm{C}$; (d) transition of $P 1$ to phase $\mathrm{D}$

Figure 7.2 Changes of Raman spectra of $\mathrm{NH}_{3} \mathrm{BH}_{3}$ with pressure at the temperature of $90 \mathrm{~K}$ temperature in the spectral region of (i) $160-1800 \mathrm{~cm}^{-1}$ and (ii) $2260-3350 \mathrm{~cm}^{-1} .104$

Figure 7.3 Raman shift of different modes of $\mathrm{NH}_{3} \mathrm{BH}_{3}$ with pressure at temperature of $90 \mathrm{~K}$ in the spectral region of (a) N-H Stretching (b) B-H stretching (c) $\mathrm{NH}_{3}$ deformation (d) $\mathrm{BH}_{3}$ deformation (e) $\mathrm{NBH}$ rocking (high frequency and low frequency) (f) B-N stretching and (g) lattice regions. 106

Figure 7.4 Schematic phase diagram of ammonia borane in the low temperature and high pressure region. 


\section{INTRODUCTION}

\subsection{Hydrogen Energy and Hydrogen Storage Materials}

\subsubsection{Hydrogen}

Hydrogen, the third most abundant element on the earth's surface, bears the potential to provide mankind a reliable, clean and affordable energy carrier. Hydrogen gas can be generated from water using renewable energy sources and converts back to water in a combustion or electrochemical process, releasing chemical energy over three times larger than that from fossil fuels on the mass basis [1]. Due to the compelling benefits, hydrogen-based economy is being considered as a solution to the world's energy, climate and environmental problems associated with our current "carbon economy" [1-4]. However, creation of a hydrogen economy faces multiple technical and scientific

challenges. The U.S. Department of Energy (DOE) has set up five key elements of a hydrogen energy system - production, storage, conversion, delivery and application, among which the safe and efficient hydrogen storage on-board a vehicle is widely recognized as the most formidable challenge.

\subsubsection{Hydrogen Storage Materials}

Currently, there are four leading approaches towards the search for a suitable hydrogen storage material [1, 5-14]:

- Physical means (high-pressure tanks),

- Porous solids (carbon materials, organic molecular crystals, metal-organic frameworks etc.),

- Metal hydrides $\left(\mathrm{AlH}_{3}, \mathrm{LiH}, \mathrm{MgH}_{2}, \mathrm{Li}_{3} \mathrm{Be}_{2} \mathrm{H}_{7}, \mathrm{LaNi}_{5} \mathrm{H}_{6}, \mathrm{Mn}_{2} \mathrm{ZrH}_{3.6}, \mathrm{Mg}_{2} \mathrm{NiH}_{6}\right.$, $\mathrm{Y}_{5} \mathrm{Fe}_{23} \mathrm{H}_{20}$, etc.) and 
- Complex and chemical hydrides $\left(\mathrm{NaAlH}_{4}, \mathrm{Li}_{3} \mathrm{Na}_{(}\left(\mathrm{NH}_{2}\right)_{4}, \mathrm{Mg}\left(\mathrm{BH}_{4}\right)_{2}, \mathrm{NaBH}_{4}\right.$, $\mathrm{N}_{2} \mathrm{H}_{4}\left(\mathrm{BH}_{3}\right)_{3}, \mathrm{LiNH}_{2} \mathrm{BH}_{3}, \mathrm{NH}_{4} \mathrm{BH}_{4}, \mathrm{NH}_{3} \mathrm{BH}_{3}$, etc.).

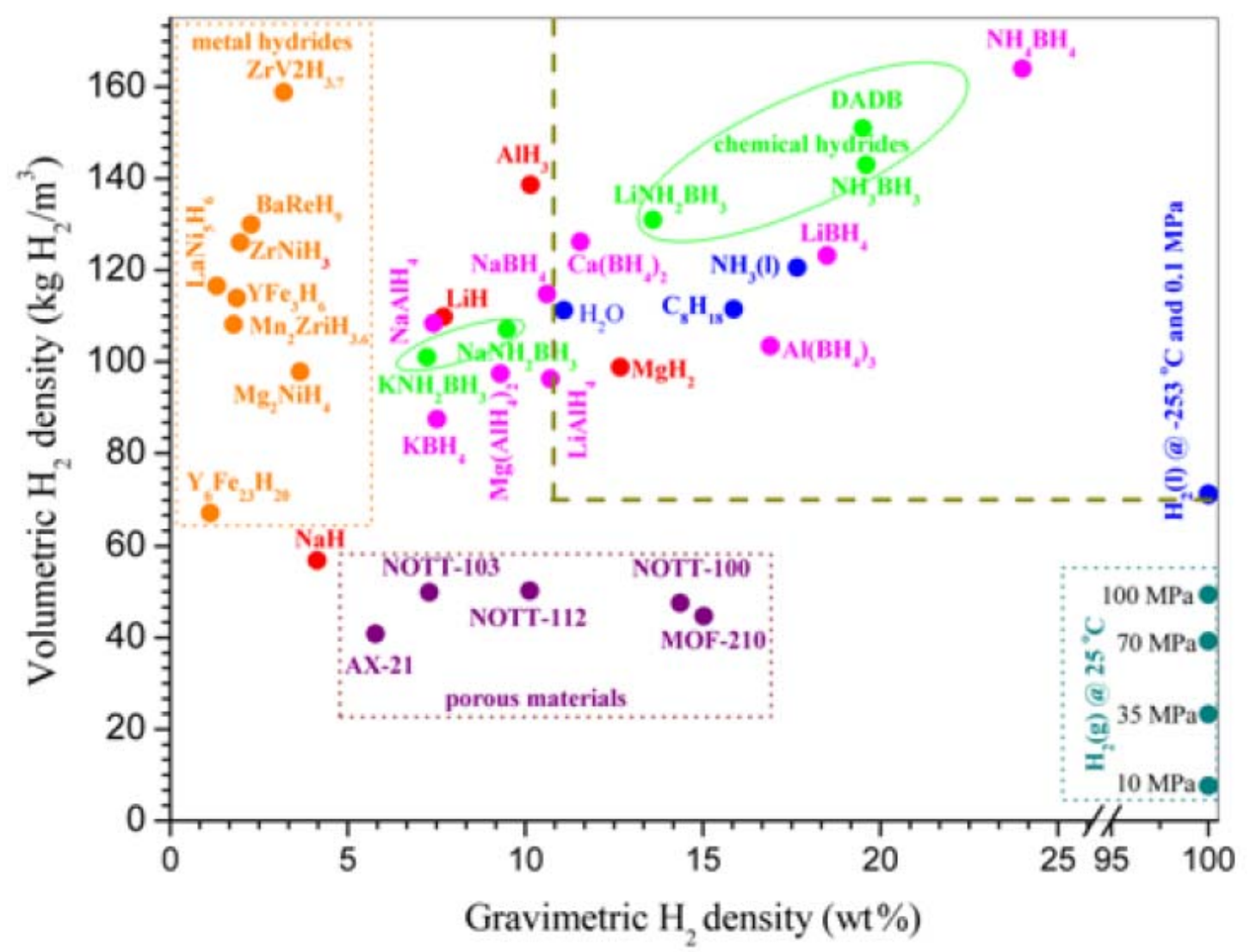

Figure 1.1 Gravimetric $\mathrm{H}_{2}$ density (wt\%) plotted against volumetric $\mathrm{H}_{2}$ density (kg $\mathrm{H}_{2} / \mathrm{m}^{3}$ ) for selected representative potential hydrogen storage materials [Adapted from $15]$.

High pressure hydrogen has a gravimetric density of $100 \mathrm{wt} \%$ and a volumetric density less than $40 \mathrm{Kg} / \mathrm{m}^{3}$ (at pressures up to $70 \mathrm{MPa}$ ). Use of pure $\mathrm{H}_{2}$ is not economical as it requires high pressure gas cylinders that can sustain pressures up to $70 \mathrm{MPa}$, or cryogenic tanks which have to be held at $21 \mathrm{~K}$. In contrast, metal hydrides have 
gravimetric densities below $15 \mathrm{wt} \%$ and volumetric densities ranging from 60 to 160 $\mathrm{Kg} / \mathrm{m}^{3}$. The porous solids and complex and chemical hydrides have gravimetric densities between 4 and $25 \mathrm{wt} \%$ and volumetric densities ranging from 40 to $170 \mathrm{Kg} / \mathrm{m}^{3}$ (Figure $1.1)$.

\subsubsection{Ammonia Borane and its Derivatives for Hydrogen Storage}

Among the various chemical hydrogen storage materials, ammonia borane is undoubtedly in the spotlight of this hot research field. Ammonia borane has several outstanding properties as a promising hydrogen storage material. First, it possesses exceptionally high hydrogen content (gravimetric hydrogen density of $19.6 \mathrm{wt} \%$ and a volumetric hydrogen density of around $145 \mathrm{Kg} / \mathrm{m}^{3}$ ) far exceeding the target set by the U.S Department of Energy and in particular, it contains a unique combination of protonic and hydridic hydrogen, and on this basis, offers new opportunities for developing a practical source for generating molecular dihydrogen [16-19]. In addition, it is a nonflammable and non-explosive white crystalline solid at ambient pressure and temperature [20]. Stepwise release of $\mathrm{H}_{2}$ takes place through thermolysis of ammonia borane, yielding one-third of its total hydrogen content $(6.5 \mathrm{wt} \%)$ in each heating step, along with emission of toxic borazine [21-23]. Many approaches have been developed focusing on how to improve discharge of $\mathrm{H}_{2}$ from ammonia borane including lowering the dehydrogenation temperature and enhancing hydrogen release rate using different techniques, e.g. nanoscaffolds [24], ionic liquids [25], acid catalysis [26], base metal catalyst [27] or transition metal catalysts [28,29]. Till now, the detailed information about bonding characteristics of ammonia borane is not sufficient to understand its dehydrogenation behavior. Recently significant attention is given to chemical 
modification of ammonia borane through substitution of one of the protonic hydrogen atoms with an alkali or alkaline-earth element [30-36]. For instance, lithium amidoborane, a derivative of ammonia borane, can be synthesized by the reaction of lithium hydride and ammonia borane [30-33]. Lithium amidoborane $\left(\mathrm{LiNH}_{2} \mathrm{BH}_{3}\right.$ or LAB), exhibits significantly different and improved dehydrogenation characteristics than its parent compound ammonia borane. It releases more than $10 \mathrm{wt} \%$ of hydrogen at around $90{ }^{\circ} \mathrm{C}$ without borazine emission [20].

Recently, the high pressure technique has been engaged in developing novel hydrogen storage materials and many promising achievements have been gained. In the following section, the high pressure phenomenon will be discussed and more experimental details will be discussed in Chapter 3.

\subsection{High Pressure Effect}

The stability and the reactivity of a chemical system are significantly affected by the application of pressure which is one of the three fundamental thermodynamic parameters. Pressure has a very broad range, from $10^{-32}$ Pascal in intergalactic space to $10^{32}$ Pascal in the center of a neutron star. Nowadays, the anvil technology, which was originally developed by Nobel laureate Percy Bridgman has facilitated the high pressure research in the laboratory. Contribution of Percy Bridgman has led the high pressure research into gigapascal $(\mathrm{GPa})$ region. Now, the maximum static pressure that can be achieved in the laboratory has exceeded $100 \mathrm{GPa}$ scale $\left(1 \mathrm{GPa}=10^{3} \mathrm{MPa}=10^{9} \mathrm{~Pa} \approx 10^{4}\right.$ atm), comparable to the pressure at the Earth's core (330-360 GPa) [37]

Under high pressure materials can be driven to a lower volume state, efficiently shortening the inter-atomic and intra-atomic distance. Consequently, a number of 
interesting phenomena can occur, such as phase transitions, metallization, ionization, polymerization, amorphization and so on [38]. The electronic, optical, magnetic and mechanical properties of materials can be tuned by applying high pressure [38]. In the discovery of superconductors and superhard materials, modern high pressure studies have demonstrated extraordinary breakthroughs. For example, superconducting behavior has been observed in the ionic salt CsI at high pressure and cubic-BN synthesized under high pressure has a comparable hardness to diamond [39,41]. Recently, high pressure scientists have broadened their research horizons on functional materials, including hydrogen storage materials and high energy density materials, which have attracted significant research attention [42-46].

\subsection{High pressure studies of hydrogen storage materials}

The structure, stability, reactivity and reversibility of hydrogen storage materials have fundamental influences on the storage performance. For developing potential hydrogen storage materials, high pressure technique has recently been demonstrated as a simple but effective as well as promising approach which is supplementary to the traditional methods. Under high pressure condition, the structure can be altered, new phases and complexes may be obtained, which has vital implications on improved hydrogen storage performance. High pressure study can also offer a unique opportunity to reveal the atomic, electronic and structural information of potential storage materials, which in turn provides guidance for future design. For these reasons, numerous potential hydrogen storage materials have been intensively studied under high pressure.

The hydrogen containing materials studied by high pressure techniques can be

classified into four groups: (1) simple hydrides (e.g., $\mathrm{LiH}, \mathrm{MgH}_{2}, \mathrm{AlH}_{3}$ ), (2) complex 
hydrides $\left(\mathrm{LiAlH}_{4}, \mathrm{NaBH}_{4}\right)$ (3) chemical hydrides (e.g., $\mathrm{B}_{2} \mathrm{H}_{6}, \mathrm{NH}_{3} \mathrm{BH}_{3}$ ) (4) hydrogen containing complexes $\left(\mathrm{NH}_{3} \mathrm{BH}_{3}-\mathrm{H}_{2}, \quad \mathrm{CH} 4-\mathrm{H}_{2}, \mathrm{H}_{2} \mathrm{O}-\mathrm{H}_{2}\right)$. Various characterization techniques have been used to monitor the high pressure behavior of potential hydrogen storage materials, such as Raman, IR spectroscopy, X-ray diffraction etc. Previous high pressure studies of different hydrogen-rich materials are summarized in Table 1.1 [47].

For instance, $\mathrm{LiAlH}_{4}$ is a complex hydride with a gravimetric hydrogen content of $10.5 \mathrm{wt} \%$. Under ambient conditions, $\mathrm{LiAlH}_{4}$ crystallizes into $\alpha$-phase with a monoclinic structure [48]. Raman spectroscopic study revealed a slow and reversible phase transition from $\alpha$ to $\beta$ was between 2.2 and $3.5 \mathrm{GPa}$ [49]. Subsequently, Chellappa et al. observed that $\beta-\mathrm{LiAlH}_{4}$ has a distorted $\left[\mathrm{AlH}_{4}{ }^{-}\right]$tetrahedron with softened $\mathrm{Al}-\mathrm{H}$ stretching mode [53]. The Al-H bond in $\mathrm{AlH}_{4}{ }^{-}$is considered to have profound influence on the hydrogen release process. The weakening of the Al- $\mathrm{H}$ bond may have important implication for the storage performance.

As another example, as a member of the simple hydride family, $\mathrm{MgH}_{2}$ has been intensively investigated under high pressure, and was found to exhibit various phases in the high pressure region. At around $2 \mathrm{GPa}$, a dramatic transition from $\alpha-\mathrm{MgH}_{2}$ to $\beta-\mathrm{MgH}_{2}$ has been observed [50]. In a subsequent experiment, a $\gamma-\mathrm{MgH}_{2}$ was observed at $3.8 \mathrm{GPa}$ [51]. Recently, the phase diagram of $\mathrm{MgH}_{2}$ has been further updated through theoretical calculation [52]. The strong ionic character of $\mathrm{MgH}_{2}$ has been suggested by both experimental and theoretical research. Thus, it can be predicted that the ionic bond can be weakened by pressure modification, which may improve the dehydrogenation process.

Pressure is an ideal tool to study the molecular crystals that are highly compressible, soft solids, small variations in the applied forces typically result in large 
changes in intermolecular separations, which often promotes dramatic reorganizations of crystal packing. Molecular crystals consist of discrete molecules bonded together by noncovalent intermolecular interactions such as van der Waals, charge transfer, or hydrogen bonds. Due to the unusual combination of strong intramolecular covalent bonds with weak intermolecular forces, molecular crystals exhibit some unexpected properties that are often remarkably different from those of covalent or ionic crystals.

Ammonia borane, a unique molecular solid, consists of $\mathrm{NH}_{3}$ and $\mathrm{BH}_{3}$ building blocks that are bonded together by the intermolecular dihydrogen bonds and the dative B-N bonds (Figure 1.2). The characteristic feature in the structure of ammonia borane is that due to the differing electronegativities of the $\mathrm{B}$ and $\mathrm{N}$ atoms, the hydrogen atoms bonded respectively to $\mathrm{B}$ and $\mathrm{N}$ have different charges. As nitrogen is strongly electronegative, the hydrogen atoms bonded to nitrogen are $\left(\mathrm{H}^{\delta+}\right)$ protonic in character; while boron is less electronegative than hydrogen and thus the hydrogen atoms bonded to boron are $\left(\mathrm{H}^{\delta-}\right)$ hydridic in character. These two hydrogen species form a network of N$\mathrm{H}^{\delta+} \ldots{ }^{-\delta} \mathrm{H}-\mathrm{B}$ dihydrogen bonds which stabilize the structure of $\mathrm{NH}_{3} \mathrm{BH}_{3}$ as molecular solid due to unusually short $\mathrm{H}$...H distances. Thus ammonia borane has much higher melting point $\left(+104{ }^{\circ} \mathrm{C}\right.$ ) compared to the isoelectronic $\mathrm{CH}_{3} \mathrm{CH}_{3}$ (with melting point of $-181{ }^{\circ} \mathrm{C}$ ) gas. Thermal or catalyzed decomposition of ammonia borane requires breaking of the N$\mathrm{H}$ and the B-H bonds. Till now, the detailed information about the bonding characteristics of ammonia borane is not sufficient to understand details about its phases and structures. 


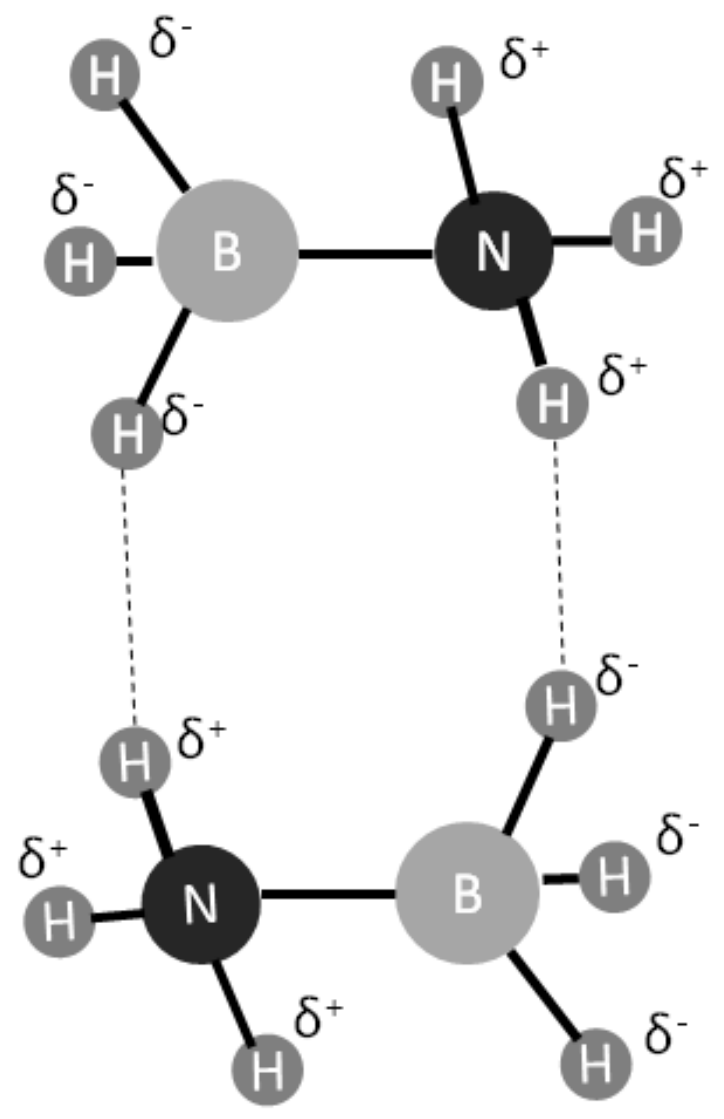

Figure 1.2 Schematic structure of two molecules of $\mathrm{NH}_{3} \mathrm{BH}_{3}:(--)$ indicates the location of dihydrogen bonding.

With excellent advantages such as high hydrogen capacity and stability, ammonia borane $\left(\mathrm{NH}_{3} \mathrm{BH}_{3}\right)$ has been examined and reviewed extensively [54-57]. Pressure and temperature has a significant effect on the structural stability of this molecular solid. In recent years, it has attracted much attention from high pressure scientists. Under ambient conditions, $\mathrm{NH}_{3} \mathrm{BH}_{3}$ crystallizes into a tetragonal structure with the space group $I 4 \mathrm{~mm}$ [54-60] and shows several kind of phase transitions which are induced by pressure. $14 \mathrm{~mm}$ to $\mathrm{Cmc2} 2_{1}$ (orthorhombic) phase transition at room temperature and high pressure is 
reported contradictorily. Two kinds of phase transitions at 0.5 and $1.5 \mathrm{GPa}$ is reported by Trudel and Gilson [61]. Although, Custelcean and Dreger reported that only one phase transition occurs at $0.8 \mathrm{GPa}$, with the delay of some mode splitting until $2.5 \mathrm{GPa}$ [59]. Lin et al. reported three possible phase transitions at 2, 5, and $12 \mathrm{GPa}$ [60]. Xie et al. reported Raman and Infrared (IR) study claiming four possible phase transitions at 2.4, 5.5, 8.5, and 10.5 GPa [62]. Chen et al. reported first order phase transition (I4mm to $\left.C m c 2_{1}\right)$ at 1.3 GPa and second order phase transition at $5 \mathrm{GPa}$ based on x-ray diffraction study [63]. Chen et al. [63] has determined the pressure-temperature phase boundary between the I $4 \mathrm{~mm}$ phase and $\mathrm{Cmc2}_{1}$ phase as negative Clapeyron slope indicating the transformation is of endothermic, although it is not in agreement with the observation of Anderson et al. [64]. Kumar et al. has reported the $\mathrm{I} 4 \mathrm{~mm}$ to $\mathrm{Cmc2} 2_{1}$ phase transition occurring at $1.22 \mathrm{GPa}$ and $\mathrm{Cmc2} 2_{1}$ to $\mathrm{Pl}$ (monoclinic) phase transition occurring at $8 \mathrm{GPa}$ by combined X-ray, Neutron and theoretical investigation [65].

Under high pressure hydrogen-containing complexes, in which hydrogen is encapsulated as guest molecules in the framework constructed by the host molecules (e.g., $\mathrm{CH}_{4}, \mathrm{SiH}_{4}$ and $\mathrm{NH}_{3} \mathrm{BH}_{3}$ ) can be formed [66]. This approach is followed from the pioneering work of Vos et al., who first reported the $\mathrm{H}_{2} \mathrm{O}-\mathrm{H}_{2}$ system under high pressure [67]. Later, other hydrogen containing complexes, such as $\mathrm{CH}_{4}-\mathrm{H}_{2}$ and $\mathrm{NH}_{3} \mathrm{BH}_{3}-\mathrm{H}_{2}$ were investigated. In this approach, most of the host molecules are already hydrogen-rich compounds. Enclosing hydrogen into the hydrogen-rich system under high pressure remarkably improved the hydrogen content, which is desirable for hydrogen storage. It has been reported that under high pressure $\mathrm{NH}_{3} \mathrm{BH}_{3}-\mathrm{H}_{2}$ compound can be formed which can store $8-12 \mathrm{wt} \%$ molecular hydrogen in addition to the chemically bound $\mathrm{H}_{2}$ in 
ammonia borane [46]. Numerous molecular compounds, $\mathrm{CH}_{4}\left(\mathrm{H}_{2}\right)_{2},\left(\mathrm{CH}_{4}\right) 2 \mathrm{H}_{2}, \mathrm{CH}_{4}\left(\mathrm{H}_{2}\right)_{4}$ and $\mathrm{CH}_{4} \mathrm{H}_{2}$ were also investigated under high pressure [68].

Temperature also affects the phase stability of ammonia borane. It transforms from the disordered $I 4 m m$ structure to the ordered orthorhombic $\left(P m n 2_{1}\right)$ structure at the temperature of $\sim 225 \mathrm{~K}[69,70,71,72]$. The transition temperature from disordered tetragonal $(\mathrm{I} 4 \mathrm{~mm})$ structure to the ordered orthorhombic $\left(P m n 2_{1}\right)$ structure increases with pressure, which indicates the Clapeyron slope is positive [73]. The positive Clapeyron slope indicates that the phase transition from $14 \mathrm{~mm}$ and $\mathrm{Cmc}_{1}{ }_{1}$ structure is of exothermic in nature, which is in good agreement with earlier DSC studies [74,75,76]. Recently, it has been reported that ammonia borane embedded in mesoporous silica does not exhibit this low temperature phase transition at $225 \mathrm{~K}[77,78]$. At low temperature and high pressure, the formation of hydrogen clathrate hydrate, $\mathrm{H}_{2}\left(\mathrm{H}_{2} \mathrm{O}\right)_{2}$, which can store $5.3 \mathrm{wt} \%$ $\mathrm{H}_{2}$ and can be preserved to ambient pressure at $77 \mathrm{~K}$ was reported [79]. Najiba et al. [80] investigated the stability of the existing phases and also explored the existence of the possible new phases of ammonia borane at the low temperature and high pressure region. During cooling, the mixed $I 4 m m+C m c 2_{1}$ phase transforms to Phase A [80], which was predicted by Filinchuk et al. [81] and also experimentally observed by Liu et al. [82]. Although, Anderson et al. [83] did not observe this phase transition as they did not continue their experiment at higher pressure and low temperature region where this new phase is stable. Najiba et al. [78] also observed phase B which is evident from the change of Raman modes. This new phase has very narrow temperature and pressure range for stability. Liu et al. [82] did not observe phase B in their experiment, which may be because of the narrow pressure-temperature stability range of this phase. 
Table 1.1 Summary of previous high pressure studies on hydrogen storage materials and systems [Adapted from Ref 47].

\begin{tabular}{|c|c|c|c|c|}
\hline Materials & \begin{tabular}{|l|} 
Hydrogen \\
content
\end{tabular} & Structural information & \begin{tabular}{|l|} 
Pressure \\
range $^{a}($ GPa $)$
\end{tabular} & $\begin{array}{l}\text { Temperature range }{ }^{\mathrm{a}} \\
\text { (K) }\end{array}$ \\
\hline \multicolumn{5}{|l|}{ Simple hydride } \\
\hline $\mathrm{LiH}$ & $12.6 \%$ & $F \mathrm{~m} \overline{3} \mathrm{~m}$ & 250 & room \\
\hline $\mathrm{NaH}$ & $4.2 \%$ & $F \mathrm{~m} \overline{3} \mathrm{~m}(B 1) ; P \mathrm{~m} \overline{3} \mathrm{~m}(B 2)$ & 54 & room \\
\hline $\mathrm{MgH}_{2}$ & $7.6 \%$ & $P 4_{2} / \mathrm{mnm}(\alpha) ; P \mathrm{a} \overline{3}(\beta) ; P \mathrm{bcn}(\gamma) ; P b c a(\delta)$ & 16 & 1070 \\
\hline $\mathrm{CaH}_{2}$ & $4.8 \%$ & $P$ nma; $P 6_{3} / \mathrm{mmc}$ & 42 & room \\
\hline $\mathrm{AlH}_{3}$ & $10.0 \%$ & $R \overline{3} c(\alpha) ; C \operatorname{mcm}\left(\alpha^{\prime}\right) ; F \mathrm{~d} \overline{3} m(\beta) ; P \mathrm{nnm}(\gamma) ; P 2(\alpha-\mathrm{II}) ; P \mathrm{~m} \overline{3} n(\alpha-\mathrm{III})$ & 164 & 4 \\
\hline \multicolumn{5}{|c|}{ Complex hydride } \\
\hline $\mathrm{LiAlH}_{4}$ & $10.5 \%$ & $P 2_{1} / \mathrm{c}(\alpha) ; I 2 / \mathrm{b}(\beta)$ & 7 & 773 \\
\hline $\mathrm{NaAlH}_{4}$ & $7.4 \%$ & $I 4_{1} / \mathrm{a}(\alpha) ; P 2_{1} / \mathrm{c}(\beta)$ & 27 & room \\
\hline $\mathrm{LiBH}_{4}$ & $18.4 \%$ & $P$ nma; $P 6_{3} \mathrm{mc} ; A \mathrm{ma} 2 ; F \mathrm{~m} \overline{3} \mathrm{~m}$ & 10 & 500 \\
\hline $\mathrm{NaBH}_{4}$ & $10.6 \%$ & $F \mathrm{~m} \overline{3} m(\alpha) ; P \overline{4} 2_{1} \mathrm{c}(\beta) ; P$ nma $(\gamma)$ & 30 & $80-673$ \\
\hline $\mathrm{Ca}\left(\mathrm{BH}_{4}\right)_{2}$ & $11.5 \%$ & $F d d d(\alpha) ; P \overline{4}(\beta) ; P b c a(\gamma) ; / \overline{4} 2 d\left(\alpha^{\prime}\right)$ & 10 & 873 \\
\hline $\mathrm{LiNH}_{2}$ & $8.8 \%$ & $I 4(\alpha) ; \mathrm{P} 21(\beta)$ & 28 & room \\
\hline $\mathrm{NaNH}_{2}$ & $5.2 \%$ & Fddd & 16 & room \\
\hline \multicolumn{5}{|c|}{ Chemical hydride } \\
\hline $\mathrm{B}_{2} \mathrm{H}_{6}$ & $22 \%$ & $P 21 / n(\beta)$ & 50 & room \\
\hline $\mathrm{NH}_{3} \mathrm{BH}_{3}$ & $19 \%$ & I4mm; Pmn21; Cmc21; P21 & 65 & $15-350$ \\
\hline \multicolumn{5}{|c|}{ H2 containing complex } \\
\hline $\mathrm{CH}_{4}-\mathrm{H}_{2}$ & $50 \%$ & $\mathrm{CH}_{4}\left(\mathrm{H}_{2}\right)_{2} ;(\mathrm{CH} 4)_{2} \mathrm{H}_{2} ; \mathrm{CH}_{4}\left(\mathrm{H}_{2}\right)_{4} ; \mathrm{CH}_{4} \mathrm{H}_{2}$ & 60 & 10 \\
\hline $\mathrm{H}_{2} \mathrm{O}-\mathrm{H}_{2}$ & $20 \%$ & $\mathrm{C} 1 ; \mathrm{C} 2 ; \mathrm{sII}$ & 80 & $10-450$ \\
\hline $\mathrm{NH}_{3} \mathrm{BH}_{3}-\mathrm{H}_{2}$ & $29 \%$ & $\mathrm{NH}_{3} \mathrm{BH}_{3}\left(\mathrm{H}_{2}\right) \mathrm{x} \mathrm{x}=1.3-2$ & 60 & 413 \\
\hline $\mathrm{Ar}-\mathrm{H}_{2} \& \mathrm{Xe}-\mathrm{H}_{2}$ & $9 \% \& 9.7 \%$ & $\operatorname{Ar}\left(\mathrm{H}_{2}\right)_{2}-P 6_{3} / \mathrm{mmc} ; \mathrm{Xe}\left(\mathrm{H}_{2}\right)_{7}-R 3$ & $200 \& 255$ & room \\
\hline
\end{tabular}

${ }^{a}$ For pressure, the range goes from ambient to the given value; for temperature, "room" refers to $298 \mathrm{~K}$, the value refers to either the maximum or the minimum

or to a range of temperature under which the materials were investigated under simultaneous high pressure conditions. 


\subsection{Motivation and Structure of Dissertation}

As discussed above, although ammonia borane is regarded as a promising hydrogen storage material, there are still several prominent problems such as high onset dehydrogenation temperature and release of borazine, which limits its practical applications. Thus, more research interests are focusing on investigations of ammonia borane derivatives in the hope of finding a more suitable hydrogen storage material, and gaining enlightenments for the design of novel materials in the future. Many ammonia borane derivatives, such as $\mathrm{LiNH}_{2} \mathrm{BH}_{3}$, have recently been investigated extensively under ambient conditions, with respect to structure, stability and dehydrogenation mechanism. However, few high pressure studies of ammonia borane derivatives have been reported. In my dissertation, ammonia borane derivative, $\mathrm{LiNH}_{2} \mathrm{BH}_{3}$, was selected to be experimented for high pressure studies of their structures and properties by Raman and X-ray diffraction, which may extend our knowledge and shed light on the future design. Moreover, this study can contribute to finding a novel phase which may have vital implications for improved hydrogen storage performance.

Phase transition of ammonia borane at low temperature and high pressure has also been explored during this dissertation. $\mathrm{NH}_{4} \mathrm{BH}_{4}$ is a promising candidate for hydrogen storage with the highest hydrogen content $(24.5 \mathrm{wt} \%)$. But $\mathrm{NH}_{4} \mathrm{BH}_{4}$ exists only at low temperature and it decomposes to ammonia borane and hydrogen above $-40^{\circ} \mathrm{C}$. Another motivation of this dissertation is to establish the phase diagram of ammonia borane at low temperature and high pressure region to search for new phases. The observed new phases of ammonia borane may be reacted with hydrogen in future research, which may form new phases of $\mathrm{NH}_{4} \mathrm{BH}_{4}$. New phase of $\mathrm{NH}_{4} \mathrm{BH}_{4}$ may be stable at ambient temperature 
and open up a new era in hydrogen storage research field. Many of the observed new phases may also have high hydrogen content.

The layout of the dissertation is divided into different chapters that include literature review, experimental procedures, experimental results and discussions, summary and recommendations for future research. Chapter 2 describes the literature review of previous study. Chapter 3 describes the experimental techniques used for the study. Chapter 4 describes the high pressure study of lithium amidoborane. Chapter 5 describes the effect of pressure on the low temperature phase transition of ammonia borane. Chapter 6 describes the effect of nanoconfinement on the low temperature phase transition of ammonia borane. Chapter 7 describes the phase stability of ammonia borane at low temperature and high pressure extended to $15 \mathrm{GPa}$. Chapter 8 describes the summary and recommendations for future work. The first pages of the publications resulting from the research of this dissertation are included in the appendix. Vita is included at the end. Figure 1.2 represents the summary of the research carried out during this dissertation. 


\section{High Pressure and Low Temperature Study of Ammonia Borane and Lithium Amidoborane}

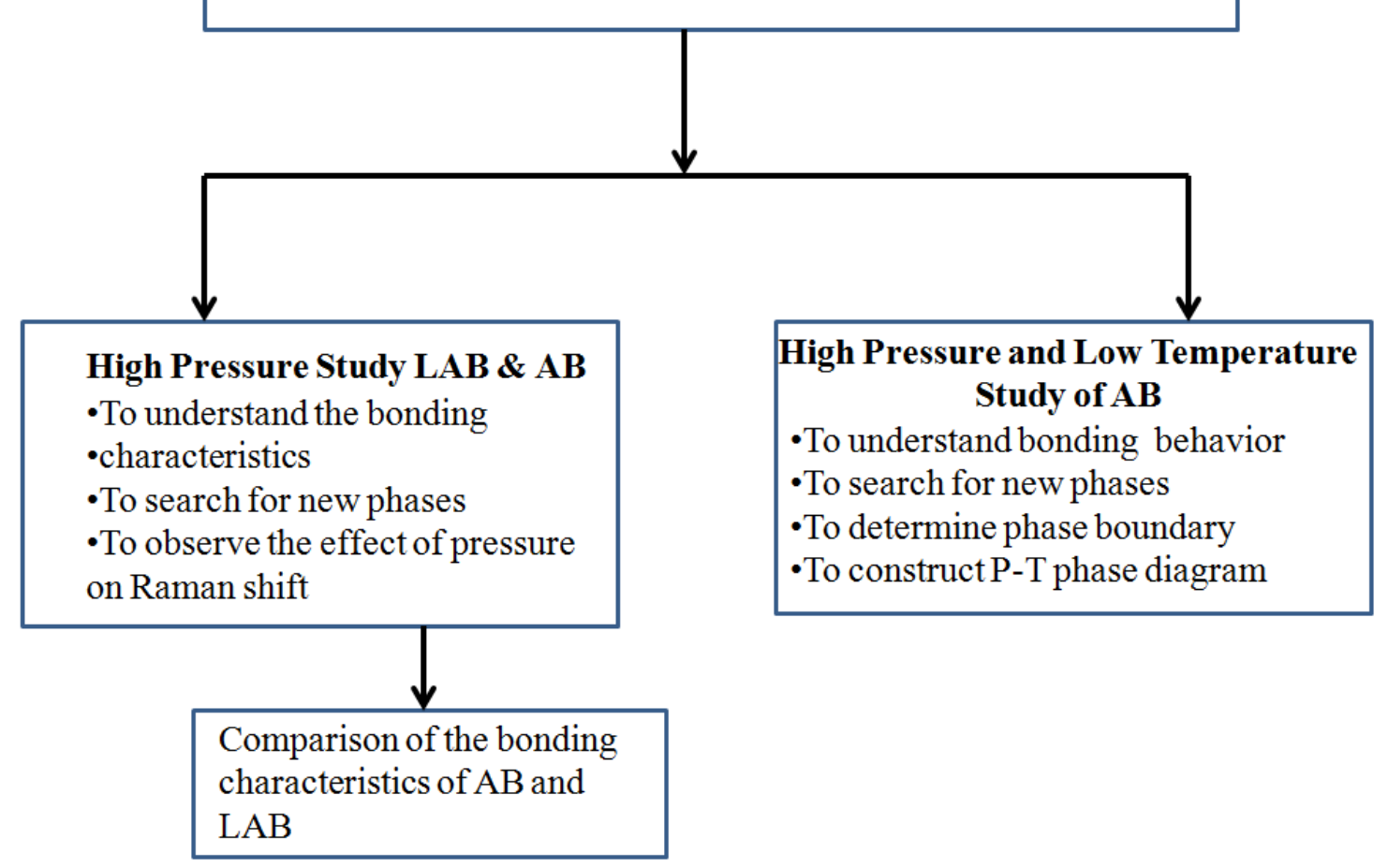

Figure 1.2 Flow chart of research plan.

\subsection{References}

[1] L. Schlapbach and A. Züttel, Nature, 2001, 414, 353-358.

[2] G. W. Crabtree, M. S. Dresselhaus and M. V. Buchanan, Phys. Today, 2004, 57, $39-44$.

[3] K. V. Kordesch and G. R. Simader, Chem. Rev., 1995, 95, 191-207.

[4] J. Tollefson, Nature, 2010, 464, 1262-1264.

[5] A.C. Dillon, K. M. Jones, T. A. Bekkehdahl, C. H. Klang, D. S. Bethune and M. J. Heben, Nature, 386, 377 (1997).

[6] C. Dillon and M. J. Heben, Appl. Phys. A, 72, 133 (2001).

[7] N. L. Rosi, J. Eckert, M. Eddaoudi, D. T. Vodak, J. Kim, M. O'Keeffe and O. M. Yaghi, Science, 300, 1127 (2003).

[8] W. Grochala and P. P. Edwards, Chem. Rev., 104, 1283 (2004). 
[9] J. L. C. Rowsell and O.M. Yaghi, Angew. Chem. Int. Ed., 44, 4670 (2005).

[10] A. Karkamkar, S. M. Kathmann, G. K. Schenter, D. J. Heldebrant, N. Hess, M. Gutowski and T. Autrey, Chem. Mater., 21, 4356 (2009).

[11] T. Hügle, M. F. Kühnel and D. Lentz, J. Am. Chem. Soc., 131, 7444 (2009).

[12] W. I. F. David, Faraday Discuss., 151, 399 (2011).

[13] P. Jena, J. Phy. Chem. Lett., 2, 206 (2011).

[14] A. Staubitz, A. P.M. Robertson and I. Manners, Chem. Rev., 110, 4079 (2010).

[15] J. Zhang, J.W. Lee, Korean J. Chem. Eng. 29, 421 (2012)

[16] P. Chen, and M. Zhu, Mater. Today 11, 36 (2008).

[17] J. Graetz, Chem. Soc. Rev. 38, 73 (2009).

[18] J. Irvine, J. Mater. Chem. 18, 2295 (2008).

[19] M. Felderhoff, C. Weidenthaler, von Helmolt R, and U. Eberle, Phys. Chem. Chem. Phys. 9, 2643 (2007).

[20] Z. Xiong, C.K. Yong, G. Wu, P. Chen, W. Shaw, A. Karkamkar, T. Autrey, M.O. Jones, S.R. Johnson, P.P. Edwards, W.I.F. David, Nat. Mater.7, 138 (2008).

[21] M. Bowden, T. Autrey, I. Brown, and M. Ryan, Curr. Appl. Phys. 8, 498 (2008).

[22] F. Baitalow, J. Baumann, G. Wolf, K. Jaenicke-Ro“ssler, and G. Leitner, Thermochim. Acta 391, 159 (2002).

[23] G. Wolf, J. Baumann, F. Baitalow, and F. P. Hoffmann, Thermochim. Acta 343, 19 (2000).

[24] A. Gutowska, L. Li, Y. Shin, C. M. Wang, X. S. Li, J. C. Linehan, R. S. Smith, B. D. Kay, B. Schmid, W. Shaw, M. Gutowski, and T. Autrey, Angew. Chem., Int. Ed. 44, 3578 (2005).

[25] M. E. Bluhm, M. G. Bradley, R. Butterick, U. Kusari, and L. G. Sneddon, J. Am. Chem. Soc. 128, 7748 (2006).

[26] F. H. Stephens, R. T. Baker, M. H. Matus, D. J. Grant, and D. A. Dixon, Angew. Chem., Int. Ed. 46, 746 (2007). 
[27] R.J. Keaton, J.M. Blacquiere, and R.T. Baker, J. Am. Chem. Soc.129, 1844 (2007).

[28] C. A. Jaska, K. Temple, A. J. Lough, and I. Manners, J. Am. Chem. Soc. 125, 9424 (2003).

[29] C.W. Hamilton, R.T. Baker, A. Staubitz A, and I. Manners, Chem. Soc. Rev. 38(1):279 (2009).

[30] Z. Xiong, et al. Nat. Mater. 7, 138 (2008).

[31] X. Kang X, et al. Adv. Mater., 20, 2756(2008).

[32] Y.S. Chua, P. Chen, G. Wu, Z. Xiong (2011), Chem. Commun. (Camb.) 47, 5116 (2011).

[33] H. Wu, W. Zhou, T. Yildirim (2008), J. Am. Chem. Soc. 130, 14834 (2008).

[34] H. V. K. Diyabalanage, et al. Angew Chem. Int. Ed. 46, 8995 (2007).

[35] H.V.K. Diyabalanage, et al., J. Am. Chem. Soc. 132, 11836 (2010).

[36] Z. Xiong, et al. Energy Environ. Sci. 1, 360 (2008).

[37] C.E. Weir, E.R. Lippincott, A. Vanvalkenburg, and E.N. Bunting, J. Res. Nbs. a Phys. Ch.63 1959, 55 (1959).

[38] W. Grochala, R. Hoffmann, J. Feng, and N.W. Ashcroft, Angew. Chem. Int. Ed. 46, 3620 (2007).

[39] R.J. Hemley, and H.K. Mao, Aip. Conf. Proc.706, 17 (2004).

[40] P.F. McMillan, Nat. Mater., 1, 19 (2002).

[41] M.I. Eremets, K. Shimizu, T.C. Kobayashi, and K. Amaya, J. Phys.: Condens. Matter 10, 11519 (1998).

[42] Y. Song, and M.R. Manaa, J. Chem. Phys. C 116, 2059 (2012).

[43] G. Vaitheeswaran, and K.R. Babu, J. Chem. Sci.124, 1391 (2012).

[44] S. Najiba, and J. Chen, Proc. Natl. Acad. Sci. U.S. A. 109, 19140 (2012).

[45] A. Liu, and Y. Song, J. Phys. Chem. C 116, 2123 (2012). 
[46] Y. Lin, W.L. Mao, and H. K. Mao, Proc. Natl. Acad. Sci. U.S. A.106, 8113 (2009).

[47] Y. Song, Phys.Chem. Chem. Phys. 15, 14524 (2013).

[48] B.C. Hauback, H.W. Brinks, and H. Fjellvag, H. J. Alloy Compd. 346, 184 (2002).

[49] A.V. Talyzin, B. Sundqvist, Phys. Rev. B 70 (2004).

[50] M. Bortz, B. Bertheville, G. Bottger, K. Yvon, J. Alloy Compd. 287, L4 (1999).

[51] P. Vajeeston, P. Ravindran, B.C. Hauback, H. Fjellvag, A. Kjekshus, S. Furuseth, M. Hanfland, Phys. Rev. B 73 (2006).

[52] D. Moser, G. Baldissin, D.J. Bull, D.J. Riley, I. Morrison, D.K. Ross, W.A. Oates, and D. Noreus, J. Phys.: Condens. Matter 23 (2011).

[53] R.S. Chellappa, D. Chandra, S.A. Gramsch, R.J. Hemley, J.F. Lin, and Y. Song, J. Phys. Chem. B 110, 11088 (2006).

[54] K. Yamauchi, I. Hamada, H.B. Huang, and T. Oguchi, Appl. Phys. Lett., 99 (2011).

[55] Y.F. Liang, and J.S. Tse, J. Phys. Chem. C 116, 2146 (2012).

[56] T.B. Marder, Angew. Chem. Int. Ed. 46, 8116 (2007).

[57] C.W. Hamilton, R.T. Baker, A. Staubitz, I. Manners, I. Chem. Soc. Rev. 38, 279 (2009).

[58] M.E. Bowden, G.J. Gainsford, W.T. Robinson, Aust. J. Chem. 60, 149 (2007).

[59] R. Custelcean and Z. A. Dreger, J. Phys. Chem. B 107, 9231(2003).

[60] Y. Lin, W. L. Mao, Vadym Drozd, J. Chen, and L. L. Daemen, J. Chem. Phys. 129, 234509 (2008).

[61] S. Trudel and D. F. R. Gilson, Inorg. Chem. 42, 2814 (2003).

[62] S. Xie, Y. Song, and Z. Liu, Can. J. Chem. 87, 1235 (2009).

[63] J. Chen, H. Couvy, H. Liu, Vadym Drozd, L. L. Daemen, Y. Zhao, C.-C. Kao, Int. J. Hydrogen Energy 35, 11064 (2010). 
[64] O. Anderson, Y. Filinchuk, V. Dmitriev, I. Quwar, A. V. Talyzin, and B. Sundqvist, Phys. Rev. B 84, 024115 (2011).

[65] R.S. Kumar, K. Xuezhi, J. Zhang, Z. Lin, S.C. Vogel, M. Hartl, et al. Chem. Phys. Lett. 495, 203 ( 2010).

[66] V.V. Struzhkin, B. Militzer, W.L. Mao, H.K. Mao, R.J. Hemley, Chem. Rev. 107, 4133 (2007).

[67] W.L. Vos, L.W. Finger, R.J. Hemley, and H.K. Mao, Phys. Rev. Lett. 71, 3150 (1993).

[68] M.S. Somayazulu, L.W. Finger, R.J. Hemley, and H.K. Mao, Science 271, 1400 (1996).

[69] C. F. Hoon and E. C. Reynhardt, J. Phys. C 16, 6129 (1983).

[70] M. E. Bowden, G. J. Gainsford, and W. T. Robinson, Aust. J. Chem. 60, 149 (2007).

[71] R.S. Kumar, K. Xuezhi, J. Zhang, Z. Lin, S.C. Vogel, M. Hartl, et al. Chem. Phys. Lett. 495, 203 ( 2010).

[72] N. J. Hess, M. E. Bowden, V. M. Parvanov, C. Mundy, S. M. Kathmann, G. K. Schenter, and T. Autrey, J. Chem. Phys. 128, 034508 (2008)

[73] S. Najiba, J. Chen, V. Drozd, A. Durygin, and Y. Sun, J. Appl. Phys. 111, 112618 (2012).

[74] G. Wolf, J.C. van Miltenburg and U. Wolf, Thermochimica Acta 317, 111 (1998).

[75] O. Palumbo, A. Paolone, P. Rispoli, R. Cantelli, T. Autrey, and M. A. Navarra, J. Alloys Compd. 509S, S709 (2011).

[76] W. J. James, L. Jagat, Q. Cai, W. B. Yelon, and J. B. Yang, Mater. Sci. Forum 610613,425 (2009).

[77] H. Kim, A. Karkamkar, T. Autrey, P. Chupas, and T. Proffen, J. Am. Chem. Soc. 131, 13749 (2009).

[78] A. Paolone, O. Palumbo, P. Rispoli, R. Cantelli, T. Autrey, and A. Karkamkar, J. Phys. Chem. C 113, 10319 (2009).

[79] W.L. Mao, and H.K. Mao, Proc. Natl. Acad. Sci. 101, 708 (2004). 
[80] S. Najiba, J. Chen, V. Drozd, A. Durygin and Y. Sun, Int. J. Hydrogen Energy 38, 4628 (2013).

[81] Y. Filinchuk, A.H. Nevidomskyy, D. Chernyshov, and V. Dmitriev, Phys. Rev. B 79, 214111 (2009).

[82] A. Liu, and Y. Song, J. Phys. Chem. C 116, 2123 (2012).

[83] O. Anderson, Y. Filinchuk, V. Dmitriev, I. Quwar, A. V. Talyzin, and B. Sundqvist, Phys. Rev. B 84, 024115 (2011). 


\section{LITERATURE REVIEW}

A hydrogen storage system should release $\mathrm{H}_{2}$ at low temperature with wide range of operation, high volumetric density and mass density. The system should also have rapid hydrogenation/dehydrogenation rates, high resistance to oxidation, high capacity, low cost, good reversibility, fast reactivity and sustainability. Main issues of hydrogen storage systems are weight, volume, cost, safety, efficiency, refueling time and durability. The U.S. DOE has set specified performance targets of hydrogen storage materials for a successful transition to hydrogen-fueled transportation by 2015 .

- $\mathrm{H}_{2}$ storage capacity: $9.0 \mathrm{wt} \%$

- Specific energy: $10.8 \mathrm{MJ} / \mathrm{kg}$

- Energy density: $9.72 \mathrm{MJ} / \mathrm{L}$

- Operating temperature: -20 to $50^{\circ} \mathrm{C}$

- Refueling rate: $2 \mathrm{~kg} \mathrm{H}_{2} / \mathrm{min}$

- Cycle life-time (absorption/desorption cycles): 1500 times

- System cost: US $\$ 3 / \mathrm{kg} / \mathrm{system}$

The transport sector requires not only cheap, safe and reliable way of storing hydrogen but also high storage capacity, fast kinetics and favorable thermodynamics. A potential hydrogen storage material which meets all the above mentioned criteria, is yet to be discovered. One of the high-priority goals of the DOE is "finding effective hydrogen storage materials".

\subsection{Solid-state Thermolysis of $\mathrm{NH}_{3} \mathrm{BH}_{3}$}

Ammonia borane, a unique molecular solid, consists of $\mathrm{NH}_{3}$ and $\mathrm{BH}_{3}$ building blocks that are bonded together by the intermolecular dihydrogen bonds and the dative 
B-N bonds [1,2]. All bonded hydrogen of AB can be released via three step decomposition reaction through thermolysis, as outlined in Eq.1 $[3,4]$.

$\mathrm{NH}_{3} \mathrm{BH}_{3}=\mathrm{NH}_{2} \mathrm{BH}_{2}+\mathrm{H}_{2}$ at about $100{ }^{\circ} \mathrm{C}$

$\mathrm{NH}_{2} \mathrm{BH}_{2}=\mathrm{NHBH}+\mathrm{H}_{2}$ at about $160{ }^{\circ} \mathrm{C}$

$\mathrm{NHBH}=\mathrm{BN}+\mathrm{H}_{2}$ at about $500{ }^{\circ} \mathrm{C}$

In each step, one-third of its total hydrogen content $(6.5 \mathrm{wt} \%)$ is released. Since the third thermal decomposition step requires high temperature [3], $\mathrm{AB}$ may practically release only $\sim 2$ equivalents of $\mathrm{H}_{2}$, corresponding to $13 \mathrm{wt} \%$, for solid-state hydrogen storage. The thermolysis of $\mathrm{AB}$ has several serious problems that hinder its application for hydrogen storage:

- The decomposition of $\mathrm{AB}$ is very rapid above its melting point at $\sim 105^{\circ} \mathrm{C}$, but its solid-state decomposition below the melting point is very slow and involves a long induction period. Kinetic problem is also encountered in the second decomposition step.

- Another major problem of the thermolysis process is that the hydrogen output is contaminated with impurity. The released $\mathrm{H}_{2}$ from $\mathrm{AB}$ is generally accompanied with the evolution of volatile by-products, e.g. borazine $[\mathrm{BHNH}]_{3}$, aminoborane $\left[\mathrm{BH}_{2} \mathrm{NH}_{2}\right]$, diborane $\left[\mathrm{B}_{2} \mathrm{H}_{6}\right]$, and aminodiborane $\left[\mathrm{BH}_{2} \mathrm{NH}_{2} \mathrm{BH}_{3}\right][3,4,5]$. The product distribution also considerably depends on the external pressure and temperature variables. For instance, a higher ramping rate during heating is always associated with higher yield of volatile byproducts [4b].

- The third and probably the most significant problem is the exothermic nature of the thermolysis reaction. Wolf and coworkers have experimentally determined the 
enthalpy changes of the first and second dehydrogenation steps to be around -21.7 and -14 to $-21.7 \mathrm{~kJ} \mathrm{~mol}^{-1} \mathrm{H}_{2}$, respectively [4a,c] which also agree with the computational results by Miranda and Ceder [4f]. As both the enthalpy and entropy changes of the dehydrogenation reaction contribute to the lowering of free energy, it is thermodynamically unfavorable to regenerate $\mathrm{AB}$ from the spent fuel via solid-gas reaction. This necessitates the development of advanced regeneration technology to make $\mathrm{AB}$ a competitive and affordable $\mathrm{H}_{2}$ carrier.

The protonic and hydridic hydrogen of $\mathrm{AB}$ combines to form molecular hydrogen. This thermodynamically favorable reaction does not proceed straightforwardly in the pristine $\mathrm{AB}$. Rather it involves complex physical and chemical transformations that can be described by an induction, nucleation and growth mechanism [6-9]. Localized disruption of the dihydrogen bonding network occurs first during the heating of $\mathrm{AB}$ at elevated temperatures resulting in an irreversible phase transformation. In the newly formed $\mathrm{AB}^{*}$ phase, the intermolecular interactions become weaker and thus molecular mobility increases. The flexible molecular geometry facilitates the conversion of the $\mathrm{AB}^{*}$ phase to the diammoniate of diborane (DADB, $\left[\left(\mathrm{NH}_{3}\right)_{2} \mathrm{BH}^{2+}\right]\left[\mathrm{BH}^{4-}\right]$ ). Due to the increased reactivity of $\mathrm{DADB}$ compared to its isomer $\mathrm{AB}$, the reaction between $\mathrm{AB}$ and DADB dominate the subsequent growth stage, leading to $\mathrm{H}_{2}$ release and the formation of $\left[\mathrm{NH}_{2} \mathrm{BH}_{2}\right]_{\mathrm{n}}$. Formation of DADB from two $\mathrm{AB}$ monomers involves a moderate energy barrier and the barrier for $\mathrm{H}_{2}$ release from DADB is just around $84 \mathrm{~kJ} \mathrm{~mol}^{-1}$, less than half of those of the direct pathways for $\mathrm{H}_{2}$ elimination from $(\mathrm{AB})_{2}$ dimer [10]. According to this molecular mechanism, dihydrogen bonds play a critical role in the dehydrogenation reaction $[11,12,13]$. Better understanding of the nature of the 
dihydrogen bond network therefore becomes a central issue in the study of physical and chemical transformations of $\mathrm{AB}$ and necessitates more studies.

\subsection{Strategies for Enhancing $\mathrm{H}_{2}$ Release from Thermolysis of $\mathrm{NH}_{3} \mathrm{BH}_{3}$}

Among the different ways of $\mathrm{H}_{2}$ release from $\mathrm{AB}$, thermal decomposition is probably the most potential way for practical hydrogen storage applications. This is because the thermolysis of $\mathrm{AB}$ involves moderate reaction exothermicity, the high hydrogen capacity, as well as the minimized system requirements for handling the solid fuel. But to make it feasible, the kinetic problem and the undesired evolution of volatile by-products during the thermal decomposition process of $\mathrm{AB}$ must be resolved. In this regard, several strategies have been recently approached and proved to be effective in improving the thermally assisted hydrogen release from $\mathrm{AB}$.

\subsubsection{Chemical modification of $\mathrm{NH}_{3} \mathrm{BH}_{3}$ : metal amidoboranes}

Hydrogen storage properties of hydride materials can be tuned by the conventional strategy 'element substitution'. Application of this strategy in AB has yielded a new class of promising chemical hydrides, metal amidoboranes $\left(\mathrm{M}\left(\mathrm{NH}_{2} \mathrm{BH}_{3}\right)_{\mathrm{n}}\right.$, where $\mathrm{n}$ denotes the valence state of $\mathrm{M}$ cation). Metal amidoboranes are a subclass of amine-boranes, where one of the acidic protons on nitrogen has been substituted by a metal. Alkali or alkaline earth metal amidoboranes have been synthesized by the stoichiometric reactions of $\mathrm{AB}$ with corresponding metal hydrides, in a mechanochemical or wet chemical process as described in Eq.2 [14-23].

$$
\mathrm{nNH}_{3} \mathrm{BH}_{3}+\mathrm{MH}_{\mathrm{n}} \rightarrow \mathrm{M}\left(\mathrm{NH}_{2} \mathrm{BH}_{3}\right)_{\mathrm{n}}+\mathrm{nH}_{2}+\Delta \mathrm{H}
$$

As metal hydride acts as a base to deprotonate $\mathrm{AB}$, increasing the ionic character of the metal cation will result in an increasing reactivity of metal hydride towards $\mathrm{AB}$. This may 
account for the diverse preparation conditions that were employed in synthesizing different metal amidoboranes. Notably, the metal substitution strategy applies to most alkali or alkaline earth metal amidoboranes, but with an exception of $\mathrm{Mg}\left(\mathrm{NH}_{2} \mathrm{BH}_{3}\right)_{2}$ [30]. A latest theoretical study found that $\mathrm{Mg}\left(\mathrm{NH}_{2} \mathrm{BH}_{3}\right)_{2}$ is structurally unstable under ambient conditions because the large $\left[\mathrm{NH}_{2} \mathrm{BH}_{3}\right]^{-}$anion is sterically insufficient to completely compensate the condensed charge borne by the relatively small $\mathrm{Mg}^{2+}$ cation [24]. This necessitates the incorporation of other structure-stabilizing ligands.

Metal amidoboranes typically show enhanced dehydrogenation kinetics and suppressed volatile by-products relative to their parent AB. Fundamentally, the observed property improvements originate from the modified electronic and bonding structures $[17,22,25,26]$. In contrast to the molecular crystal nature of $\mathrm{AB}$, metal amidoboranes are ionic salts consisting of $\mathrm{M}^{\mathrm{n}+}$ and $\left[\mathrm{NH}_{2} \mathrm{BH}_{3}\right]^{-}$. As a result of the increased electron donation from $\mathrm{M}$ to $\mathrm{N}$, the $\mathrm{B}-\mathrm{N}$ bonds are strengthened and $\mathrm{B}-\mathrm{H}$ bonds are weakened, which means an increased reactivity of the hydridic H. More significantly, the substitution of the amine $\mathrm{H}$ by $\mathrm{M}$ cation results in the disappearance of dihydrogen bonding and the formation of a $\mathrm{BH}^{\delta-} \ldots \mathrm{M}^{\mathrm{n}+}$ interaction as a major stabilizing factor for the extended structure $[22,25]$. Such a dramatically altered intermolecular interaction exerts profound influence on the decomposition mechanism. Experimentally, it was observed that the decomposition of alkali metal amidoboranes does not involve the formation of $\mathrm{DADB}$, a key intermediate in the dehydrogenation reaction of $\mathrm{AB}$ [25]. According to the recent ab initio studies, dehydrogenation of $\mathrm{LiNH}_{2} \mathrm{BH}_{3}$ proceeds through a $\mathrm{Li}^{+}$- assisted hydride transfer mechanism [27,28]. As a critical mechanistic step, a hydridic $\mathrm{H}^{\delta-}$ from the adjacent $\left[\mathrm{NH}_{2} \mathrm{BH}_{3}\right]^{-}$groups is transferred to a migrated $\mathrm{Li}^{+}$, 
resulting in the local formation of LiH-like species. This is followed by the redox reaction between the $\mathrm{H}^{\delta-}$ in $\mathrm{LiH}$ and the $\mathrm{H}^{\delta+}$ bonded to $\mathrm{N}$, leading to $\mathrm{H}_{2}$ liberation. $\mathrm{Li}^{+}$ mobility is the basis of the dehydrogenation mechanism of $\mathrm{LiNH}_{2} \mathrm{BH}_{3}$. Increasing the $\mathrm{Li}^{+}$ mobility via creating disordered structure is therefore likely to further improve the dehydrogenation performance of $\mathrm{LiNH}_{2} \mathrm{BH}_{3}$ [29].

\subsubsection{Nano-confinement of $\mathrm{NH}_{3} \mathrm{BH}_{3}$ using scaffolds}

Nano-confinement using foreign scaffolds has become a welltraveled bridge connecting bulk and nanoscale hydrogen storage materials. Tailoring nanophase structure may result in unique properties that are not observed in the bulk materials. The unique structures and size-specific chemistry of nanomaterials, as well as the additional control by surface chemistry of scaffolds, opens up new opportunities for tuning the kinetics and thermodynamics of hydrogen storage/release. But until recently, this nano-engineering approach has remained largely unexplored in the field of hydrogen storage materials due to the technical difficulties in synthesis of nanosized hydride particles. Autrey and coworkers have recently demonstrated that $\mathrm{AB}$ could be readily incorporated into mesoporous silica using a wet impregnation method [36]. The resulting nanophase AB inside the silica host exhibits significant improvements in thermodynamics and dehydrogenation kinetics as well as suppression of borazine release relative to neat $\mathrm{AB}$. This nano-confinement strategy using foreign scaffolds has become a welltraveled bridge connecting bulk and nanoscale hydrogen storage materials. The unique structures and size-specific chemistry of nanomaterials, as well as the additional control by surface chemistry of scaffolds, opens up new opportunities for tuning the kinetics and thermodynamics of hydrogen storage/release. Subsequently, the nano-confinement 
approach has been extensively employed in different types of hydrogen storage materials (metal hydride [37], alanate [38], borohydride [39] and multicomponent hybrid material [40]) and proven effective in improving their hydrogen storage properties. As a further indication of the strategy's generality, several other nanoporous materials with different chemical nature and/or pore structure were utilized as structure-directing scaffolds, e.g. carbon aerogel [39], activated carbon [40], carbon cryogel [41] and metal-organic frameworks $[42,43]$.

The AB-mesoporous silica (MCM-41) nanocomposite has been further studied to determine the structural properties of the confined $\mathrm{AB}$ nanophase. A careful study using hyperpolarized ${ }^{129} \mathrm{Xe}$ NMR techniques showed that overloading of $\mathrm{AB}$ in MCM-41 causes the aggregation of the excess $\mathrm{AB}$ outside the meso-channels [44]. Autrey and coworkers further found that the $\mathrm{AB}$ aggregates are similar in nature to neat $\mathrm{AB}$; whereas the infused $\mathrm{AB}$ nanophase within mesoporous silica exhibits distinct phase transition behaviors from neat $\mathrm{AB}$. It stays in the hightemperature tetragonal phase at unexpectedly low temperatures down to $110 \mathrm{~K}$ and most likely undergoes a crystalline-to-amorphous transition at $240 \mathrm{~K}[45,46]$. Interestingly, the amorphous-like $\mathrm{AB}$ within MCM-41 exhibits a quite similar ${ }^{11} \mathrm{~B}$ resonance signal to the $\mathrm{AB}^{*}$ mobile phase that is formed in the heating process of neat AB.39 This finding is consistent with the improved dehydrogenation kinetics that was observed in the $\mathrm{AB}$-mesorporous silica nanocomposite relative to neat $\mathrm{AB}$. Fundamentally, the significant differences in the physical and chemical properties between the confined nanophase and neat $\mathrm{AB}$ should be understood as a combination of nanosize effect and the AB-scaffold interaction [36,41-43,47]. Since both effects are dominated by the large number of atoms at the nanoparticle surface, it is 
very difficult to experimentally evaluate their individual contributions to the property changes. In this regard, computational simulations may provide a powerful tool for independently studying the two effects.

\subsection{Equation of State}

Crystal structure or the atomic arrangements are usually changed during the phase transition of solids at high pressure. In the high pressure transition, co-ordination number (z) is an important parameter, because thermodynamically the molar volume of high pressure phase must be smaller than that of the low pressure phase. Either a more efficient packing of co-ordination polyhedra or an increase in co-ordination number or both can cause the reduction in molar volume. All materials are theoretically predicted to be metallic at extremely high pressures. A variation in temperature $(\mathrm{T})$, pressure $(\mathrm{P})$ or composition $(\mathrm{x})$ causes a phase transition in materials. A mathematical expression defining the physical state of homogeneous material which relates thermodynamic parameters $\mathrm{P}, \mathrm{V}$ and $\mathrm{T}$ is referred to as an EoS. In solid-solid phase transformations, generally $\mathrm{T}$ and $\mathrm{P}$ remain constant while entropy $(\mathrm{S})$ and molar volume $(\mathrm{V})$ undergo finite changes [48]. Phase transitions involve change in entropy and volume ( $\Delta \mathrm{St}$ and $\Delta \mathrm{Vt})$ according to the Clapeyron equation (Eq. 1).

$$
\mathrm{dT} / \mathrm{dP}=\Delta \mathrm{V}_{\mathrm{t}} / \Delta \mathrm{S}_{\mathrm{t}}
$$

This equation explainss that phase transition is induced either by a change in $\mathrm{T}$ at constant $\mathrm{P}$ or by a change in $\mathrm{P}$ at a constant $\mathrm{T}$. In the first order phase transitions the value of $\Delta \mathrm{St}$ for temperature induced transition must be positive, where as $\Delta \mathrm{Vt}$ may be any value. While for pressure induced transitions as $\mathrm{P}$ increases $\Delta \mathrm{Vt}$ must be negative but there will not be any restriction on the values of $\Delta \mathrm{St}$. In the case of second order phase 
transitions, phase changes occur at constant $\mathrm{P}$ and $\mathrm{T}$ with no volume or entropy changes. Past few years, researchers have attempted to reveal the properties of materials in terms of universal relationship with minimum parameters. A fair knowledge of the behavior of thermodynamic parameters at elevated pressure is significant for devising a system independent equation of state (EoS) of materials.

\subsection{References}

[1] T.B. Richardson, S.D. Gala, and R.H. Crabtree, J. Am. Chem. Soc. 117:12875 (1995).

[2] W.T. Klooster, T.F. Koetzle, P.E.M. Siegbahn, T.B. Richardson, R.H. Crabtree (1999) J. Am. Chem. Soc. 121, 6337 (1999).

[3] (a) M. G. Hu, R. A. Geanangel and W. W. Wendlandt, Thermochim. Acta 23, 249 (1978); (b) R. A. Geanangel and W. W. Wendlandt, Thermochim. Acta 86, 375 (1985); (c) V. Sit, R. A. Geanangel and W. W. Wendlandt, Thermochim. Acta 113, 379 (1987).

[4] (a) G. Wolf, J. Baumann, F. Baitalow, and F. P. Hoffmann, Thermochim. Acta 343, 19 (2000); (b) F. Baitalow, J. Baumann, G. Wolf, K. Jaenicke-Rößler and G. Leitner, Thermochim. Acta 391, 159 (2002); (c) J. Baumann, F. Baitalow and G. Wolf, Thermochim. Acta 430, 9 (2005); (d) F. Baitalow, G. Wolf, J. P. E. Grolier, F. Dan and S. L. Randzio, Thermochim. Acta 445, 121-125 (2006); (e) R. Schellenberg, L. Kriehme and G. Wolf, Thermochim. Acta 457, 103 (2007); (f) C. R. Miranda and G. Ceder, J. Chem. Phys.126, 184703 (2007).

[5] O. Palumbo, A. Paolone, P. Rispoli, R. Cantelli and T. Autrey, J. Power Sources, 195, 1615 (2010).

[6] A.C. Stowe, W. J. Shaw, J. C. Linehan, B. Schmid and T. Autrey, Phys. Chem. Chem. Phys. 9, 1831 (2007).

[7] M. Bowden, T. Autrey, I. Brown and M. Ryan, Curr. Appl. Phys. 8, 498 (2008).

[8] D. J. Heldebrant, A. Karkamkar, N. J. Hess, M. Bowden, S. Rassat, F. Zheng, K. Rappe and T. Autrey, Chem. Mater. 20, 5332 (2008).

[9] W. J. Shaw, M. Bowden, A. Karkamkar, C. J. Howard, D. J. Heldebrant, N. J. Hess, J. C. Linehan and T. Autrey, Energy Environ. Sci. 3, 796 (2010). 
[10] V. S. Nguyen, M. H. Matus, D. J. Grant, M. T. Nguyen and D. A. Dixon, J. Phys. Chem. A 111, 8844 (2007).

[11] R. Custelcean and J. E. Jackson, Chem. Rev. 101, 1963 (2001).

[12] G. N. Patwari, J. Phys. Chem. A 109, 2035 (2005).

[13] D. Hugas, S. Simon, M. Duran, C. F. Guerra and F. M. Bickelhaupt, Chem.--Eur. J. 15,5814 (2009).

[14] H. V. K. Diyabalanage, R. P. Shrestha, T. A. Semelsberger, B. L. Scott, M. E. Bowden, B. L. Davis and A. K. Burrell, Angew. Chem., Int. Ed. 46, 8995 (2007).

[15] Z. T. Xiong, C. K. Yong, G. T. Wu, P. Chen, W. Shaw, A. Karkamkar, T. Autrey, M. O. Jones, S. R. Johnson, P. P. Edwards and W. I. F. David, Nat. Mater. 7, 138 (2008).

[16] X. D. Kang, Z. Z. Fang, L. Y. Kong, H. M. Cheng, X. D. Yao, G. Q. Lu and P. Wang, Adv. Mater. 20, 2756 (2008).

[17] H. Wu, W. Zhou and T. Yildirim, J. Am. Chem. Soc. 130, 14834 (2008).

[18] Z. T. Xiong, Y. S. Chua, G. T. Wu, W. L. Xu, P. Chen, W. Shaw, A. Karkamkar, J. Linehan, T. Smurthwaite and T. Autrey, Chem. Commun. 5595 (2008).

[19] Z. T. Xiong, G. T. Wu, Y. S. Chua, J. J. Hu, T. He, W. L. Xu and P. Chen, Energy Environ. Sci. 1, 360 (2008).

[20] K. J. Fijałkowski and W. Grochala, J. Mater. Chem. 19, 2043 (2009).

[21] Q. A. Zhang, C. X. Tang, C. H. Fang, F. Fang, D. L. Sun, L. Z. Ouyang and M. Zhu, J. Phys. Chem. C 114, 1709 (2010).

[22] H. V. K. Diyabalanage, T. Nakagawa, R. P. Shrestha, T. A. Semelsberger, B. L. Davis, B. L. Scott, A. K. Burrell, W. I. F. David, K. R. Ryan, M. O. Jones and P. P. Edwards, J. Am. Chem. Soc. 132, 11836 (2010).

[23] K. J. Fijalkowski, R. V. Genova, Y. Filinchuk, A. Budzianowski, M. Derzsi, T. Jaroń, P. J. Leszczyński and W. Grochala, Dalton Trans. 40, 4407 (2011).

[24] Y. S. Chua, G. T. Wu, Z. T. Xiong, A. Karkamkar, J. P. Guo, M. X. Jian, M. W. Wong, T. Autrey and P. Chen, Chem. Commun. 46, 5752 (2010).

[25] A.T. Luedtke and T. Autrey, Inorg. Chem. 49, 3905 (2010). 
[26] M. Ramzan, F. Silvearv, A. Blomqvist, R. H. Scheicher, S. Lebègue and R. Ahuja, Phys. Rev. B 79, 132102 (2009).

[27] D. Y. Kim, N. J. Singh, H. M. Lee and K. S. Kim, Chem.-Eur. J.15, 5598 (2009).

[28] T. B. Lee and M. L. Mckee, Inorg. Chem. 48, 7564 (2009).

[29] W. I. F. David, M. O. Jones, D. H. Gregory, C. M. Jewell, S. R. Johnson, A. Walton and P. P. Edwards, J. Am. Chem. Soc. 129, 1594 (2007).

[30] X. D. Kang, L. P. Ma, Z. Z. Fang, L. L. Gao, J. H. Luo, S. C. Wang and P. Wang, Phys. Chem. Chem. Phys. 11, 2507 (2009).

[31] W. J. Shaw, M. Bowden, A. Karkamkar, C. J. Howard, D. J. Heldebrant, N. J. Hess, J. C. Linehan and T. Autrey, Energy Environ. Sci. 3, 796 (2010).

[32] V. S. Nguyen, M. H. Matus, D. J. Grant, M. T. Nguyen and D.A. Dixon, J. Phys. Chem. A 111, 8844 (2007).

[33] R. Custelcean and J. E. Jackson, Chem. Rev. 101, 1963 (2001).

[34] G. N. Patwari, J. Phys. Chem. A 109, 2035 (2005).

[35] D. Hugas, S. Simon, M. Duran, C. F. Guerra and F. M. Bickelhaupt, Chem.-Eur. J. 15,5814 (2009).

[36] A. Gutowska, L. Y. Li, Y. Shin, C. M. Wang, X. S. Li, J. C. Linehan, R. S. Smith, B. D. Kay, B. Schmid, W. Shaw, M. Gutowski and T. Autrey, Angew. Chem., Int. Ed. 44, 3578 (2005).

[37] S. Zhang, A. F. Gross, S. L. V. Atta, M. Lopez, P. Liu, C. C. Ahn, J.J. Vajo and C. M. Jensen, Nanotechnology 20, 204027 (2009).

[38] S. Y. Zheng, F. Fang, G. Y. Zhou, G. R. Chen, L. Z. Quyang, M. Zhu and D. L. Sun, Chem. Mater. 20, 3954 (2008).

[39] A.F. Gross, J. J. Vajo, S. L. V. Atta and G. L. Olson, J. Phys. Chem. C 112, 5651 (2008).

[40] H. Wu, W. Zhou, K. Wang, T. J. Udovic, J. J. Rush, T. Yildirim, L. A. Bendersky, A. F. Gross, S. L. V. Atta, J. J. Vajo, F. E. Pinkerton and M. S. Meyer, Nanotechnology, 20, 204002 (2009). 
[41] A. Feaver, S. Sepehri, P. Shamberger, A. Stowe, T. Autrey and G. Z. Cao, J. Phys. Chem. B 111, 7469 (2007).

[42] Z. Y. Li, G. S. Zhu, G. Q. Lu, S. L. Qiu and X. D. Yao, J. Am. Chem. Soc. 132, 1490 (2010).

[43] S. Gadipelli, J. Ford, W. Zhou, H. Wu, T. J. Udovic and T. Yildirim, Chem.--Eur. J. 17, 6043 (2011).

[44] L. Q. Wang, A. Karkamkar, T. Autrey and G. J. Exarhos, J. Phys. Chem. 113, 6485 (2009).

[45] H. Kim, A. Karkamkar, T. Autrey, P. Chupas and T. Proffen, J. Am. Chem. Soc. 131, 13749 (2009).

[46] A. Paolone, O. Palumbo, P. Rispoli, R. Cantelli, T. Autrey and A. Karkamkar, J. Phys. Chem. C 113, 10319 (2009).

[47] S. Sepehri, B. B. García and G. Z. Cao, Eur. J. Inorg. Chem. 599 (2009).

[48] L.Liu, W.A.Bassett, Elements, oxides, Silicates: High pressure phases with implications for the earth's interior, Oxford University Press, USA, 1986. 


\section{EXPERIMENTAL TECHNIQUES}

\subsection{Diamond Anvil Cell Technique}

The diamond anvil cell (DAC) is a portable high pressure device. The basic principle of the cell is that a force is applied over a small area and because pressure is defined as force divided by area, very large pressures can be generated between very small faces of diamonds with relatively modest forces. In DAC technique, the sample is placed in the hole of a gasket (metal, rhenium, graphite etc.) inserted between the flat faces of two diamonds which are pushed together. The pressure in the sample is made hydrostatic, or close to it, by surrounding it with a fluid or fluid-like medium confined by a gasket. The pressure limit is controlled by the ability of the diamonds, gasket and diamondbacking plates to withstand the applied stresses. Because the diamonds are transparent to most part of the electromagnetic spectrum (X-rays, gamma rays, UV, IR, visible light etc.), the sample may be examined in situ by spectroscopic and diffraction techniques. Different types of DACs generally used are Merril- Baset, P series, MaoBell, compact cylinder cell, and four post high pressure cells. Figure 3.1 shows a schematic of the sample chamber in DAC. 


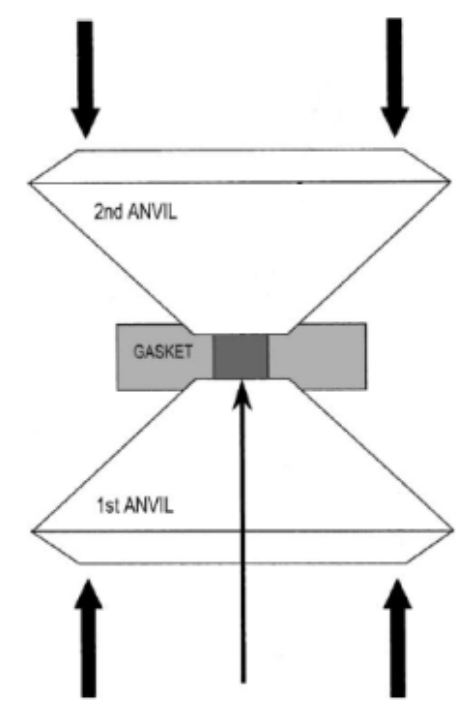

Figure 3.1 Schematic diagram of a DAC. The compressed area is shaded. Hydrostatic conditions at low and moderate pressures are ensured by a pressure-transmitting medium. Short arrows indicate the direction of force applied. Long arrows show the path of incident laser.

Compressive strength, hardness, and transparency to a broad electromagnetic spectrum are the impressive properties of diamond that make it a good choice for anvils. The remarkable simplicity and versatility of the diamond anvil cell has led to a proliferation of analytical techniques that can be applied to samples at high pressures. Two of the most important properties of a material are crystal structure and lattice dimensions that can be used for determining fundamental thermodynamic quantities, such as the effect of temperature and pressure on molar volume. X-ray diffraction using DAC 
is the best tool for such studies as the building block of diamond, the $\mathrm{C}$ atoms, has low atomic number and hence very low X-ray absorption. DACs can also be used for a number of investigations using IR, UV, gamma rays, sound waves etc., because of the extraordinary optical and elastic properties of diamonds [1]. Insertion of a gasket between the diamonds of the DAC helps to encapsulate a hydrostatic pressure medium, also to carry out viscosity measurements, chemical reactions, and structure determinations of molecular species in solution.

\subsubsection{Measurement of pressure in a DAC}

An embedded pressure marker or ruby $\left(\mathrm{Cr}^{3+}\right.$ doped $\left.\mathrm{Al}_{2} \mathrm{O}_{3}\right)$ can be used to measure pressure in the DAC. There are pressure markers for which the effects of both pressure and temperature on lattice dimensions are well known. A material of known pressurevolume $\mathrm{EoS}$ such as $\mathrm{NaCl}, \mathrm{MgO}, \mathrm{Pt}, \mathrm{Au}, \mathrm{W}, \mathrm{Ag}, \mathrm{Cu}$ etc., are generally used as pressure marker. If the pressure marker is mixed with sample, the lattice parameters can be obtained by X-ray diffraction which in turn can be used in 'calibration' software to determine pressure. Ruby pressure scale is a faster method to measure pressure in the DAC experiments. A small chip of ruby placed in a sample in the diamond cell fluoresces. The wavelength of the fluorescence emission changed with pressure. Ruby has a series of spectral bands (R, U, B and Y) in the visible ranges. The high energy lines $\mathrm{U}, \mathrm{B}$ and $\mathrm{Y}$ can be excited by a laser and they relax to R lines. The R lines (R1 and R2 with wave lengths 694.2 and $692.8 \mathrm{~nm}$, respectively at ambient conditions) are metastable with long lifetime which shift to higher wave length under pressure, and relax to ground state by fluorescence. The ruby method had another very important benefit. There are two closely spaced peaks in the ruby emission spectrum. The depth of the 
trough between the two peaks is very sensitive to peak broadening. Peak broadening, in turn, is very sensitive to deviatoric stress or non-hydrostaticity. The ruby method has been so successful that it continues to be the favored way to measure pressure in the diamond anvil cell even for XRD studies. Although it remains a secondary method, i.e., one that must be calibrated, it has been greatly improved and extended over the years as increased intensity of lasers has allowed ever smaller ruby chips to be used and better primary standards have yielded more reliable sources of calibration to much higher pressures. In the present study, ruby is used for pressure measurement in high pressure and high pressure-low temperature experiments.

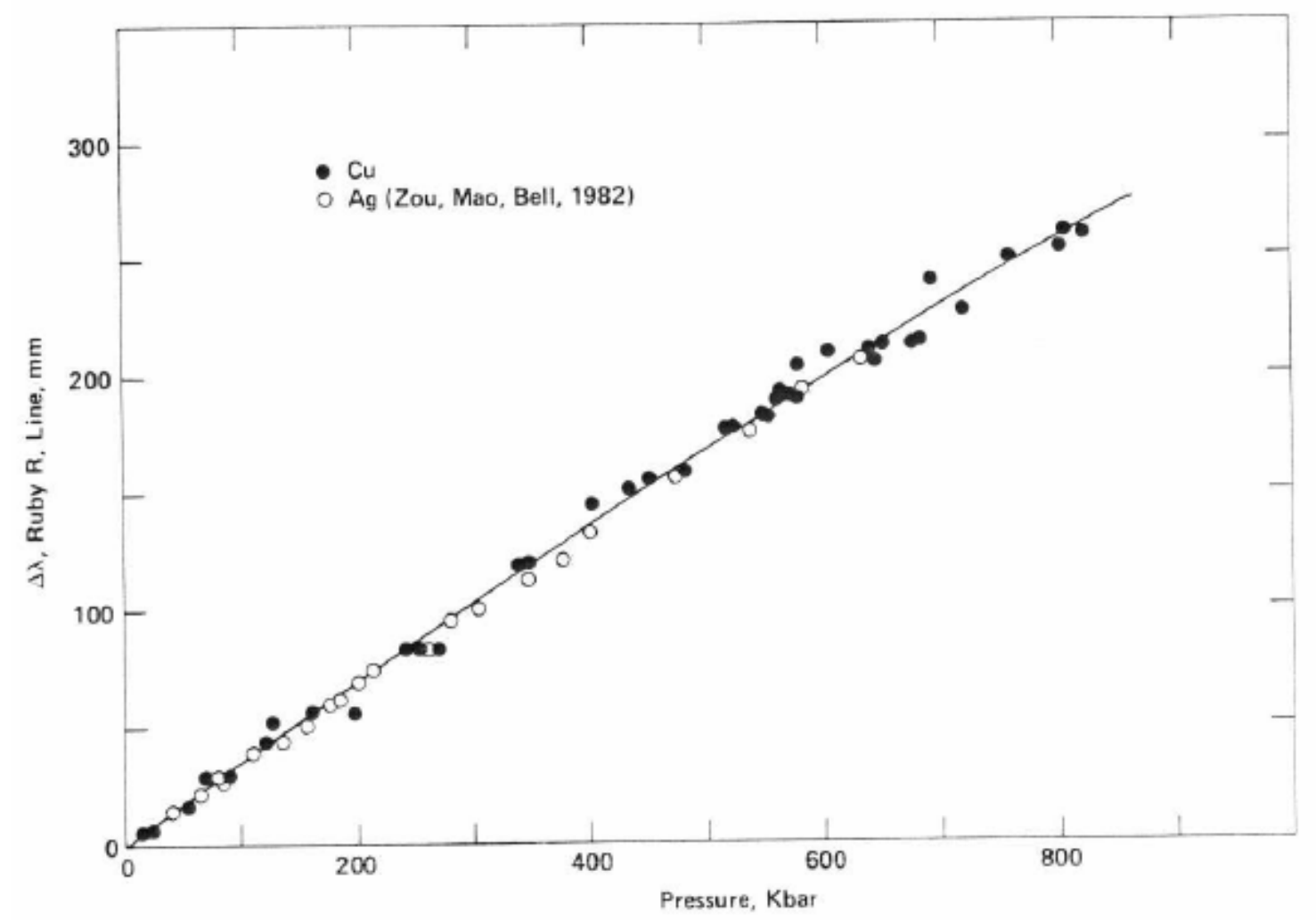

Figure 3.2 Calibration curve of the shift with pressure of the wavelength of the ruby R1 luminiscent line. Solid circles, copper standard; open circles, silver; argon pressuretransmitting medium [adapted from 2] 
Mao et al. [2], has calibrated the pressure shift of R1 emission line of ruby up to 80 GPa under quasi hydrostatic conditions with argon gas as a pressure transmitting medium (Figure 3.2). The shift of R1 line with pressure has been observed to be linear with pressure about $0.274 \mathrm{GPa} \AA^{-1}$ and can be fitted to the formula; $\mathrm{P}(\mathrm{GPa})=$ $(\mathrm{A} / \mathrm{B})\left[(\lambda / \lambda 0)^{\mathrm{B}}-1\right]$ where $\mathrm{A}=1904 \mathrm{GPa}, \mathrm{B}=7.665, \lambda$ is the wavelength of $\mathrm{R} 1$ line at pressure $\mathrm{P}$ and $\lambda_{0}$ is that at ambient conditions. Later, Silvera et al. [3], calibrated the ruby pressure gauge up to $150 \mathrm{GPa}$ with a difference in $\mathrm{A}$ and $\mathrm{B}$ parameters with helium as the pressure transmitting medium. The pressure can be estimated from the equation using change in wave length of $\mathrm{R} 1$ line; $\mathrm{P}=\Delta \lambda / 0.365$ where $\mathrm{P}$ is in GPa. The ruby fluorescence was captured using a USB based fluorescence spectrometer (Ocean Optics) and the operating software-OOIBase32. To minimize the effect of pressure gradients in the compressed sample, reduction in the X-ray beam divergence and collimation diameter $(\sim 0.15 \mathrm{~mm})$ can be helpful.

\subsubsection{Sample loading in the DAC}

White crystalline powder (several micrometers of average grain size) of ammonia borane was purchased from Sigma Aldrich. Sample loading of AB was carried out at open atmosphere, as $\mathrm{AB}$ is very stable at open atmosphere. $\mathrm{LiNH}_{2} \mathrm{BH}_{3}$ sample loadings were handled inside argon filled glove box, because of the reactivity of these materials at open atmosphere. Symmetric DAC with diamonds of $0.4 \mathrm{~mm}$ culets and stainless steel (T302) gasket of 0.16-0.18 mm hole was used. Steel gaskets were of thickness 0.27-0.32 $\mathrm{mm}$ and were indented to $0.05-0.07 \mathrm{~mm}$ using the DAC before drilling hole. The principle used for drilling is the spark erosion in which a high voltage spark erodes the metallic gasket immersed into a dielectric liquid like isopropanol (Figure 3.3). As these 
materials are very soft, no pressure transmitting medium was used. To accurately measure the pressure, ruby chips were added to the sample in the experiments. For the low temperature study, the cell was pressurized first and then it was loaded in the cryogenic system of liquid nitrogen cooling media. Raman spectra of the sample and the ruby fluorescence spectra were collected at every step during cooling. Temperature was controlled by Cryogenic Temperature Controller which has two Si-diode sensors. Temperature was regulated within \pm 0.5 Kelvin. Because of high refractive index of diamonds in DAC, a correction has been carried out on the diffractometer stage or goniometer to obtain accurate sample position. 


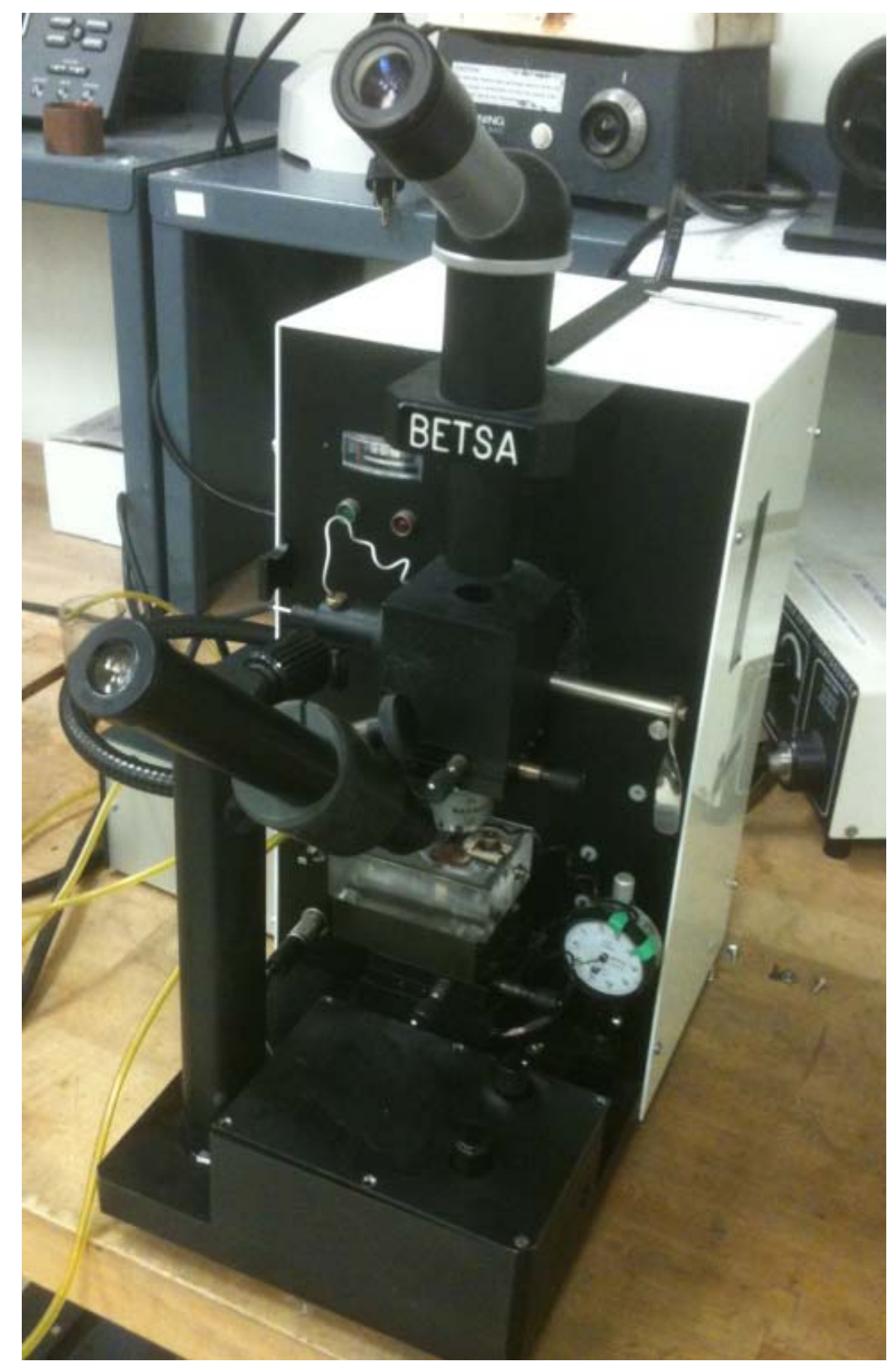

Figure 3.3 Drilling machine for drilling holes in the gaskets using spark erosion method. 


\subsection{Raman Spectroscopy}

Raman spectroscopy is used to observe vibrational, rotational, and other lowfrequency modes in a system. A monochromatic light, usually from a laser in the visible, near infrared, or near ultraviolet range, is used for Raman scattering. The energy of the laser photons shifts up or down due to the interaction of the laser light with molecular vibrations, phonons or other excitations in the system. The Raman shift is the change in the frequency of the scattered light from the laser frequency which indicates that energy is deposited in the sample in the form of phonons. The collected spectra is analyzed for the frequency shift which is an intrinsic property of the sample. The equilibrium structure of the material determines the vibrational patterns of atoms and the polarization dependence of scattering, through the rules of group theory. As the Raman tensor also decomposes into the basis of irreducible representations of the crystal space group, phonons are also classified by their irreducible representation. Raman-active phonon modes can be classified according to the irreducible representations of the crystal space group and its orthogonality. The classical vibrational frequency of a diatomic molecule is; $v=(1 / 2 \pi \mathrm{c})(\mathrm{k} / \mu) 1 / 2$, where $\mathrm{c}$ is the velocity of light, $\mathrm{k}$ is the force constant and $\mu$ is the reduced mass of the constituting atoms. The Raman shift from incident laser frequency $\left(v_{0}\right)$ is termed as Stokes $\left(v_{0}-v_{m}\right)$ and anti- Stokes $\left(v_{0}+v_{m}\right)$ lines.

Generally, a laser beam illuminates the sample. Light from the illuminated spot is collected with a lens and passed through a monochromator. Wavelengths close to the laser line due to elastic Raleigh scattering are filtered out and the rest of the collected light is sent to a detector. Raman scattering is usually very weak, and as a result the main difficulty of Raman spectroscopy is separating the weak inelastically scattered light from 
the intense Rayleigh scattered laser light. For that reason, Raman spectrometers are equipped with holographic gratings and multiple dispersion stages to achieve a high degree of laser rejection.

Raman spectroscopy experiments has been performed with an argon ion $\left(\mathrm{Ar}^{+}\right)$ laser system (Spectra Physics, model 177G02) of $\lambda=514.5 \mathrm{~nm}$. Backscattered Raman spectra were collected by high throughput holographic imaging spectrograph (Kaiser Optical Systems, model HoloSpec $f / 1.8 \mathrm{i}$ ) with volume transmission grating, holographic notch filter and thermoelectrically cooled CCD detector (Andor Technology). The spot size of the used laser beam used was $\sim 0.005 \mathrm{~mm}$ and the Raman spectrometer system has a spectral resolution of $4 \mathrm{~cm}^{-1}$. The sample was exposed for duration of $300-1800 \mathrm{~s}$ to collect the spectra. A monochromatic beam is observed by filtering the laser from argon ion laser. The monochromatic beam is then directed by a system of mirrors to a focusing/collecting lens and focused onto the sample. The back scattered light from sample is directed to the spectrometer through gratings and filters. Collection of Raman scattered light closer to the Rayleigh line with less ripple, is allowed by the holographic notch filter. Entire Raman spectrum can be acquired simultaneously due to the use of holographic transmission gratings. The system detector which is a multichannel CCD array, reads the signal as a function of position. The detector can read the different positions (wavelengths) simultaneously. The wavelength-intensity information is then sent to a computer and converted in Andor software to intensity versus frequency shift plots. In order to resolve a Raman peak of a certain width, the resolution of the spectrometer (final slit width) should be smaller than the peak width. The slit width estimates the extent to which the image may shift along the face of the CCD array, and 
hence the frequency resolution. The dark current of CCD array is a function of the detector temperature which is reduced by cooling. In the present setup at CeSMEC, CCD is cooled by the use of Joule Thomson effect. When the apparatus is properly aligned, the intensity of Raman spectrum depends on several factors such as the applied laser power, the sample properties (how absorptive or reflective the sample is, and the intrinsic strength of the Raman modes), and the width of the slits.

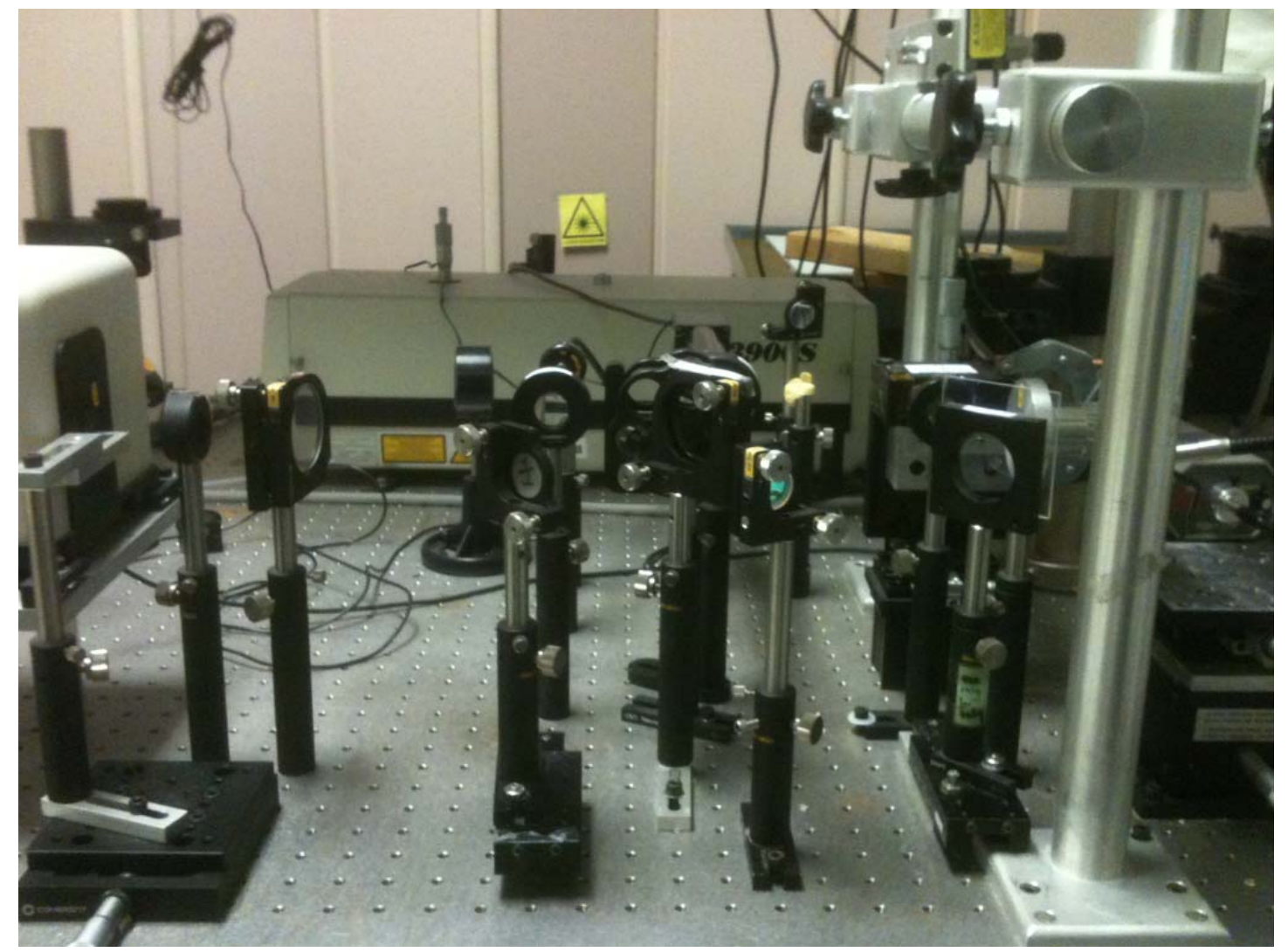

Figure 3.4 Raman spectroscopy setup with in situ ruby pressure measurement system at CeSMEC. 


\subsection{Synchrotron X-ray source}

Ammonia borane related compounds are light materials with low scattering power. Furthermore, the use of DAC limits the amount of sample which can be used. In order to obtain good quality diffraction pattern to resolve dynamic structural data, synchrotron XRD can be used. A very intense and well collimated beam of X-rays with high resolution is produced from the high energy synchrotron source, which can be used to study less amount of sample such as in a DAC.

Synchrotron X-rays are electromagnetic (EM) radiation produced by accelerating electrons. The produced high-energy electron beam is then directed into auxiliary components such as bending magnets and insertion devices (undulaters or wigglers) in storage rings and free electron lasers. A strong magnetic fields perpendicular to the beam is generated, which helps to convert the high-energy of electron into an EM radiation. Finally, the radiation is projected at a tangent to the electron storage ring and delivered to the beam lines. The beam lines can be at the bending magnets located at the corners, or insertion devices placed in the straight sections of the storage ring. Both types of beamlines have different spectrum and energy. A beam line consists of optical devices (slits, attenuators, crystal monochromators, and mirrors) which control the bandwidth, photon flux, beam dimensions, focus, and collimation of the X-ray beam. The experimental section is at the end of the beam line, where the samples are placed along the way of the radiation and the detector (image plate or charge-coupled device) is positioned to measure the resulting diffraction. Longer exposure time is required to collect a reasonably good diffraction pattern from DAC when using light ammonia borane related compounds. In such cases, use of large sized image plates may be helpful 
to get better resolution and to avoid dark current accumulation. Mar345 image plate detector was used to collect the diffracted X-rays. MEDM, Java, and IDL based display and control softwares were used. Calibration of the sample position and detector distances has been carried out using $\mathrm{CeO}_{2}$ standard. The resolution was $1 \times 10^{-4}$. The high pressure XRD measurements were mainly conducted at:

- Sector 16-ID-B, HPCAT, Advanced Photon Source of Argonne National Laboratory using X-rays of wavelength $\sim 0.406620 \AA$ (Figure 3.5, Figure 3.6).

Table 3.1 lists the major features of the beamline 16-ID-B at APS 


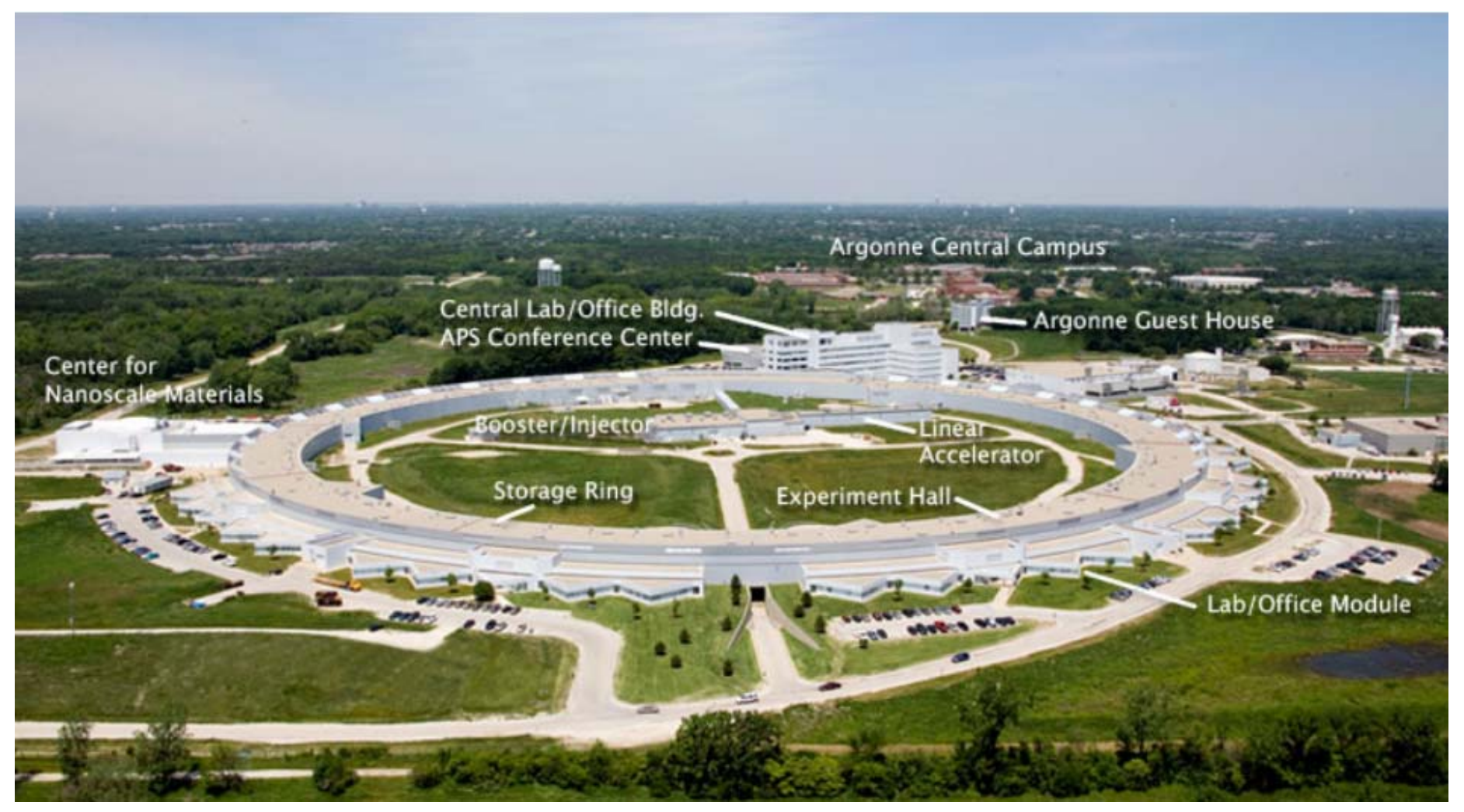

Figure 3.5 Aerial photo of the Advanced Photon Source [adapted from 4]. 


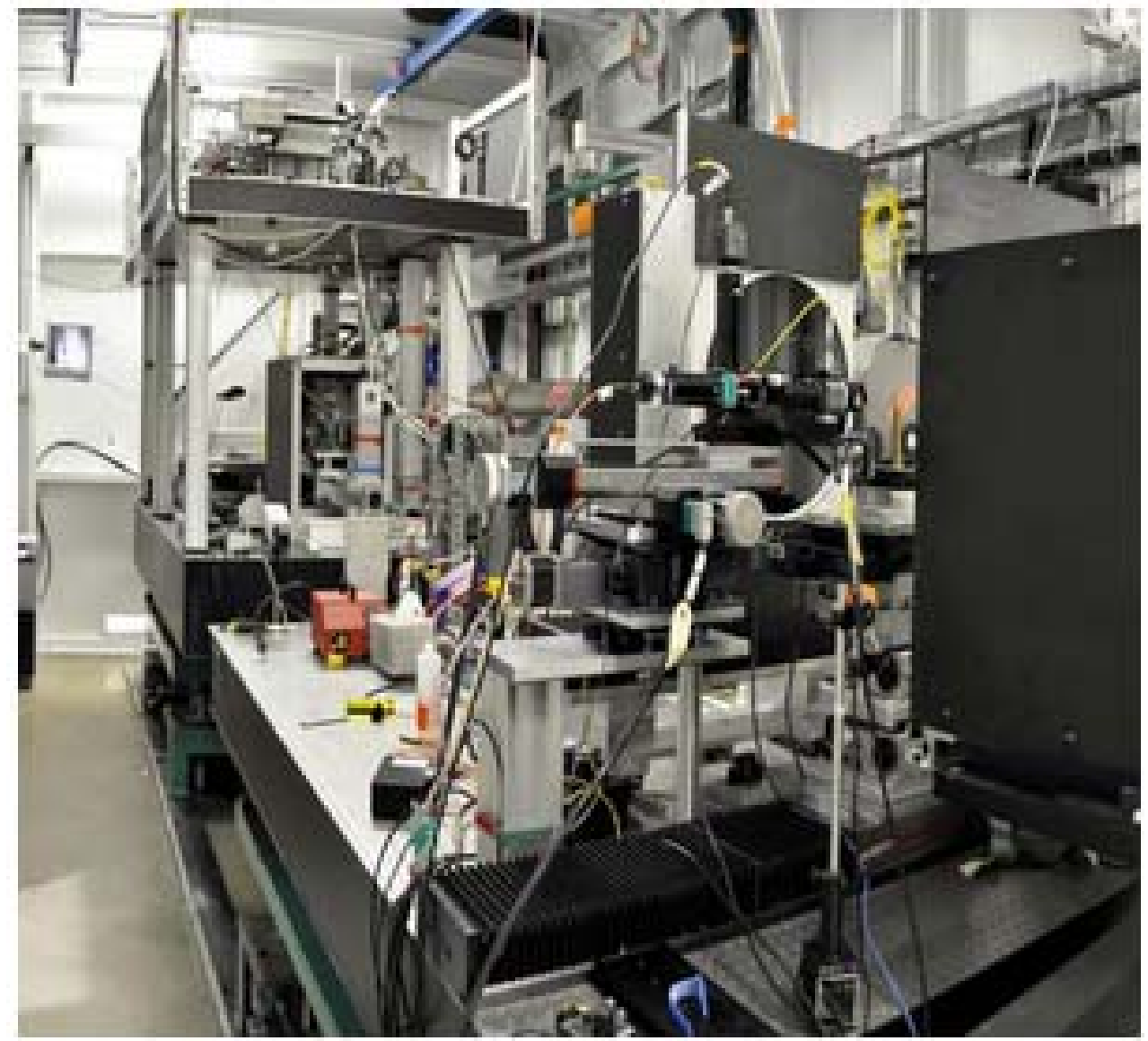

Figure 3.6 Inside of 16-ID-B hutch at APS [adapted from 5].

Table 3.1 Major ID-B features [adapted from 5]

\begin{tabular}{|l|l|}
\hline Feature & Description \\
\hline Source & Dual undulators Type A, single or in tandem mode \\
\hline Monochromator & Si double crystal \\
\hline Energy Range & $27-36 \mathrm{keV}$ \\
\hline $\begin{array}{l}\text { Beam Size and Focusing } \\
\text { Optics }\end{array}$ & $\sim 4 \times 5 \mathrm{~mm}^{2}, 200 \mathrm{~mm} \mathrm{~K}$ B mirrors \\
\hline Flux at Sample Position & $5 \times 10^{10} \mathrm{ph} / \mathrm{s}$ \\
\hline Established Techniques & $\begin{array}{l}\text { Micro XRD angle-dispersive X-ray diffraction (powder and } \\
\text { single crystal) with double-sided laser heating, external } \\
\text { heating, room temperature, and cryogenic conditions }\end{array}$ \\
\hline Detectors & MAR imaging plate and MAR CCD detectors \\
\hline Support Equipments & $\begin{array}{l}\text { Membrane and mechanical pressure control, various online } \\
\text { cryostats, online Ruby and Raman systems, offline } \\
\text { alignment and Ruby systems }\end{array}$ \\
\hline
\end{tabular}




\subsection{References}

[1] W.A.Bassett, High Pressure Research: An International Journal 29, 163 (2009).

[2] H.K.Mao, J.Xu, P.M.Bell, Journal of Geophysical research 91, 4673 (1986).

[3] I.F.Silvera, A.D.Chijioke, W.J.Nellis, A.Soldatov, J.Tempere, Physica Status Solidi B, 244, 460 (2007).

[4] http://www.aps.anl.gov/About/APS_Overview/

[5] http://hpcat.gl.carnegiescience.edu/beamlines/id-b 


\section{HIGH PRESSURE STUDY OF LITHIUM AMIDOBORANE}

One of the major obstacles to the use of hydrogen as an energy carrier is the lack of proper hydrogen storage material. As mentioned earlier, lithium amidoborane has attracted significant attention as hydrogen storage material. It releases $\sim 10.9 \mathrm{wt} \%$ hydrogen, which is beyond the DOE target, at remarkably low temperature $\left(\sim 90{ }^{\circ} \mathrm{C}\right)$ without borazine emission. It is essential to study the bonding behavior of this potential material to improve its dehydrogenation behavior further and also to make rehydrogenation possible. We have studied the high pressure behavior of lithium amidoborane in a diamond anvil cell using in situ Raman spectroscopy. We have discovered that there is no dihydrogen bonding in this material, as the N-H stretching modes do not show redshift with pressure. The absence of the dihydrogen bonding in this material is an interesting phenomenon, as the dihydrogen bonding is the dominant bonding feature in its parent compound ammonia borane. This observation may provide guidance to the improvement of the hydrogen storage properties of this potential material and to design new material for hydrogen storage application. Also two phase transitions were found at high pressure at 3.9 and $12.7 \mathrm{GPa}$ which are characterized by sequential changes of Raman modes.

\subsection{Introduction}

As discussed earlier, hydrogen economy has been considered as potentially efficient and environmental friendly alternative energy solution [1]. However, one of the most important scientific and technical challenges facing the "hydrogen economy" is the development of safe and economically viable on-board hydrogen storage for fuel cell applications, especially to the transportation sector. As mentioned earlier, ammonia 
borane $\left(\mathrm{BH}_{3} \mathrm{NH}_{3}\right)$, a solid state hydrogen storage material, possesses exceptionally high hydrogen content (19.6 wt\%) and in particular, it contains a unique combination of protonic and hydridic hydrogen, and on this basis, offers new opportunities for developing a practical source for generating molecular dihydrogen [2-5]. Stepwise release of $\mathrm{H}_{2}$ takes place through thermolysis of ammonia borane, yielding one-third of its total hydrogen content $(6.5 \mathrm{wt} \%)$ in each heating step, along with emission of toxic borazine [6-8]. Recently research interests are focusing on how to improve discharge of $\mathrm{H}_{2}$ from ammonia borane including lowering the dehydrogenation temperature and enhancing hydrogen release rate using different techniques, e.g. nanoscaffolds [9], ionic liquids [10], acid catalysis [11], base metal catalyst [12] or transition metal catalysts [1314]. More recently, significant attention is given to chemical modification of ammonia borane through substitution of one of the protonic hydrogen atoms with an alkali or alkaline-earth element [15-21]. Lithium amidoborane $\left(\mathrm{LiNH}_{2} \mathrm{BH}_{3}\right)$ has been successfully synthesized by ball milling $\mathrm{LiH}$ with $\mathrm{NH}_{3} \mathrm{BH}_{3}$ [15-18]. One of the driving forces suggested for the formation of $\mathrm{LiNH}_{2} \mathrm{BH}_{3}$ is the chemical potential of the protonic $\mathrm{H}^{\delta+}$ in $\mathrm{NH}_{3}$ and the hydridic $\mathrm{H}^{\delta-}$ in alkali metal hydrides making them tend to combine producing $\mathrm{H}_{2}+\mathrm{LiNH}_{2} \mathrm{BH}_{3}$. $\mathrm{LiNH}_{2} \mathrm{BH}_{3}$ exhibits significantly different and improved dehydrogenation characteristics from its parent compound ammonia borane. It releases more than $10 \mathrm{wt} \%$ of hydrogen at around $90{ }^{\circ} \mathrm{C}$ without borazine emission. Also, the dehydrogenation process of lithium amidoborane is much less exothermic $\left(\sim 3-5 \mathrm{kJmole}^{-}\right.$ $\left.{ }^{1}\right)$ (15-17) than that for $\mathrm{NH}_{3} \mathrm{BH}_{3}\left(\sim 22.5 \mathrm{kJmole}^{-1}\right)$ [6-8], which greatly enhances the search for suitable regeneration routes (prerequisite for a hydrogen storage material). While the rationale behind the improved dehydrogenation behavior is still unclear, these 
improved property modifications evidently originate from the substitution of one $\mathrm{H}$ in the $\mathrm{NH}_{3}$ group by the more electron-donating $\mathrm{Li}$, which exerts influences on the bonding characteristics, especially on the dihydrogen bonding which is one of the characteristic bonds of ammonia borane [15]. So, it is essential to understand details about the bonding behavior of this potential material.

High pressure study of molecular crystals can provide unique insight into the intermolecular bonding forces, such as hydrogen bonding and phase stability in hydrogen storage materials and thus provides insight into the improvement of design [22-30]. For instance, Raman spectroscopic study of ammonia borane at high pressure provided insight about its phase transition behavior and the presence of dihydrogen bonding in its structure [25-30]. We have investigated $\mathrm{LiNH}_{2} \mathrm{BH}_{3}$ at high pressure using Raman spectroscopy. We have found that other than in $\mathrm{NH}_{3} \mathrm{BH}_{3}$ dihydrogen bonding is absent in lithium amidoborane structure and $\mathrm{LiNH}_{2} \mathrm{BH}_{3}$ shows two phase transitions at high pressure.

\subsection{Experimental}

$\mathrm{LiNH}_{2} \mathrm{BH}_{3}$ and $\mathrm{NH}_{3} \mathrm{BH}_{3}$ were purchased from Sigma Aldrich with stated purities of $90 \%$ and $97 \%$ respectively and were used without further purification. Due to air sensitivity of lithium amidoborane, all sample handlings were done inside an argon-filled glovebox. The sample was loaded into a capillary inside the glovebox and then sealed. A symmetric diamond anvil cell (DAC) with two type-I diamonds of $400 \mu \mathrm{m}$ culet size was used for the high pressure experiments. A stainless steel gasket was pre-indented to 55 $\mu \mathrm{m}$ thickness and then a hole of $160 \mu \mathrm{m}$ in diameter was drilled in the center as a sample chamber. Lithium amidoborane powders, along with some ruby chips for in situ pressure 
measurement, were loaded in the sample chamber inside the glovebox. Pressure was calibrated from the shift of Ruby fluorescence [31,32]. No pressure medium was used in the sample chamber as the sample is fairly soft. Raman spectroscopy measurements were conducted in the Center for the Study of Matter at Extreme Condition (CeSMEC) at Florida International University. This system uses a 514-nm $\mathrm{Ar}^{+}$laser excitation line and has $2 \mathrm{~cm}^{-1}$ spectra resolution. Direct microscopic observation through diamond windows were recorded before and after the first phase transition.

\subsection{Results and Discussions}

We have used in situ Raman spectroscopy to characterize bonding changes in the sample. For collecting the Raman spectra at ambient condition, we have loaded ammonia borane and lithium amidoborane samples into glass capillaries. Raman spectra (Figure 4.1) of ammonia borane [25-30] and lithium amidoborane [33] at ambient condition have been well documented and the major Raman modes can be described by their molecular nature as follows: $\mathrm{N}-\mathrm{H}$ stretching, $\mathrm{B}-\mathrm{H}$ stretching and $\mathrm{B}-\mathrm{N}$ stretching modes. In the Raman spectra, B-H stretching modes of lithium amidoborane appear at lower wavenumbers compared to those of ammonia borane (Figure 4.1), indicating that lithium amidoborane has weaker B-H bond than ammonia borane. This is consistent with the reported B-H bond strength by the previous X-ray studies [15,18,33-36]. Likewise, both the $\mathrm{N}-\mathrm{H}$ and $\mathrm{B}-\mathrm{N}$ stretching modes in lithium amidoborane appear at higher wavenumbers with respect to those in ammonia borane, i.e. the $\mathrm{N}-\mathrm{H}$ and $\mathrm{B}-\mathrm{N}$ bonds become stronger in lithium amidoborane, in consistent with the prediction by Armstrong et al. regarding B-N bond strength [37]. 
We have conducted diamond anvil cell (DAC) experiments at room temperature on lithium amidoborane sample from ambient pressure to 19 GPa. Two phase transformations are observed at high pressure. The first phase transition occurs at 3.9 GPa. This phase transformation is demonstrated by remarkable change in the B-H stretching region. The low frequency B-H stretching mode splits and the high frequency B-H stretching modes merge into singlet (Figure 4. 2a). Also notable change in optical image occurs at this phase transition. The sample is opaque to light before and is transparent to light after phase transformation (Figure 4.3). With further compression, another phase transition occurs at $12.7 \mathrm{GPa}$, with the clear splitting of $\mathrm{N}-\mathrm{H}$ stretching vibrational modes and merging of high frequency B-H stretching modes (Figure 42a, b and c). Both phase transitions are associated with splitting of the major vibrational modes indicating that the structural complexity increases with pressure. 


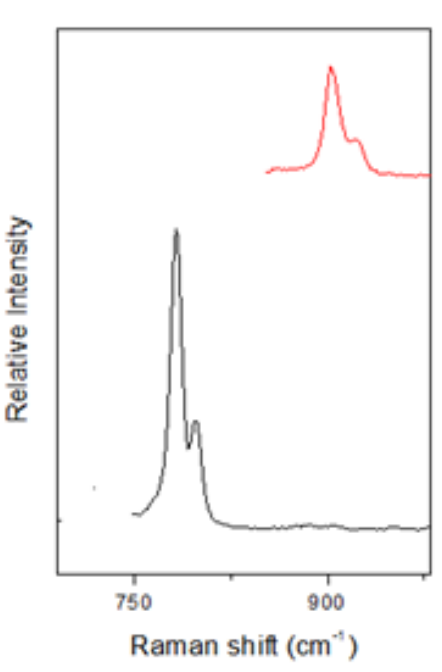

(a)

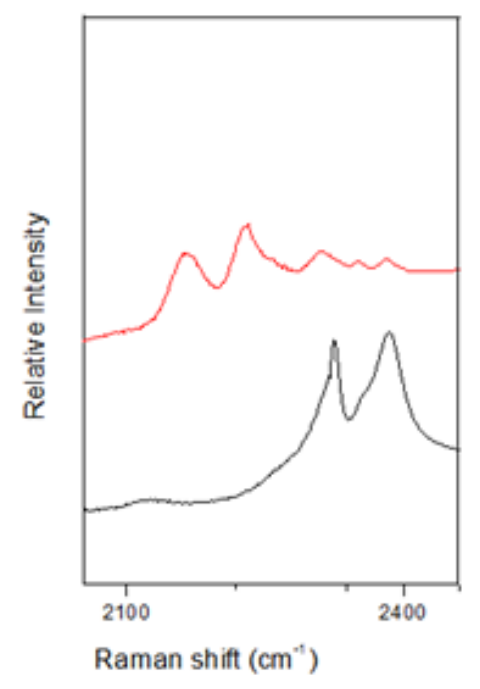

(b)

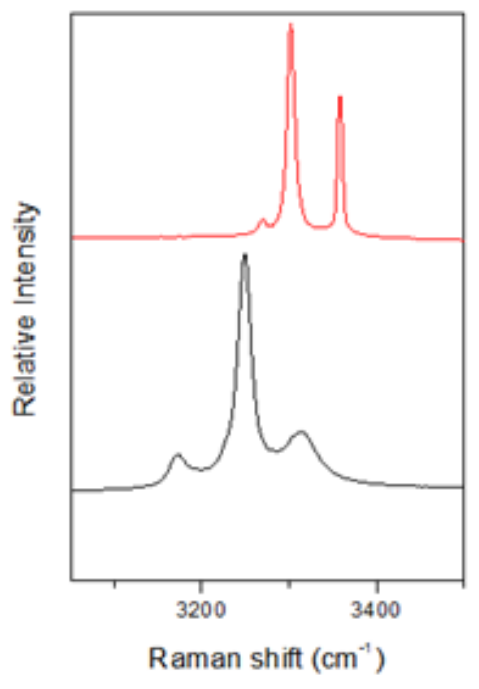

(c)

Figure 4.1 Comparison of the major Raman modes of ammonia borane (-) and lithium amidoborane (-): (a) B-N (b) B-H and (c) N-H stretching modes.

The characteristic feature in the structure of ammonia borane is that due to the differing electronegativities of the $\mathrm{B}$ and $\mathrm{N}$ atoms, the hydrogen atoms bonded respectively to $\mathrm{B}$ and $\mathrm{N}$ have different charges. As nitrogen is strongly electronegative, the hydrogens bonded to nitrogen are protonic $\left(\mathrm{H}^{\delta+}\right)$ in character; while boron is less electronegative than hydrogen and thus the hydrogens bonded to boron are hydridic $\left(\mathrm{H}^{\delta-}\right)$ in character. These two hydrogen species form a network of $\mathrm{N}-\mathrm{H}^{\delta+} \ldots{ }^{-\delta} \mathrm{H}-\mathrm{B}$ dihydrogen bonds which stabilize the structure of $\mathrm{NH}_{3} \mathrm{BH}_{3}$ as molecular solid with much higher melting point $\left(+104{ }^{\circ} \mathrm{C}\right)$ compared to the isoelectronic $\mathrm{CH}_{3} \mathrm{CH}_{3}$ (melting point is $-181{ }^{\circ} \mathrm{C}$ ) gas and most importantly, the existence of these dihydrogen bonds facilitates the formation of molecular hydrogen during dehydrogenation of ammonia borane. In fact, formation or strengthening of such dihydrogen bonds results in weakening of N-H bonds and therefore a corresponding red shift of $\mathrm{N}-\mathrm{H}$ stretching frequency to lower wavenumbers in Raman spectra [38]. For example, the frequency of $\mathrm{O}-\mathrm{H}$ stretching in 
phenol (proton donor)- BDMA (borane-dimethylamine) complex has been reported to show a red shift by $174 \mathrm{~cm}^{-1}$ when the dihydrogen bonding forms [39]. Likewise, the $\mathrm{N}$ $\mathrm{H}$ stretching in the complex between 2-pyridone (as the proton donor) and boranetrimethylamine also shows a red shift by $5 \mathrm{~cm}^{-1}$ upon the formation of dihydrogen [39]. Other than in those compounds we have observed that the N-H stretching frequency of lithium amidoborane is blue shifted than its parent compound (Figure 4.1), which indicates that either the dihydrogen bonding becomes weaker compared to ammonia borane or it disappears in lithium amidoborane structure.

Existence of dihydrogen bonding shows unique behavior at high pressure. According to Lipincott model [40a], existence of $\mathrm{N}-\mathrm{H}^{\delta+} \ldots \mathrm{H}^{\delta-}-\mathrm{B}$ dihydrogen bonding (Figure 4.4) in the structure will result in a large redshift in the N-H stretching frequencies as the $\mathrm{N} \ldots \mathrm{H}^{\delta-}$ (intermolecular) distance decreases. The $\mathrm{H}^{\delta+} \ldots \mathrm{H}^{\delta-}$ dihydrogen bonding strengthens in the $\mathrm{N}-\mathrm{H}^{\delta+} \ldots \mathrm{H}^{\delta-}-\mathrm{B}$ configuration, with the sacrifice of $\mathrm{N}-\mathrm{H}^{\delta+}$ bond strength. That is, as the intermolecular $\left(\mathrm{N} \ldots . \mathrm{H}^{\delta-}\right)$ distance decreases, the $\mathrm{N}-\mathrm{H}^{\delta+}$ bond length increases, therefore the $\mathrm{N}-\mathrm{H}^{\delta+}$ restoring force decreases, i.e. the frequency shifts to lower wavenumbers. Applying external pressure is a mean to decrease the intermolecular $\mathrm{N} . . . \mathrm{H}^{\delta-}$ distance. So, if there is any presence of dihydrogen bonding in the material, the $\mathrm{N}-\mathrm{H}$ stretching should exhibit redshift with pressure [25-27, 30] with some exceptions which have very strong symmetric dihydrogen bonding [40b-i]. As shown in Figures 4.2(b) and (c), the N-H stretching frequency of lithium amidoborane shows blue shift with increasing pressure, in contrary to its parent compound ammonia borane [25-27, 30]. The observation of blueshift of $\mathrm{N}-\mathrm{H}$ stretching frequency with pressure indicates a likely absence of dihydrogen bond in lithium amidoborane as illustrated by Lipincott model, 
unless there is an extremely strong symmetric dihydrogen bonding. Cambdrige Structural Database (CSD) structural search provides characteristic metric data for twenty six NH...H-B intermolecular dihydrogen bonds with H...H distance in the range of 1.7-2.2 $\AA$ in 18 crystal structures [41-44]. X-ray diffraction data, however, indicate that the $\mathrm{NH}$...HB intermolecular distance of lithium amidoborane is $2.249 \AA$ [18], $10 \%$ longer than that of ammonia borane $(2.02 \AA)[18]$ and close to the expected van der Waals distance $(2.4 \AA)$. This may rule out the possibility of extremely strong dihydrogen bonding in lithium amidoborane. 


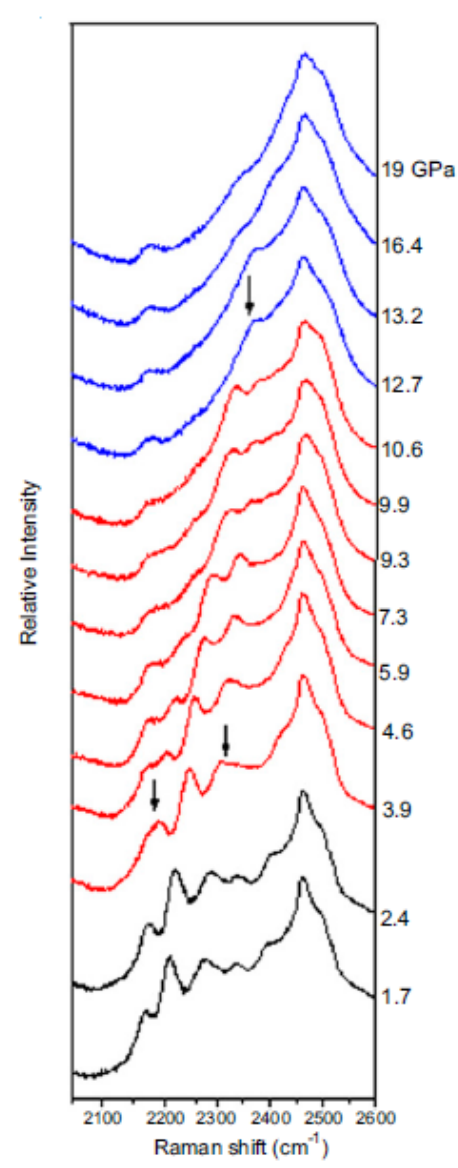

(a)

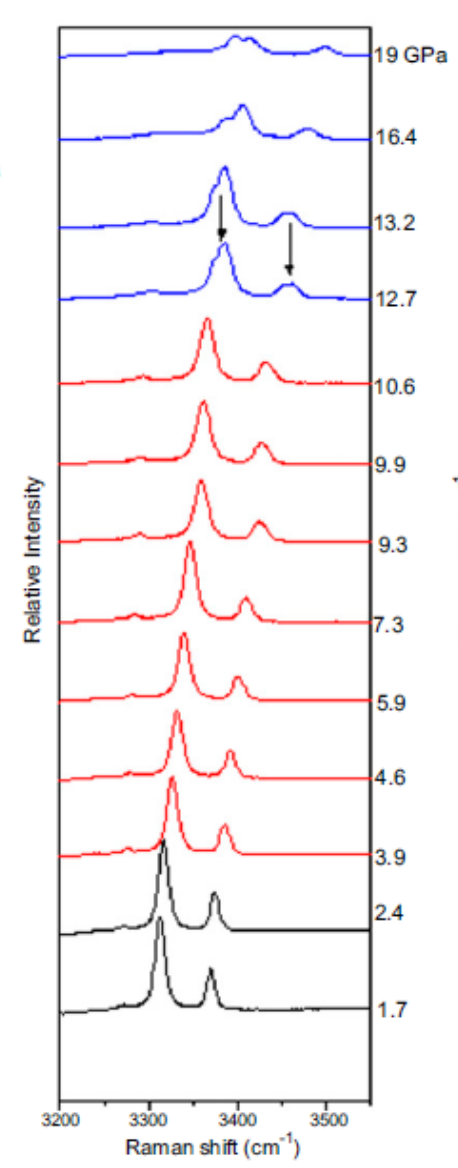

(b)

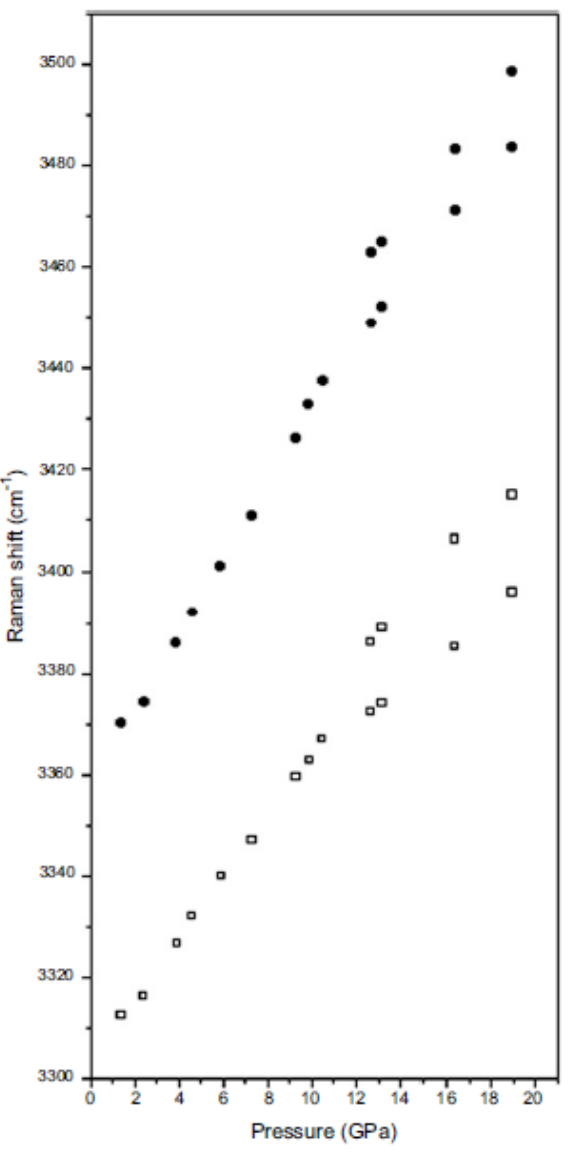

(c)

Figure 4.2 Evolution of N-H and B-H stretching modes at high pressure: (a) B-H and (b) N-H stretching modes, arrow ( $\downarrow$ ) indicates the position of merging and/or splitting of Raman modes; (c) pressure dependence of Raman shift of N-H stretching modes. 


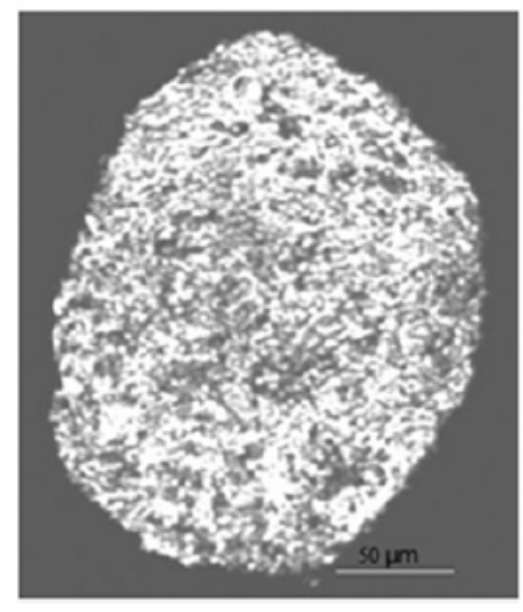

(a)

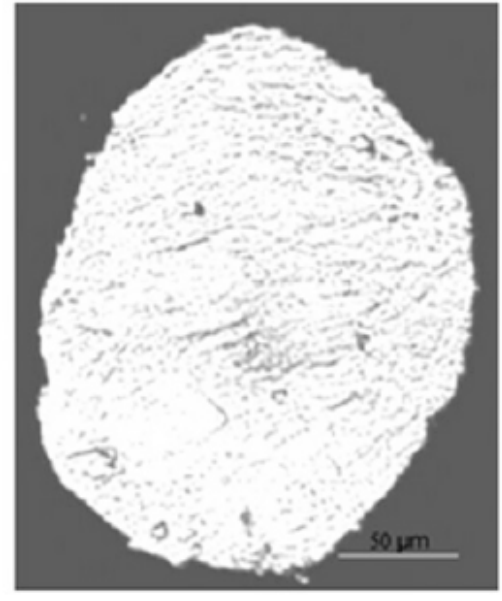

(b)

Figure 4.3 Change of photomicrograph of lithium amidoborane in gasket hole associated with the first phase transition: (a) at $2.4 \mathrm{GPa}$ (before first phase transition) and (b) at 3.9 GPa (after the first phase transition).

The Li-N bond length of $\mathrm{LiNH}_{2} \mathrm{BH}_{3} \sim 2.032 \AA[15,45,47]$ is significantly longer than the $\mathrm{H}-\mathrm{N}$ bond length $(1.07 \AA)$ in ammonia borane $(46,47)$. Each $\mathrm{Li}^{+}$is tetrahedrally surrounded by three other $\mathrm{BH}_{3}{ }^{\delta-}$ units with the experimentally determined Li...B distance

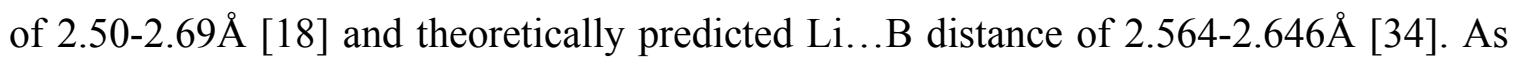
lithium is more electron-donating, $\mathrm{N}$ attracts more electrons from lithium than the hydrogen atoms. So, N-H bond approaches to the covalent character, i.e. its bond length decreases, whereas Li-N shows more ionic character. So, there may be significant van der Waals interaction between $\mathrm{Li}^{+} \ldots \mathrm{BH}_{3}{ }^{\delta-}$, which acts as the stabilizing factor for the molecular structure of $\mathrm{LiNH}_{2} \mathrm{BH}_{3}$ although the dihydrogen bonding is absence in its structure. The absence of the dihydrogen bonding not only alters the structure stabilizing factor of $\mathrm{LiNH}_{2} \mathrm{BH}_{3}$, it may also cause significant change in the dehydrogenation mechanism of this complex. In principle the attractive interaction between the dihydrogen 
bonded atoms strongly lowers the activation energy for hydrogen release of ammonia borane [39,48,49] and also some potential complexes for hydrogen storage [46]. Although there is no dihydrogen bond, $\mathrm{LiNH}_{2} \mathrm{BH}_{3}$ dehydrogenates at lower temperature than ammonia borane, which refers to a different dehydrogenation mechanism other than mere $\mathrm{H}^{\delta+} \ldots \mathrm{H}^{\delta-}$ interaction mechanism claimed by Chen et al. [15]. As B-H bond is weaker in lithium amidoborane, B-H shows more reactivity in dehydrogenation and the transfer of hydrogen from boron to lithium is the rate determining step of dehydrogenation process of lithium amidoborane [50,51]. It will open new opportunity for the design of hydrogen storage material by tuning the reactivity of N-H and/or B-H by substituting protonic and/or hydridic hydrogen by more electroposive and/or electronegative elements. If both of the $\mathrm{N}-\mathrm{H}$ and $\mathrm{B}-\mathrm{H}$ bonding can be made weaker by simultaneously substituting protonic and hydridic hydrogen, then dihydrogen bonding may appear in the structure, which may dehydrogenate more easily than metal amidoboranes. 


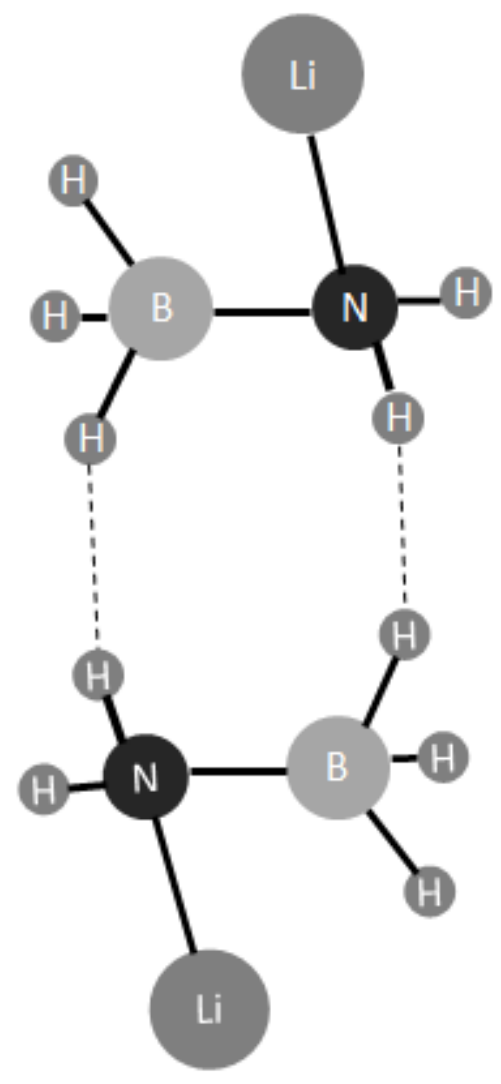

Figure 4.4 Schematic structure of two molecules of $\mathrm{LiNH}_{2} \mathrm{BH}_{3}$ : (- - -) indicates the location of possible dihydrogen bonding.

\subsection{High pressure study of Lithium Amidoborane using synchrotron X-ray diffraction}

Lithium amidoborane was investigated at high pressure using synchrotron X-ray source at Argonne National Laboratory (Figure 4.5). One phase transition is observed at 9.6 GPa. 


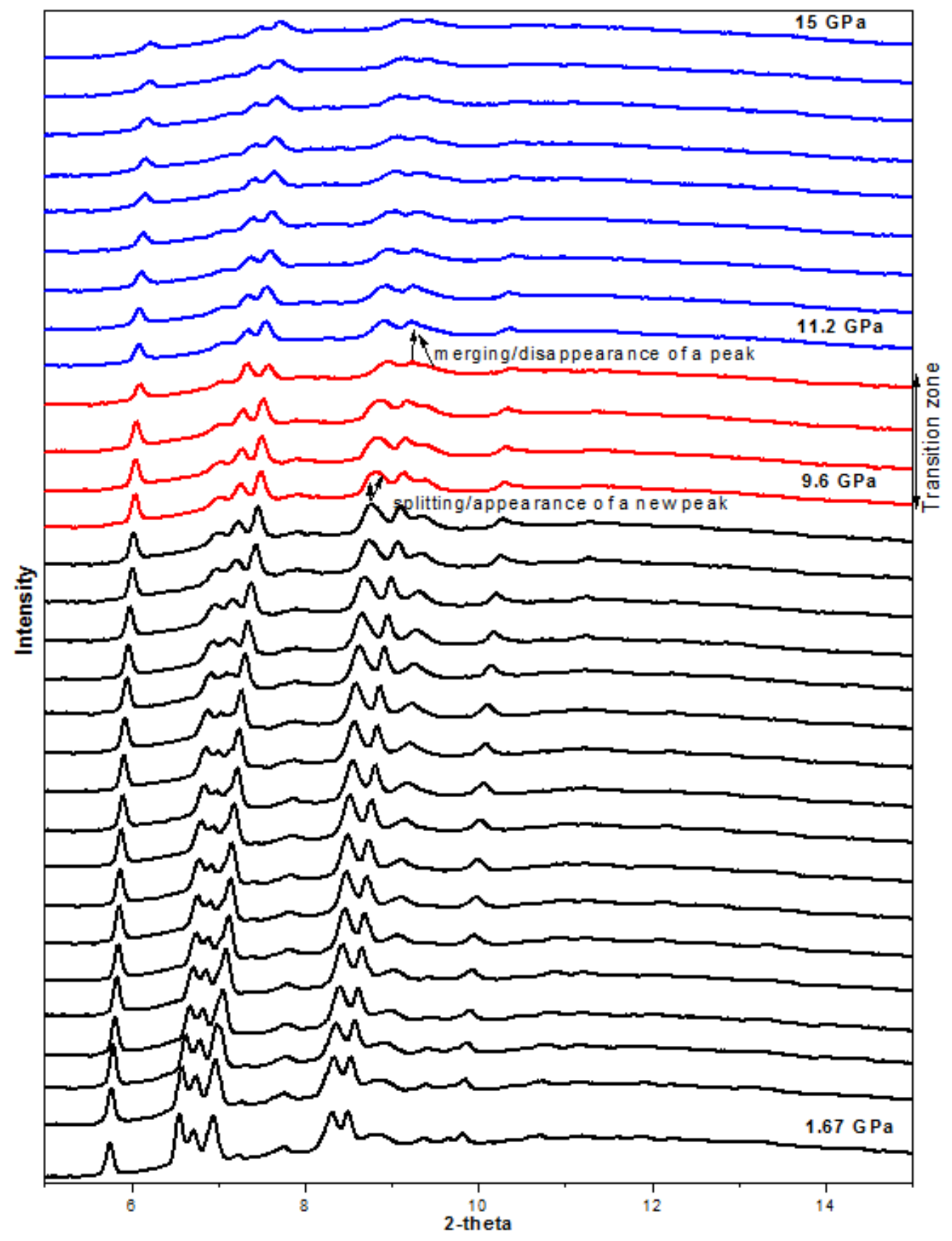

Figure 4.5 Synchrotron X-ray diffraction data of lithium amidoborane at high pressure (pressure increases from bottom to top spectra). 


\subsection{Conclusion}

Raman spectroscopy was used to investigate the bonding behavior of lithium amidoborane structure and the phase stability of lithium amidoborane at high pressure and room temperature. In the lithium amidoborane structure, the bonding behavior is significantly altered than its parent compound ammonia borane. The characteristic dihydrogen bonding of ammonia borane, is absence in lithium amidoborane. This phenomenon is evidenced by the blueshift of N-H stretching frequency compared to its parent compound ammonia borane in the ambient condition Raman spectra along with the positive pressure dependence of $\mathrm{N}-\mathrm{H}$ stretching frequency of lithium amidoborane at high pressure observed in this experiment. Also, B-H bonding becomes weaker in lithium amidoborane structure, which will show more reactivity in dehydrogenation. The different bonding characteristics are likely responsible for improved dehydrogenation behavior of lithium amidoborane. The Raman spectroscopy study and optical microscopy study identifies two phase transitions of lithium amidoborane at high pressure and room temperature. The first phase transition occurs at $3.9 \mathrm{GPa}$ and the second phase transition occurs at $12.7 \mathrm{GPa}$. Although X-ray diffraction study indicates that only one phase transition occurs at around 9.6 GPa. This implies that the first phase transition at $3.9 \mathrm{GPa}$, observed by Raman spectroscopy, may be isostructural phase transition. The new phases

are likely to have more volumetric hydrogen content. Future neutron diffraction study is required to further investigate the phase transition and the absence of dihydrogen bonding.

\subsection{References}

[1] L. Schlapbach, and A. Züttel, Nature 414(6861), 353 (2001). 
[2] P. Chen, and M. Zhu, Mater. Today 11, 36 (2008).

[3] J. Graetz, Chem. Soc. Rev. 38, 73 (2009).

[4] J. Irvine, J. Mater. Chem. 18, 2295 (2008).

[5] M. Felderhoff, C. Weidenthaler, von Helmolt R, and U. Eberle, Phys. Chem. Chem. Phys. 9, 2643 (2007).

[6] M. Bowden, T. Autrey, I. Brown, and M. Ryan, Curr. Appl. Phys. 8, 498 (2008).

[7] F. Baitalow, J. Baumann, G. Wolf, K. Jaenicke-Ro“ssler, and G. Leitner, Thermochim. Acta 391, 159 (2002).

[8] G. Wolf, J. Baumann, F. Baitalow, and F. P. Hoffmann, Thermochim. Acta 343, 19 (2000).

[9] A. Gutowska, L. Li, Y. Shin, C. M. Wang, X. S. Li, J. C. Linehan, R. S. Smith, B. D. Kay, B. Schmid, W. Shaw, M. Gutowski, and T. Autrey, Angew. Chem., Int. Ed. 44, 3578 (2005).

[10] M. E. Bluhm, M. G. Bradley, R. Butterick, U. Kusari, and L. G. Sneddon, J. Am. Chem. Soc. 128, 7748 (2006).

[11] F. H. Stephens, R. T. Baker, M. H. Matus, D. J. Grant, and D. A. Dixon, Angew. Chem., Int. Ed. 46, 746 (2007).

[12] R.J. Keaton, J.M. Blacquiere, and R.T. Baker, J. Am. Chem. Soc.129, 1844 (2007).

[13] C. A. Jaska, K. Temple, A. J. Lough, and I. Manners, J. Am. Chem. Soc. 125, 9424 (2003).

[14] C.W. Hamilton, R.T. Baker, A. Staubitz A, and I. Manners, Chem. Soc. Rev. 38(1):279 (2009).

[15] Z. Xiong, et al. Nat. Mater. 7, 138 (2008).

[16] X. Kang X, et al. Adv. Mater., 20, 2756(2008).

[17] Y.S. Chua, P. Chen, G. Wu, Z. Xiong (2011), Chem. Commun. (Camb.) 47, 5116 (2011).

[18] H. Wu, W. Zhou, T. Yildirim (2008), J. Am. Chem. Soc. 130, 14834 (2008). 
[19] H. V. K. Diyabalanage, et al. Angew Chem. Int. Ed. 46, 8995 (2007).

[20] H.V.K. Diyabalanage, et al., J. Am. Chem. Soc. 132, 11836 (2010).

[21] Z. Xiong, et al. Energy Environ. Sci. 1, 360 (2008).

[22] W.L. Mao, H.K. Mao, Proc. Natl. Acad. Sci. USA 101, 708 (2004).

[23] W. L. Mao, C. A. Koh, E.D. Sloan, Phys. Today 60, 42 (2007).

[24] W.L. Mao WL, et al. Science 297, 2247 (2002).

[25] S. Trudel and D. F. R. Gilson, Inorg. Chem. 42, 2814 (2003).

[26] R. Custelcean and Z. A. Dreger, J. Phys. Chem. B 107, 9231(2003).

[27] Y. Lin, W. L. Mao, Vadym Drozd, J. Chen, and L. L. Daemen, J. Chem. Phys. 129, 234509 (2008).

[28] R.S. Chellappa, M. Somayazulu, V.V. Struzhkin, T. Autrey, R.J. Hemley (2009) J. Chem. Phys. 131, 2245151 (2009).

[29] J. Chen, H. Couvy, H. Liu, Vadym Drozd, L. L. Daemen, Y. Zhao, C.-C. Kao, Int. J. Hydrogen Energy 35, 11064 (2010).

[30] S. Xie, Y. Song, and Z. Liu, Can. J. Chem. 87, 1235 (2009).

[31] K.R. Ryan, et al. Phys. Chem. Chem. Phys. 13, 12249 (2011).

[32] S.M. Lee, X.D. Kang, P. Wang, H.M. Cheng, Y.H.A. Lee Chem. Phys. Chem. 10, 1825 (2009).

[33] M. Ramzan, et al. Phys. Rev. B 79, 1321021 (2009).

[34] L. Cai-Lin, et al. Commun. Theor. Phys. 53, 1167 (2010).

[35] D.R. Armstrong, P.G. Perkins, and G.T. Walker, J. Mol. Struct. THEOCHEM 122, 189 (1985).

[36] T. Kar, S. Scheiner (2003), J. Chem. Phys. 119, 1473 (2003). 
[37] A. Fujii, G.N. Patwari, T. Ebata, and N. Mikami, Int. J. Mass Spectrom. 220, 289 (2002).

[38] E.R. Lippincott, R. Schroeder, J. Chem. Phys. 23, 1099 (1955).

[39] S.H. Moon, H.G. Drickamer, J. Chem. Phys. 61, 48 (1974).

[40] S.D. Hamann, M. Linton, Aust. J. Chem. 28, 2567 (1975).

[41] S.D. Hamann, M. Linton, Aust. J. Chem. 29, 479 (1976).

[42] S.D. Hamann, M. Linton, Aust. J. Chem. 29, 1641 (1976).

[43] S.D. Hamann, M. Linton, Aust. J. Chem. 29, 1825 (1976).

[44] S.D. Hamann, Aust. J. Chem. 30, 71 (1977).

[45] S.D. Hamann, Aust. J. Chem. 31, 11 (1978).

[46] S.D. Hamann, Aust. J. Chem. 41, 1935 (1988).

[47] R.H. Crabtree, P.E.M. Siegbahn, O. Eisenstein, A.L. Rheingold, and T.F. Koetzle, Acc. Chem. Res. 29, 348 (1996).

[48] W.T. Klooster, T.F. Koetzle, P.E.M. Siegbahn, T.B. Richardson, R.H. Crabtree (1999) J. Am. Chem. Soc. 121, 6337 (1999).

[49] T.B. Richardson, S.D. Gala, and R.H. Crabtree, J. Am. Chem. Soc. 117:12875 (1995).

[50] T.B. Richardson, T.F. Koetzle, R.H. Crabtree (1996) Inorg. Chim. Acta. 250, 69 (1996).

[51] C. Wu, et al. (2010), Inorg. Chem. 49, 4319 (2010).

[52] C. F. Hoon and E. C. Reynhardt, J. Phys. C 16, 6129 (1983).

[53] Li W, et al., J. Phys. Chem. C 114, 19089 (2010).

[54] W. Grochala, P.P. Edwards, Chem. Rev. 104, 1283 (2004).

[55] J. Lu, Z.Z. Fang, H.Y. Sohn, Inorg. Chem. 45, 8749 (2006).

[56] S. Swinnen, V.S. Nguyen, M.T. Nguyen, Chem. Phys. Lett. 489, 148 (2010). 
[57] D.Y. Kim, H.M. Lee, J. Seo, S.K. Shin, and K.S. Kim, Phys. Chem. Chem. Phys. 12, 5446 (2010).

[58] H.K. Mao, and P.M. Bell, J. Appl. Phys. 49, 3276 (1978).

[59] H.K. Mao, J. Xu, and P.M. Bell, J. Geophys. Res. 91, 4673 (1986). 


\section{PRESSURE INFLUENCE ON THE LOW TEMPERATURE PHASE TRANSITION OF AMMONIA BORANE}

The effect of pressure on the low temperature tetragonal $(14 \mathrm{~mm})$ to orthorhombic $\left(P m n 2_{1}\right)$ phase transition of ammonia borane $\left(\mathrm{NH}_{3} \mathrm{BH}_{3}\right)$, was investigated in diamond anvil cell using Raman spectroscopy. With applied pressure the transition occurs at higher temperature, which indicates pressure enhances the ordering of the structure. The Clapeyron slope of the transition was determined to be $\mathrm{dP} / \mathrm{dT}=\sim 25.7 \mathrm{MPa} / \mathrm{K}$, indicating the transformation is of exothermic. Appearance of some of the characteristic Raman modes of orthorhombic phase requires undercooling of around $\sim 15 \mathrm{~K}$ below the transition, indicating possible existence of an intermediate phase.

\subsection{Introduction}

As mentined earlier, ammonia borane $\left(\mathrm{NH}_{3} \mathrm{BH}_{3}\right)$ has recently drawn great attention as high potential hydrogen storage material due to high gravimetric and volumetric hydrogen density [1-4]. However, a fairly high temperature of $500{ }^{\circ} \mathrm{C}$ is required to release all the hydrogen atoms [5]. Recently significant research efforts have been taken to lower the dehydrogenation temperature of $\mathrm{NH}_{3} \mathrm{BH}_{3}$ and to enhance the discharge rate of hydrogen using the nanoscaffolds [6], ionic liquids [7], acid [8] and transition metal catalysts $[9,10]$. In fact, the development of methods to enhance hydrogen discharge rate from ammonia borane requires a detailed study about the structural and dynamical properties that control the stability and the intermolecular interactions of this material.

As discussed earlier, ammonia borane exhibits an unusual bonding system that is responsible for some unexpected physical properties. For example, its melting point (104 
$\left.{ }^{\circ} \mathrm{C}\right)$ is much higher than the isoelectronic $\mathrm{C}_{2} \mathrm{H}_{6}\left(-181{ }^{\circ} \mathrm{C}\right)$. Part of this difference comes from the polarity of $\mathrm{NH}_{3} \mathrm{BH}_{3}(5.2 \mathrm{D})$. However, the polar $(1.8 \mathrm{D}) \mathrm{CH}_{3} \mathrm{~F}$ has a proportionally much lower melting point $\left(-140^{\circ} \mathrm{C}\right)$ elevation relative to ethane, so other factors might exist behind this unexpected property. One of the characteristic features of ammonia borane is that due to the differing electronegativities of the $\mathrm{B}$ and $\mathrm{N}$ atoms, the hydrogen atoms have different charges. As nitrogen is strongly electronegative, the hydrogens bound to nitrogen are protonic $\left(\mathrm{H}^{\delta+}\right)$ in character; while boron is less electronegative than hydrogen and thus the hydrogens bound to boron are hydridic $\left(\mathrm{H}^{\delta-}\right)$ in character. These two hydrogen species form a network of N-H ${ }^{\delta+} \ldots{ }^{-\delta} \mathrm{H}-\mathrm{B}$ dihydrogen bonds and stabilizes the structure as solid due to unusually short H...H distances.

Pressure and temperature has a significant effect on the structural stability of this molecular solid. At ambient condition, ammonia borane crystallizes as body centered tetragonal $(14 \mathrm{~mm})$ structure [10-15], which transforms to the low temperature orthorhombic $\left(\mathrm{Pmn}_{1}\right)$ phase at $\sim 218-225 \mathrm{~K}$ during cooling $[14,15]$ and to the high pressure orthorhombic phase $\left(\mathrm{Cmc}_{1}\right)$ at $\sim 1.3-2.4 \mathrm{GPa}$ during compression $[16,19,20]$. These transitions result in a significant change in the lattice dynamics although the molecular structure of $\mathrm{NH}_{3} \mathrm{BH}_{3}$ molecule is preserved. In the $14 \mathrm{~mm}$ phase the molecular axes are aligned along the lattice $\mathrm{c}$ axis, while the molecular axes become inclined relative to the $\mathrm{c}$ axis in these two orthorhombic phases. The pressure-temperature phase boundary between the $14 \mathrm{~mm}$ and $\mathrm{Cmc2} 2_{1}$ phaseS has been determined which has a negative Clapeyron slope indicating the transformation is of endothermic [20]. However, there is no study about the pressure-temperature phase boundary between the $14 \mathrm{~mm}$ and low temperature orthorhombic $P m n 2_{1}$ phase. Recently this transition attracts more 
attention because of the absence of this transition in ammonia borane embedded in mesoporous silica which reduces dehydrogenation temperature significantly [21,22]. Therefore it is important to understand details about this phase transition. Here a Raman spectroscopic study of the $I 4 \mathrm{~mm}$ to $\mathrm{Pmn}_{1}$ phase transformation at high pressures has been reported.

The chapter is organized as follows. First, all necessary information on experimental techniques has been discussed. Second, experimental data has been described to characterize the room temperature tetragonal phase and low temperature orthorhombic phase to compare with the previous study about characteristic Raman modes of this material. Third, the effect of annealing time at the onset transition temperature on the appearance of all characteristic Raman modes of orthorhombic phase has been described. Finally, the pressure-temperature data collected during different cooling cycles has been plotted and the phase boundary between these two phases has been described. The aim of this study is to obtain the phase boundary between $14 \mathrm{~mm}$ and $P m n 2_{1}$ phases. So, the pressure range studied in this experiment is kept well below the pressure at which the $\mathrm{Cmc} 2{ }_{1}$ phase transition starts at room temperature.

\subsection{Experimental}

The experiment was carried out with ammonia borane powder purchased from Sigma Aldrich, with a purity greater than 97\%, and was used without further purification. A symmetric diamond anvil cell (DAC) with two type-I diamonds of $400 \mu \mathrm{m}$ culet size was used for the experiment. A stainless steel gasket was indented to $70 \mu \mathrm{m}$ thickness and then a hole of $180 \mu \mathrm{m}$ diameter was drilled in the center as a sample chamber. Ammonia borane powders, along with few ruby chips for pressure measurement, were 
loaded in the sample chamber. Few ruby chips were placed on the backside of one diamond anvil (on the table side) for measuring the ruby fluorescence at ambient pressure and low temperatures, in order to determine the effect of temperature on ruby fluorescence shift. The cell was pressurized first and then it was loaded in the cryogenic system of liquid nitrogen cooling media. Raman spectra of the sample and the ruby fluorescence spectra were collected at every step during cooling. Temperature was controlled by Cryogenic Temperature Controller which has two Si-diode sensors. Temperature was regulated with a gradient of $\sim \pm 0.5$ Kelvin. At every step of the data collection, the system was held for $\sim 15$ minutes to allow the system to reach thermal equilibrium. Raman spectroscopy was conducted by using a $514 \mathrm{~nm} \mathrm{Ar}^{+}$laser as excitation source.

\subsection{Results and discussion}

\subsubsection{Raman mode change: Tetragonal}

Based on the earlier vibrational studies [26,28], the Raman spectrum (Figure 5.1) of tetragonal ammonia borane (295 K, $0.7 \mathrm{GPa})$ can be conveniently discussed in several segments defined by its molecular nature as follows: $\mathrm{N}-\mathrm{H}$ stretching region (2750-3400 cm $\left.\mathrm{cm}^{-1}\right)$; B-H stretching region $\left(2100-2700 \mathrm{~cm}^{-1}\right) ; \mathrm{N}-\mathrm{H}$ rocking and deformation modes, $\mathrm{B}-\mathrm{H}$ rocking and deformation modes, and the $\mathrm{B}-\mathrm{N}$ stretching region $\left(600-1650 \mathrm{~cm}^{-1}\right)$.

The N-H asymmetric and symmetric stretching vibrations are observed at 3311 and $3245 \mathrm{~cm}^{-1}$ respectively and an additional peak is seen at $3173 \mathrm{~cm}^{-1}$ due to the Fermi resonance mode (overtone of an $\mathrm{NH}_{3}$ deformation mode and $\mathrm{NH}_{3}$ stretching fundamental). The Raman spectra of the B-H stretching region shows two intense peaks 
at 2277 and $2375 \mathrm{~cm}^{-1}$ and a very weak shoulder peak at $2329 \mathrm{~cm}^{-1}$. There is disagreement over the symmetry assignment of peaks in this region. Based on their observation that only the $2375 \mathrm{~cm}^{-1}$ peak splitted with the application of pressure, whereas the 2277 and $2328 \mathrm{~cm}^{-1}$ did not split, Lin et al., assigned the $2277 \mathrm{~cm}^{-1}$ peak to the symmetric B-H stretching mode and the $2375 \mathrm{~cm}^{-1}$ peak to the asymmetric B-H stretching mode. However, in powder studies the $2328 \mathrm{~cm}^{-1}$ shoulder peak was assigned as the asymmetric B-H stretch and the $2277 \mathrm{~cm}^{-1}$ peak as the symmetric B-H stretch $[25,26]$. Also, recent single crystal studies assign the $2277 \mathrm{~cm}^{-1}$ peak to the $\mathrm{B}-\mathrm{H}$ symmetric stretch and the $2328 \mathrm{~cm}^{-1}$ to the B-H asymmetric stretch based on $88 \mathrm{~K}$ polarization measurements [28]. We are tentatively assigning the $2328 \mathrm{~cm}^{-1}$ peak as the asymmetric and $2277 \mathrm{~cm}^{-1}$ to the symmetric, as these two peaks show splitting at low temperature and generally the asymmetric mode has higher wavenumber than the symmetric one. There are two $\mathrm{NH}_{3}$ deformation modes: the asymmetric mode at $1595 \mathrm{~cm}^{-}$ ${ }^{1}$ (due to scissor like motion) and the symmetric mode at $1376 \mathrm{~cm}^{-1}$ (due to umbrella like motion). There is also an overtone mode at $1446 \mathrm{~cm}^{-1}$. Because of strong diamond peak, the symmetric mode at $1376 \mathrm{~cm}^{-1}$ and the overtone mode at $1446 \mathrm{~cm}^{-1}$ are not obvious. Asymmetric $\mathrm{BH}_{3}$ deformation mode (due to umbrella like motion) and symmetric $\mathrm{BH}_{3}$ deformation mode (due to scissor like motion) are seen at 1186 and $1160 \mathrm{~cm}^{-1}$ respectively. A combination of $\mathrm{N}-\mathrm{H}$ and $\mathrm{B}-\mathrm{H}$ rocking modes (due to the torsional motion of $\mathrm{H}$ atoms of $\mathrm{NH}_{3}$ and $\mathrm{BH}_{3}$ around the $\mathrm{BN}$ bond) are seen at frequencies of 727 and $1055 \mathrm{~cm}^{-1}$. The peak at $1055 \mathrm{~cm}^{-1}$ is of very low intensity. The B-N stretching consists of two modes: ${ }^{11} \mathrm{BN}$ mode at $783 \mathrm{~cm}^{-1}$ and ${ }^{10} \mathrm{BN}$ at $799 \mathrm{~cm}^{-1}$. 


\subsubsection{Raman mode change: Orthorhombic}

Upon cooling, the tetragonal structure transforms into the orthorhombic structure, which can be characterized by changes of Raman modes assigned by N.J. Hess et al. [28]. Figure 5.1 shows the collected Raman spectra during one cooling cycle. Mode assignments are listed in Table 5.1. Generally the pressure increases during cooling due to thermal contraction of the system. The sample pressure was calculated from ruby fluorescence with temperature correction [23-25]. Temperature and corresponding pressure of the system is mentioned in each spectrum.

The asymmetric N-H stretching mode starts to broaden at $\sim(260 \mathrm{~K}, 0.9 \mathrm{GPa})$ and at $\sim(250 \mathrm{~K}, 0.8 \mathrm{GPa})$ it splits in to two components at 3327 and $3302 \mathrm{~cm}^{-1}$, which splits again into four modes upon further cooling to $\sim(245 \mathrm{~K}, 0.8 \mathrm{GPa})$ as expected from full factor group splitting. Symmetric N-H stretching mode at $3245 \mathrm{~cm}^{-1}$ remains unchanged across the phase transition and unassigned mode at $3173 \mathrm{~cm}^{-1}$ splits into two modes at 3192 and $3165 \mathrm{~cm}^{-1}$. At $\sim(250 \mathrm{~K}, 0.8 \mathrm{GPa})$, symmetric B-H stretching mode at $2277 \mathrm{~cm}^{-1}$ clearly splits into two components, the asymmetric mode at $2328 \mathrm{~cm}^{-1}$ splits into two modes which is poorly resolved at $(245 \mathrm{~K}, 0.8 \mathrm{Gpa})$ and one additional peak at $2394 \mathrm{~cm}^{-1}$ can be discerned. At $(255 \mathrm{~K}, 0.8 \mathrm{GPa})$ asymmetric $\mathrm{NH}_{3}$ deformation mode at $1595 \mathrm{~cm}^{-1}$ splits into only two components and these modes each split into two additional components at $(245 \mathrm{~K}, 0.8 \mathrm{GPa})$. Likewise, asymmetric $\mathrm{BH}_{3}$ deformation mode splits into two modes upon cooling to $(260 \mathrm{~K}, 0.9 \mathrm{GPa})$ which splits again upon further cooling to $(245 \mathrm{~K}, 0.8 \mathrm{GPa})$. The symmetric $\mathrm{BH}_{3}$ deformation mode splits into two components at $(245 \mathrm{~K}, 0.8 \mathrm{GPa})$. NBH rocking mode at $1055 \mathrm{~cm}^{-1}$ becomes intense during cooling and splits into three modes at $(245 \mathrm{~K}, 0.8 \mathrm{GPa})$. The lower frequency rocking mode at 727 
$\mathrm{cm}^{-1}$ displays similar behavior and splits into three peaks at $(260 \mathrm{~K}, 0.9 \mathrm{GPa}) .{ }^{11} \mathrm{~B}-\mathrm{N}$ and ${ }^{10} \mathrm{~B}-\mathrm{N}$ stretching modes appear at 800 and $818 \mathrm{~cm}^{-1}$ respectively at $(245 \mathrm{~K}, 0.8 \mathrm{GPa})$. No peak splitting is observed at tetragonal to orthorhombic phase transition for the $\mathrm{BN}$ stretching region.

\subsubsection{Undercooling: presence of an intermediate phase}

Based on the above discussion, it can be concluded that although the $14 \mathrm{~mm}$ to Pmn2 ${ }_{1}$ phase transition starts at $\sim(260 \mathrm{~K}, 0.9 \mathrm{GPa})$ with the occurrence of splitting of some of the Raman modes, the transition completes at $\sim(245 \mathrm{~K}, 0.8 \mathrm{GPa})$ with full factor group splitting. Asymmetric N-H and B-H stretching modes, symmetric B-H stretch, asymmetric $\mathrm{NH}_{3}$ and $\mathrm{BH}_{3}$ deformation modes, symmetric $\mathrm{BH}_{3}$ deformation modes, high frequency NBH rocking mode, are examples of this delayed behavior. This delayed behavior may indicate presence of an intermediate phase below the phase transition temperature. Raman study [28] of single crystal at ambient pressure also shows the similar kind of behavior. However, inelastic spectroscopy study claims the opposite phenomenon that the transition occurs within fraction of a Kelvin [30-32]. Once the phase transition completes at $(245 \mathrm{~K}, 0.8 \mathrm{GPa})$, no further peak splitting is observed on cooling down to $\sim(90 \mathrm{~K}, 3 \mathrm{GPa})$, only the splitting resolution becomes more discernible due to lowering the temperature of the system. 


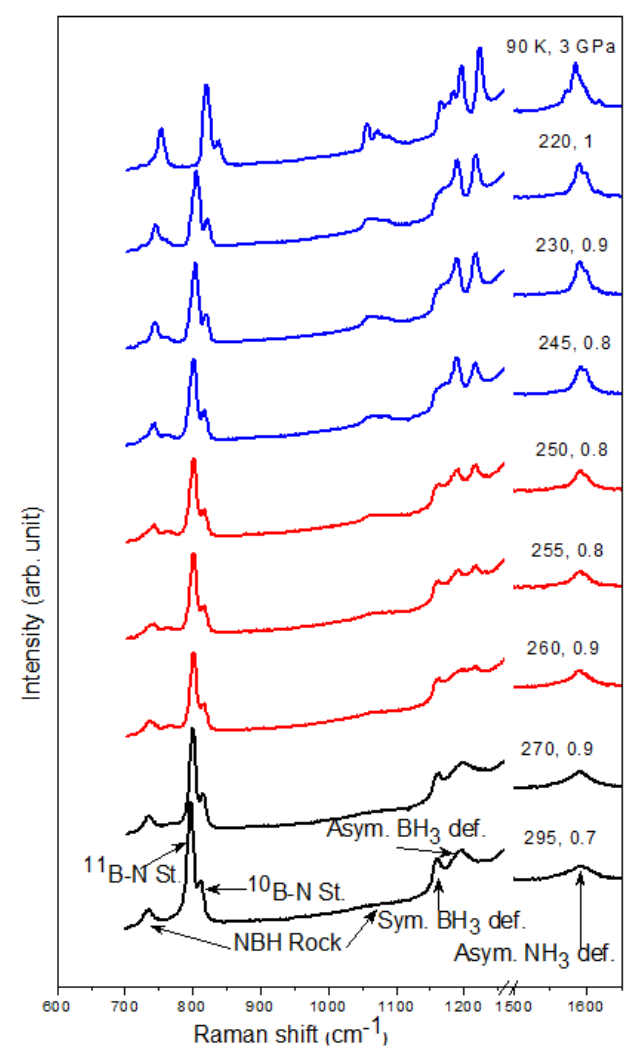

(a)

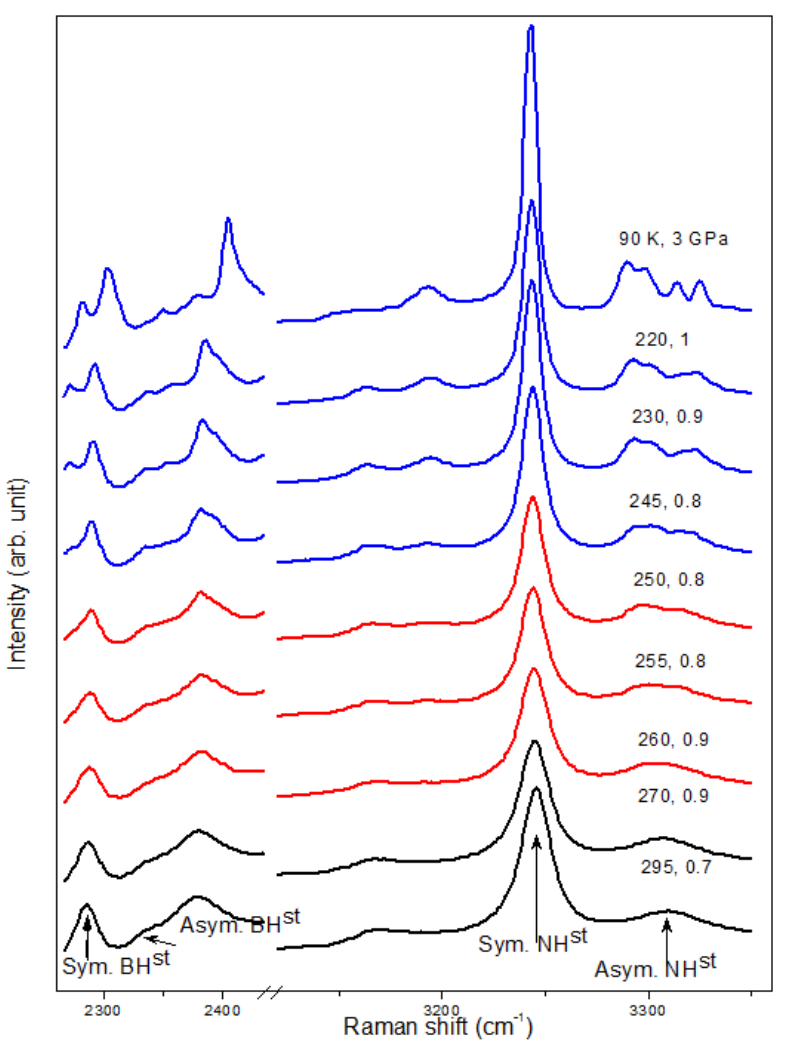

(b)

Figure 5.1 Selected Raman spectra of $\mathrm{NH}_{3} \mathrm{BH}_{3}$ at different temperature and pressure in the spectral region of (a) $700-1650 \mathrm{~cm}^{-1}$ and (b) $2260-3350 \mathrm{~cm}^{-1}$. The intense Raman mode of Diamond anvil is truncated in the region of $1250-1550 \mathrm{~cm}^{-1}$ and $2430-3120 \mathrm{~cm}^{-1}$. The sample pressure and temperature are indicated in each spectrum.

To see whether there is any effect of time to the appearance of full factor group splitting for the transition, the sample was annealed at the onset transition temperature for both short and long period during cooling of another sample (Figure 4.2). At the onset temperature, the sample was annealed for short period ( $\sim 15$ minutes) and for long period ( $\sim 40$ minutes) before recording Raman spectra. Longer annealing time did not enhance the splitting of all the Raman modes characteristic of the orthorhombic phase. This 
illustrates that the appearance of all the Raman modes of the orthorhombic phase is not kinetically controlled; rather it requires certain undercooling $(\sim 15 \mathrm{~K})$ 
Table 5.1 Raman modes of ammonia borane observed under different conditions (n.r.: not resolved due to strong diamond peak).

\section{Mode}

Asymmetric N-H stretch

Symmetric N-H stretch

3170

Unassigned

Assymetric B-H stretch

Symetric B-H stretch

$\mathrm{NH}_{3}$ deformation

3312

2316

2277

2115

1597

$\begin{array}{llll} & & \text { This study } & \text { Single } \\ \text { Powder (Ref. } & \text { Powder } & \begin{array}{l}\text { (298 K, 0.7 } \\ \text { crystal (Ref }\end{array} \\ \text { (Ref. 19) } & \text { GPa) } & \text { 28) }\end{array}$

3319

3311

3316

3253

3245

3173

2376

2375

2375

2329

2280

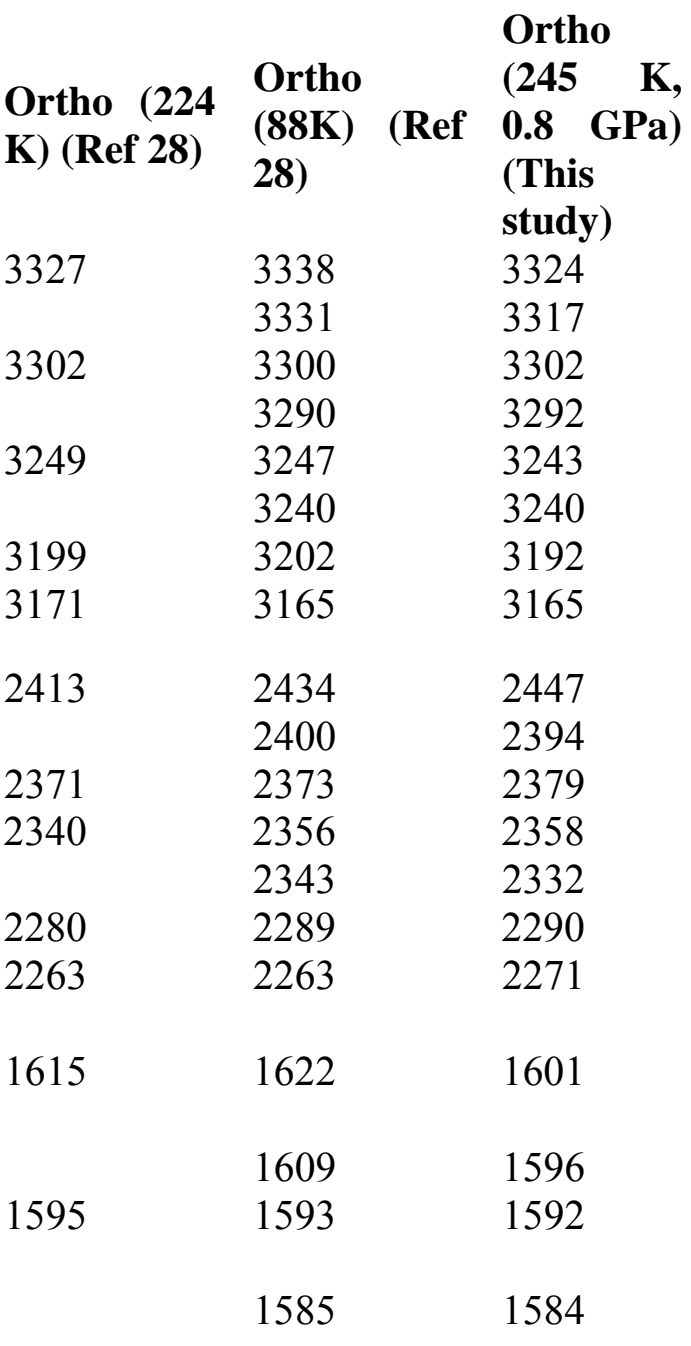




\begin{tabular}{|c|c|c|c|c|c|c|c|}
\hline & 1374 & 1377 & 1446 & 1450 & 1467 & 1470 & n.r. \\
\hline & & & & & 1453 & 1454 & n.r. \\
\hline $\mathrm{NH}_{3}$ deformation & & & 1376 & 1357 & 1405 & 1400 & n.r. \\
\hline & & & & & 1376 & 1374 & n.r. \\
\hline $\mathrm{BH}_{3}$ deformation & 1165 & 1188 & 1186 & 1189 & 1209 & 1220 & 1218 \\
\hline & & & & & & 1214 & 1214 \\
\hline & & & & & 1178 & 1180 & 1190 \\
\hline & & & & & & 1173 & 1180 \\
\hline $\mathrm{BH}_{3}$ deformation & & 1161 & 1160 & 1155 & 1164 & 1166 & 1168 \\
\hline & & & & & 1156 & 1157 & 1159 \\
\hline NBH rock & 1058 & 1067 & 1055 & 1065 & 1080 & 1086 & 1084 \\
\hline & & & & & 1066 & 1073 & 1066 \\
\hline & 1026 & & & & 1062 & 1056 & 1056 \\
\hline${ }^{10} \mathrm{~B}-\mathrm{N}$ & & & & & & & \\
\hline Stretch & 790 & 798 & 799 & 800 & 804 & 813 & 818 \\
\hline & & & & & & 810 & \\
\hline${ }^{11} \mathrm{~B}-\mathrm{N}$ & & & & & & & \\
\hline Stretch & 776 & 783 & 783 & 784 & 789 & 798 & 800 \\
\hline & & & & & & 794 & \\
\hline NBH rock & 715 & 728 & 727 & 727 & 734 & 740 & 761 \\
\hline & & & & & 727 & 731 & 742 \\
\hline & & & & & 723 & 721 & 732 \\
\hline
\end{tabular}




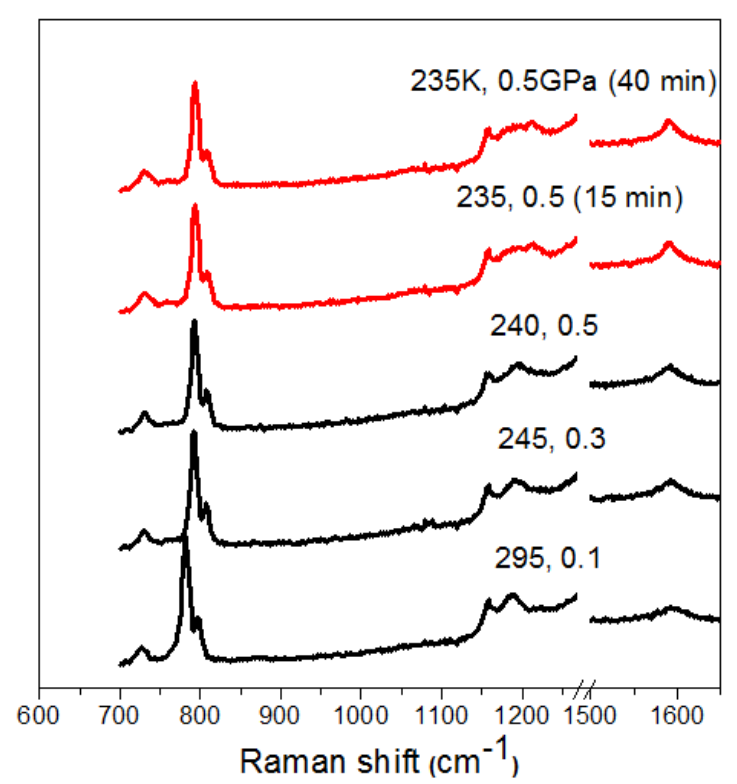

(a)

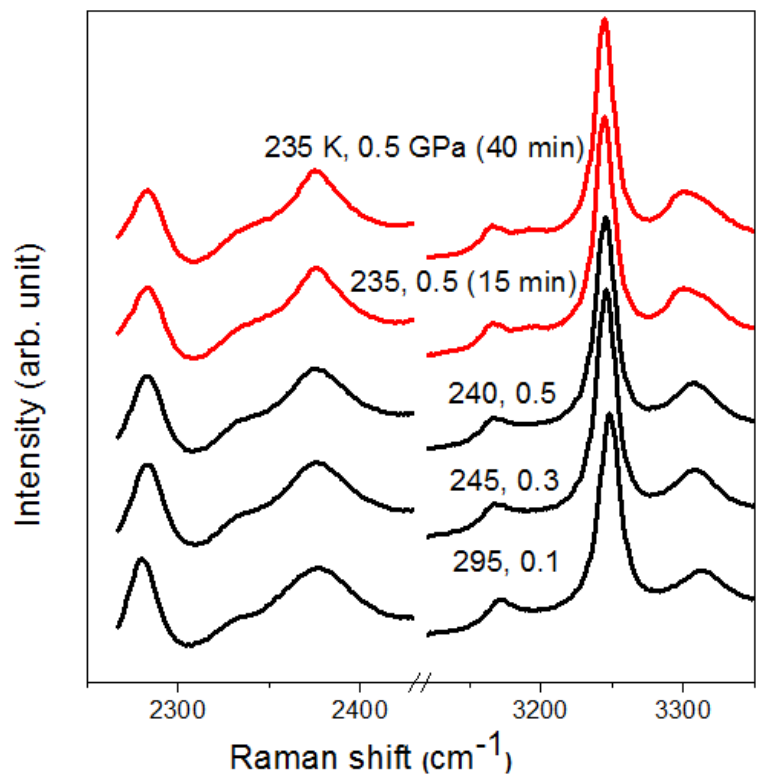

(b)

Figure 5.2 Effect of annealing time at the onset transition temperature: selected Raman spectra of $\mathrm{NH}_{3} \mathrm{BH}_{3}$ at different temperature and pressure in the spectral region of (a) 700$1650 \mathrm{~cm}^{-1}$ and (b) 2260-3350 $\mathrm{cm}^{-1}$. The intense Raman mode of Diamond anvil is truncated in the region of $1250-1550 \mathrm{~cm}^{-1}$ and $2430-3120 \mathrm{~cm}^{-1}$. The sample pressure and temperature are indicated in each spectrum.

\subsubsection{P-T phase boundary between $I 4 \mathrm{~mm}$ and $P m n 2_{1}$ phases}

At ambient pressure, tetragonal to orthorhombic phase transition occurs at around 218-225 K $[2-4,14,15]$. Due to application of pressure, the transition temperature increases. The derived phase boundary between $I 4 m m$ and $P m n 2_{1}$ phases is shown in Figure 5.3 and the positive Clapeyron slope is estimated to be $\sim 25.7 \mathrm{MPa} / \mathrm{K}$. The positive Clapeyron slope indicates that the phase transition from $14 \mathrm{~mm}$ and $\mathrm{Cmc2}{ }_{1}$ structure is of exothermic in nature, which is in good agreement with earlier DSC studies [29,32,33]. According to Chen et al. [20], the $I 4 m m$ to $C m c 2_{1}$ transition has a negative Clapeyron 
slope of $1.67 \mathrm{MPa} / \mathrm{K}$. So, although $C m c 2_{1}$ and $P m n 2_{1}$ have structural similarity, the nature of $I 4 m m$ to $C m c 2_{1}$ and $I 4 m m$ to $P m n 2_{1}$ phase transition is quite different.

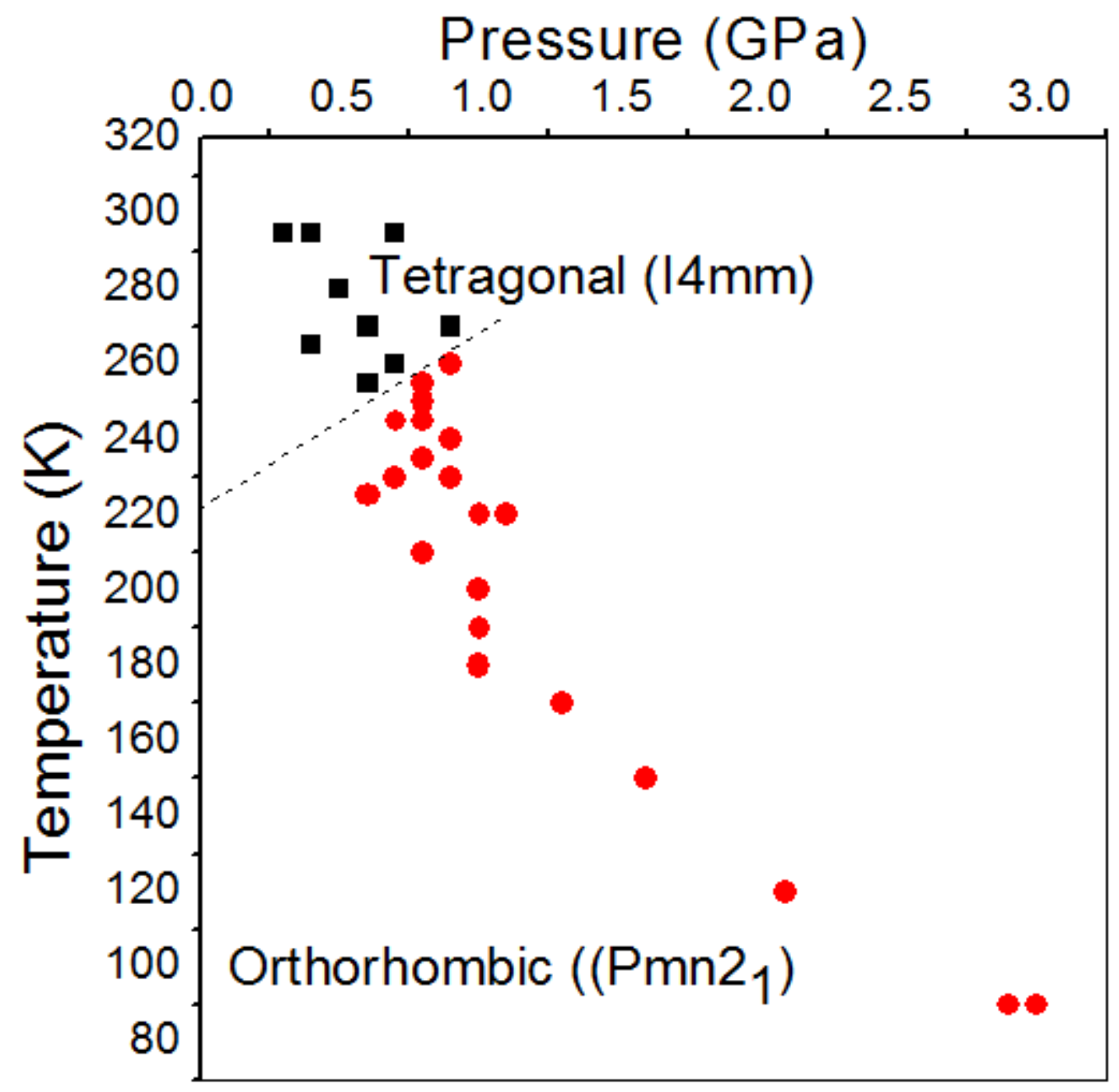

Figure 5.3 Phase boundary between the Tetragonal ( $\mathrm{I} 4 \mathrm{~mm})$ and Orthorhombic $\left(\mathrm{Pmn} 2_{1}\right)$ phase.

\subsection{Conclusion}

The transition temperature from disordered tetragonal $(14 \mathrm{~mm})$ structure to the ordered orthorhombic $\left(\mathrm{Pmn}_{1}\right)$ structure increases with pressure, which indicates the 
Clapeyron slope is positive, i.e. the transition is exothermic. The appearance of full factor group splitting of orthorhombic is not kinetic-controlled, rather it requires undercooling of around $\sim 15 \mathrm{~K}$ below the transition temperature.

\subsection{References}

[1] G. Wolf, J. Baumann, F. Baitalow, and F. P. Hoffmann, Thermochim. Acta 343, 19 (2000).

[2] F. Baitalow, J. Baumann, G. Wolf, K. Jaenicke-Ro"ssler, and G. Leitner, Thermochim. Acta 391, 159 (2002).

[3] P. A. Storozhenko, R. A. Svitsyn, V. A. Ketsko, A. K. Buryak, and A. V. Ulyanov, Russ. J. Inorg. Chem. 50, 980 (2005).

[4] M. Bowden, T. Autrey, I. Brown, and M. Ryan, Curr. Appl. Phys. 8, 498 (2008).

[5] M. G. Hu, R. A. Geanangel, and W. W. Wendlandt, Thermochim. Acta 23, 249 (1978).

[6] A. Gutowska, L. Li, Y. Shin, C. M. Wang, X. S. Li, J. C. Linehan, R. S. Smith, B. D. Kay, B. Schmid, W. Shaw, M. Gutowski, and T. Autrey, Angew. Chem., Int. Ed. 44, 3578 (2005).

[7] M. E. Bluhm, M. G. Bradley, R. Butterick, U. Kusari, and L. G. Sneddon, J. Am. Chem. Soc. 128, 7748 (2006).

[8] F. H. Stephens, R. T. Baker, M. H. Matus, D. J. Grant, and D. A. Dixon, Angew. Chem., Int. Ed. 46, 746 (2007).

[9] C. A. Jaska, K. Temple, A. J. Lough, and I. Manners, J. Am. Chem. Soc. 125, 9424 (2003).

[10] M. C. Denney, V. Pons, T. J. Hebden, M. Heinekey, and K. I. Goldberg, J. Am. Chem. Soc. 128, 12048 (2006).

[11] M. E. Bowden, G. J. Gainsford, and W. T. Robinson, Aust. J. Chem. 60, 149 (2007).

[12] S. G. Shore and R. W. Parry, J. Am. Chem. Soc. 77, 6085 (1955).

[13] E. W. Hughes, J. Am. Chem. Soc. 78, 502 (1956).

[14] C. F. Hoon and E. C. Reynhardt, J. Phys. C 16, 6129 (1983). 
[15] M. E. Bowden, G. J. Gainsford, and W. T. Robinson, Aust. J. Chem. 60, 149 (2007).

[16] Y. Lin, W. L. Mao, Vadym Drozd, J. Chen, and L. L. Daemen, J. Chem. Phys. 129, 234509 (2008).

[17] S. Trudel and D. F. R. Gilson, Inorg. Chem. 42, 2814 (2003).

[18] R. Custelcean and Z. A. Dreger, J. Phys. Chem. B 107, 9231(2003).

[19] S. Xie, Y. Song, and Z. Liu, Can. J. Chem. 87, 1235 (2009).

[20] J. Chen, H. Couvy, H. Liu, Vadym Drozd, L. L. Daemen, Y. Zhao, C.-C. Kao, Int. J. Hydrogen Energy 35, 11064 (2010).

[21] H. Kim, A. Karkamkar, T. Autrey, P. Chupas, and T. Proffen, J. Am. Chem. Soc. 131,13749 (2009).

[22] A. Paolone, O. Palumbo, P. Rispoli, R. Cantelli, T. Autrey, and A. Karkamkar, J. Phys. Chem. C 113, 10319 (2009).

[23] D. E. Mccumber and M. D. Sturge, J. Appl. Phys. 34, 1682 (1963).

[24] W. L. Vos and J. A. Schouten, J. Appl. Phys. 69, 6744(1991).

[25] H. K. Mao, J. Xu, and P. M. Bell, J. Geophys. Res. 91, 4673, (1986).

[26] T. B. Marder, Angew. Chem. Int. Ed. 46, 8116 (2007).

[27] A. C. Stowe, W. J. Shaw, J. C. Linehan, B. Schmid, and T. Autrey, Phys. Chem. Chem. Phys. 15, 1831 (2007).

[28] N. J. Hess, M. E. Bowden, V. M. Parvanov, C. Mundy, S. M. Kathmann, G. K. Schenter, and T. Autrey, J. Chem. Phys. 128, 034508 (2008).

[29] G. Wolf, J. C. van Miltenburg, and U. Wolf, Thermochim. Acta 317, 111(1998).

[30] A. Paolone, O. Palumbo, P. Rispoli, R. Cantelli, and T. Autrey, J. Phys. Chem. C $113,5872(2009)$.

[31] A. Paolone, O. Palumbo, P. Rispoli, R. Cantelli, and T. Autreye, Mater. Sci. Eng. A 521-522, 169 (2009).

[32] O. Palumbo, A. Paolone, P. Rispoli, R. Cantelli, T. Autrey, and M. A. Navarra, J. Alloys Compd. 509S, S709 (2011). 
[33] W. J. James, L. Jagat, Q. Cai, W. B. Yelon, and J. B. Yang, Mater. Sci. Forum 610613, 425 (2009). 


\section{NANOCONFINEMENT INFLUENCE ON THE PHASE TRANSITION OF NANOCONFINED AMMONIA BORANE}

Nanoconfinement of ammonia borane inside mesoporous silica improves its hydrogen storage property. Mesoporous silica scaffolds SBA-15 and MCM-41 were used to nanoconfine ammonia borane to investigate the thermodynamic property modification due to nanoconfinement. The effect of different pore size nanoconfinement on the transition temperature of the characteristic tetragonal $(\mathrm{I} 4 \mathrm{~mm})$ to orthorhombic $\left(P m n 2_{1}\right)$ phase transition of ammonia borane, was investigated using Raman spectroscopy. In neat ammonia borane, the phase transition occurs at around $217 \mathrm{~K}$, whereas SBA-15 nanoconfinement of ammonia borane lowers the transition temperature to around $195 \mathrm{~K}$ and MCM-41 nanoconfinement of ammonia borane suppresses the transition temperature to below $90 \mathrm{~K}$. The lowering of the phase transition temperature can be related to the decrease of the pore size of mesoporous silica.

\subsection{Introduction}

The discovery of mesoporous silica, MCM-41 early in 1992 by Mobil Corporation [1] with ordered uniform pore sizes, followed by in 1998 of SBA-15 with larger pore sizes [2], has stimulated a wide variety of research. The common research areas include fundamental studies of sorption and phase transitions in confined spaces, and effect of pore size and surface characteristics on ion exchange, and inclusion of various metal complexes and other guests [3-6]. MCM-41 and SBA-15 are two forms of mesoporous silica with different pore sizes and particle morphology. Recently, it has been reported that nanocomposition of ammonia borane inside mesoporous silica scaffold shows dramatically improved hydrogen storage properties in many aspects: 
nanoconfinement significantly improves the kinetics of hydrogen discharge at lower temperature and also the contamination of borazine is reduced [7]. Recently, it has also been reported that use of mesoporous materials as scaffolds for nanoconfinement of ammonia borane significantly changes the thermodynamic property of ammonia borane $[8,9]$. Fundamental study is required to understand the mechanism behind improved hydrogen storage property.

At ambient condition, ammonia borane crystallizes as body centered tetragonal $(I 4 m m)$ structure [10-15], which transforms to the low temperature orthorhombic $\left(P m n 2_{1}\right)$ phase at $\sim 218-225 \mathrm{~K}$ during cooling $[14,15]$. This characteristic phase transition temperature is suppressed in nanophase $A B$ embedded within mesoporous silica MCM41. In our study, we have used SBA-15 and MCM-41 mesoporous silica to investigate the tetragonal to orthorhombic phase transition phenomenon in nanoconfined ammonia borane. Here we report a Raman spectroscopic study of the $I 4 m m$ to $P m n 2_{1}$ phase transformation in nanoconfined ammonia borane.

\subsection{Experimental}

Ammonia borane powder was purchased from Sigma Aldrich, with the purity greater than $97 \%$, and was used without further purification. MCM-41 was purchased from Sigma Aldrich with pore size from 2.1-2.7 $\mathrm{nm}$ and BET surface area of $\sim 1000 \mathrm{~m}^{2} / \mathrm{g}$. SBA-15 was purchased from Novel Chemistry Corp. with $\sim 8 \mathrm{~nm}$ pore size and BET surface area $>650 \mathrm{~m}^{2} / \mathrm{g}$.

The sample of MCM-41 and SBA-15 nanoconfined ammonia borane was prepared following the procedure described by Kim et al. and Paolone et al. A solution of AB (50 $\mathrm{mg})$ in tetrahydrofuran $(\mathrm{THF})(1 \mathrm{~mL})$ was prepared and the solution was added to MCM- 
41 (100 mg) in small aliquots. The solution infiltrate into channels of MCM-41 by capillary effect. Infiltrated MCM-41 was dried by vacuum evaporation. This produces a sample of MCM-41 internally coated with ammonia borane (approximately 1:2 AB to MCM-41). The same procedure was followed to synthesize 1:2 AB to SBA-15 sample.

A symmetric diamond anvil cell with two type-I diamonds of $400 \mu \mathrm{m}$ culet size (due to high thermal conductivity of diamond) was used for the experiment. A stainless steel gasket was prepared with a hole of $250 \mu \mathrm{m}$ diameter drilled in the center as a sample chamber. Neat ammonia borane and SBA-15 embedded with ammonia borane samples were loaded in the sample chamber side by side. Few ruby chips for pressure measurement, were loaded in the sample chamber and few ruby chips were placed on the backside of one diamond anvil (on the table side) for measuring the ruby fluorescence at ambient pressure and low temperatures. The ruby outside and inside chamber showed same fluorescence shift, indicating ambient pressure inside the chamber. The cell was loaded in the cryogenic system of liquid nitrogen cooling medium. Raman spectra of the sample were collected during cooling. Temperature was controlled by Cryogenic Temperature Controller which has two Si-diode sensors. Temperature was regulated with a gradient of $\sim \pm 0.5$ Kelvin. At every step of the data collection, the system was held for $\sim 15$ minutes to allow the system to reach thermal equilibrium. Raman spectroscopy was conducted by using a $514 \mathrm{~nm} \mathrm{Ar}^{+}$laser as excitation source.

\subsection{Results and discussion}

\subsubsection{Raman mode change: Tetragonal}

As mentioned earlier, based on the earlier vibrational studies [18-20], the Raman spectra (black spectra in Figure 6.1a) of tetragonal ammonia borane (226 K) can 
be conveniently discussed in several segments defined by its molecular nature as follows: $\mathrm{N}-\mathrm{H}$ stretching region (2750-3400 $\left.\mathrm{cm}^{-1}\right)$; B-H stretching region $\left(2100-2700 \mathrm{~cm}^{-1}\right) ; \mathrm{N}-\mathrm{H}$ rocking and deformation modes, $\mathrm{B}-\mathrm{H}$ rocking and deformation modes, and the $\mathrm{B}-\mathrm{N}$ stretching region $\left(600-1650 \mathrm{~cm}^{-1}\right)$.

The asymmetric and symmetric $\mathrm{N}-\mathrm{H}$ stretching vibrations are observed at 3311 and $3245 \mathrm{~cm}^{-1}$ respectively and an additional peak is seen at $3173 \mathrm{~cm}^{-1}$ due to the Fermi resonance mode (overtone of an $\mathrm{NH}_{3}$ deformation mode and $\mathrm{NH}_{3}$ stretching fundamental). The Raman spectra of the B-H stretching region shows two intense peaks at 2277 and $2375 \mathrm{~cm}^{-1}$ and a very weak shoulder peak at $2328 \mathrm{~cm}^{-1}$. We are tentatively assigning the $2328 \mathrm{~cm}^{-1}$ peak as the asymmetric and $2277 \mathrm{~cm}^{-1}$ to the symmetric, as these two peaks show splitting at low temperature and generally the asymmetric mode has higher wavenumber than the symmetric one. There are two $\mathrm{NH}_{3}$ deformation modes: the asymmetric mode at $1595 \mathrm{~cm}^{-1}$ (due to scissor like motion) and the symmetric mode at $1376 \mathrm{~cm}^{-1}$ (due to umbrella like motion). Because of strong diamond peak, the symmetric mode at $1376 \mathrm{~cm}^{-1}$ is not obvious. Asymmetric $\mathrm{BH}_{3}$ deformation mode (due to umbrella like motion) and symmetric $\mathrm{BH}_{3}$ deformation mode (due to scissor like motion) are seen at 1186 and $1160 \mathrm{~cm}^{-1}$ respectively. A combination of N-H and B-H rocking modes (due to the torsional motion of $\mathrm{H}$ atoms of $\mathrm{NH}_{3}$ and $\mathrm{BH}_{3}$ around the $\mathrm{BN}$ bond) are seen at frequencies of 727 and $1055 \mathrm{~cm}^{-1}$. The peak at $1055 \mathrm{~cm}^{-1}$ is of very low intensity. The B$\mathrm{N}$ stretching consists of two modes: ${ }^{11} \mathrm{BN}$ mode at $783 \mathrm{~cm}^{-1}$ and ${ }^{10} \mathrm{BN}$ at $799 \mathrm{~cm}^{-1}$.

\subsubsection{Raman mode change: Orthorhombic}

As mentioned earlier, upon cooling, the tetragonal structure transforms into the orthorhombic structure, which can be characterized by changes of Raman modes assigned 
by N.J. Hess et al. [20]. Figure 6.1a (blue spectra) shows the collected Raman spectra during cooling cycle. Temperature of the system is mentioned in each spectrum.

The asymmetric N-H stretching mode splits into four modes as expected from full factor group splitting. Symmetric N-H stretching mode at $3245 \mathrm{~cm}^{-1}$ remains unchanged across the phase transition and the unassigned mode at $3173 \mathrm{~cm}^{-1}$ splits into two modes at 3192 and $3165 \mathrm{~cm}^{-1}$. The symmetric B-H stretching mode at $2277 \mathrm{~cm}^{-1}$ clearly splits into two components, the asymmetric mode at $2328 \mathrm{~cm}^{-1}$ splits into two modes. The asymmetric $\mathrm{NH}_{3}$ deformation mode at $1595 \mathrm{~cm}^{-1}$ splits into four components. Likewise, asymmetric $\mathrm{BH}_{3}$ deformation mode splits into four modes. The symmetric $\mathrm{BH}_{3}$ deformation mode splits into two components. NBH rocking mode at $1055 \mathrm{~cm}^{-1}$ becomes intense during cooling and splits into three modes. The lower frequency rocking mode at $727 \mathrm{~cm}^{-1}$ displays similar behavior and splits into three peaks at $217 \mathrm{~K} .{ }^{11} \mathrm{~B}-\mathrm{N}$ and ${ }^{10} \mathrm{~B}-\mathrm{N}$ stretching modes appear at 800 and $818 \mathrm{~cm}^{-1}$ respectively. No peak splitting is observed at tetragonal to orthorhombic phase transition for the $\mathrm{BN}$ stretching region.

The tetragonal to orthorhombic phase transition occurs at $\sim 217 \mathrm{~K}$ in neat ammonia borane (Figure 6.1a), whereas SBA-15 embedded ammonia borane shows the phase transition at $\sim 195 \mathrm{~K}$ (Figure 6.1b). In a separate experimental run, MCM-41 nanoconfined ammonia borane was cooled inside the diamond anvil cell installed in the cryostat. The Raman spectra were recorded during cooling and $14 \mathrm{~mm}$ phase is stable in MCM-41 embedded ammonia borane till $95 \mathrm{~K}$ (Figure 6.2) which is consistent with the previous results $[8,9]$. As ammonia borane is embedded inside the mesoporous silica, the low frequency Raman peaks are weak to resolve clearly. The general trend that is observed in this study is that as the pore size of the scaffold decreases, the tetragonal to 
orthorhombic phase transition temperature decreases. As the pore size decreases, the disordered tetragonal phase becomes stable at lower temperature. 

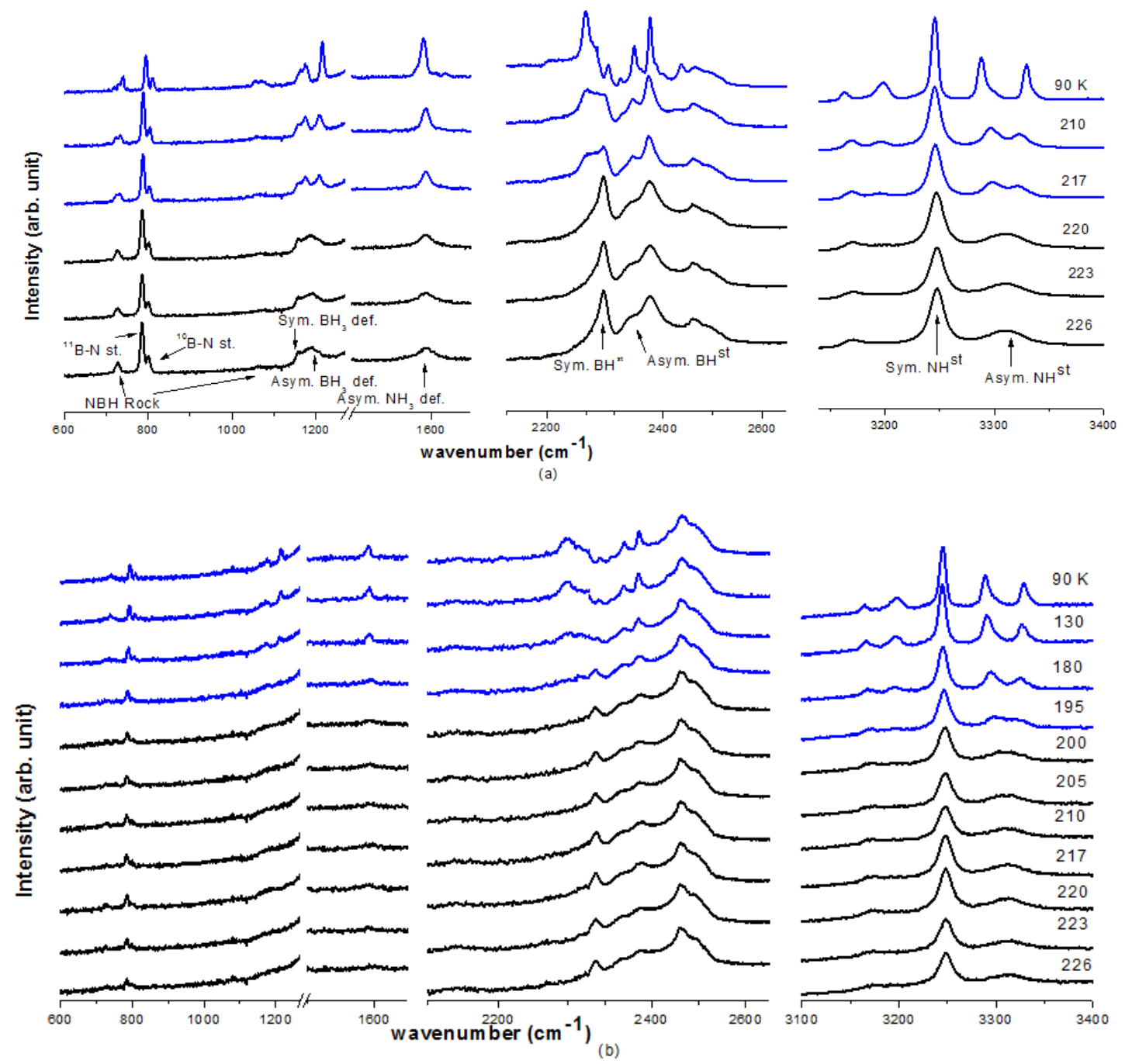

Figure 6.1 Selected Raman spectra of $\mathrm{NH}_{3} \mathrm{BH}_{3}$ at different temperature in the spectral region of $600 \mathrm{~cm}^{-1}-3400 \mathrm{~cm}^{-1}$ : (a) neat ammonia borane, (b) nanoconfined ammonia borane in SBA-15. The intense Raman mode of Diamond anvil is truncated in the region of $1270-1500 \mathrm{~cm}^{-1}$. The sample temperature is indicated in each spectrum. 


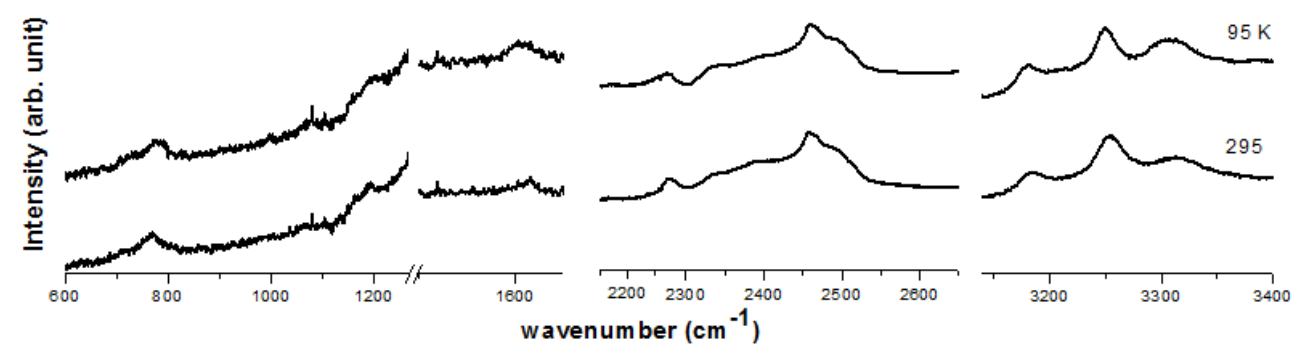

Figure 6.2 Selected Raman spectra of $\mathrm{NH}_{3} \mathrm{BH}_{3}$ at different temperature in the spectral region of $600 \mathrm{~cm}^{-1}-3400 \mathrm{~cm}^{-1}$ : nanoconfined ammonia borane in MCM-41. The intense Raman mode of Diamond anvil is truncated in the region of $1270-1500 \mathrm{~cm}^{-1}$. The sample temperature is indicated in each spectrum.

\subsection{Conclusion}

In conclusion the remarkable insight obtained through Raman spectroscopic study indicates the dependence of the physical properties of ammonia borane embedded in mesoporous silica on its pore size. Nanoscaffolding of $\mathrm{NH}_{3} \mathrm{BH}_{3}$ suppresses the structural phase transition observed in bulk $\mathrm{NH}_{3} \mathrm{BH}_{3}$. The occurrence of different electronic and lattice interactions in nanoscaffolded ammonia borane may be responsible for this change in the characteristic physical properties of ammonia borane. The nanoconfinement could provide an alternative approach to modify the physical characteristics of other bulk hydrogen storage materials to obtain enhanced dehydrogenation and rehydrogenation properties. Further fundamental property investigation is required to understand the nanoconfined $\mathrm{AB}$ in mesoporous silica to tune its hydrogen storage property.

\subsection{References}

[1] C.T. Kresge, M.E. Leonowicz, W.J. Roth, J.C. Vartuli, J.S. Beck, Nature 359, 710712 (1992).

[2] D. Zhao, J. Feng, Q. Huo, N. Melosh, G. H. Fredrickson, B. F. Chmelka, G. D. Stucky, Science 279 (1998). 
[3] K. Moller and T. Bein, Chem. Mater. 10, 2950 (1998).

[4] H. Takahashi, B. Li, T. Sasaki, C. Miyazaki, T. Kajino, and S. Inagaki, Chem. Mater. 12, 3301 (2000).

[5] M. Iwamoto, Y. Tanaka, N. Sawamura, and S. Namba, J. Am. Chem. Soc. 125, 13032 (2003).

[6] F. Qu, G. Zhu, S. Huang, S. Li, J. Sun, D. Zhang, S. Qiu, Microporous and Mesoporous Materials 92, 1 (2006).

[7] A. Gutowska, L. Li, Y. Shin, C. M. Wang, X. S. Li, J. C. Linehan, R. S. Smith, B. D. Kay, B. Schmid, W. Shaw, M. Gutowski, and T. Autrey, Angew. Chem., Int. Ed. 44, 3578 (2005).

[8] A. Paolone, O. Palumbo, P. Rispoli, R. Cantelli, T. Autrey, and A. Karkamkar, J. Phys. Chem. C 113, 10319 (2009).

[9] H. Kim, A. Karkamkar, T. Autrey, P. Chupas, and T. Proffen, J. Am. Chem. Soc. 131,13749 (2009).

[10] M. C. Denney, V. Pons, T. J. Hebden, M. Heinekey, K. I. Goldberg, J. Am. Chem. Soc. 128,12048 (2006).

[11] M. E. Bowden, G. J. Gainsford, and W. T. Robinson, Aust. J. Chem. 60, 149 (2007).

[12] S.G. Shore, R.W. Parry, J. Am. Chem. Soc. 77, 6085 (1955).

[13] EW Hughes, J. Am. Chem. Soc. 78, 502 (1956).

[14] C.F. Hoon, E.C. Reynhardt, J. Phys. C: Solid State Phys. 16, 6129 (1983).

[15] Bowden ME, Gainsford GJ, Robinson WT. Aust J Chem 60,149 (2007).

[16] S. Najiba, J. Chen, V. Drozd, A. Durygin, and Y. Sun J. App. Physi. 111, 112618 (2012).

[17] N. J. Hess, M. E. Bowden, V. M. Parvanov, C. Mundy, S. M. Kathmann, G. K. Schenter, and T. Autrey, J. Chem. Phys. 128, 034508 (2008); G. Wolf, J. Baumann, F. Baitalow, and F. P. Hoffmann, Thermochim.Acta 343, 19 (2000).

[18] F. Baitalow, J. Baumann, G. Wolf, K. Jaenicke-Rössler, and G. Leitner, Thermochim. Acta 391, 159 (2002). 
[19] P. A. Storozhenko, R. A. Svitsyn, V. A. Ketsko, A. K. Buryak, and A. V. Ulyanov, Russ. J. Inorg. Chem. 50, 980 (2005).

[20] M. Bowden, T. Autrey, I. Brown, and M. Ryan, Curr. Appl. Phys. 8, 498 (2008).

[21] M. G. Hu, R. A. Geanangel, and W. W. Wendlandt, Thermochim. Acta 23, 249 (1978).

[22] Li-Qiong Wang, Abhi Karkamkar, Tom Autrey, and Gregory J. Exarhos, J. Phys. Chem. C 113, 6485 (2009). 


\section{PHASE STABILITY OF AMMONIA BORANE AT LOW TEMPERATURE AND HIGH PRESSURE}

The phase transformation behavior of ammonia borane at low temperature (from room temperature down to $90 \mathrm{~K}$ ) and high pressure (from ambient pressure to $9.5 \mathrm{GPa}$ at room temperature and up to $15 \mathrm{GPa}$ at $90 \mathrm{~K}$ ) region has been studied using the diamond anvil cell. This material shows four new phase transitions in this pressure and temperature region. The phase transition phenomenon is evidenced by the splitting of the peak and/or the appearance of the new peak in the Raman spectra as well as by the change of the pressure coefficient of the Raman modes. The phase boundaries between these phases are also established from the data collected during different cooling cycles. These results provide the information about the stability of the bonding characteristics of this potential hydrogen storage material at low temperature and high pressure region.

\subsection{Introduction}

As mentioned earlier, ammonia borane $\left(\mathrm{NH}_{3} \mathrm{BH}_{3}\right)$ has attracted significant attention as high potential hydrogen storage material due to its high gravimetric and volumetric hydrogen density [1-4]. Stepwise release of $\mathrm{H}_{2}$ takes place through thermolysis of ammonia borane, yielding one-third of its total hydrogen content (6.5 $w t \%)$ in each heating step, along with the emission of toxic borazine [2-3]. Recently significant research interest is focusing on ammonia borane to lower the dehydrogenation temperature with an enhanced dehydrogenation rate using different techniques, e.g. nanoscaffolds [5], ionic liquids [6] and acid [7-8] or transition metal catalysts [9-10]. A molecule of ammonia borane consists of protonic $(\mathrm{NH})$ and hydritic $(\mathrm{BH})$ hydrogens bonded by the polarized dative bond. Thermal or catalyzed decomposition of ammonia 
borane requires breaking of the $\mathrm{N}-\mathrm{H}$ and the $\mathrm{B}-\mathrm{H}$ bonds. Till now, the detailed information about the bonding characteristics of ammonia borane is not sufficient to understand details about its phases and structures.

At ambient condition, ammonia borane has the body centered tetragonal (I4mm) structure with disorder in the position of $\mathrm{H}$ atoms [9-15]. It transforms from the disordered $14 \mathrm{~mm}$ structure to the ordered orthorhombic $\left(P m n 2_{1}\right)$ structure at the temperature of $\sim 225 \mathrm{~K}$ [14-15]. Recently, it has been reported that ammonia borane embedded in mesoporous silica does not exhibit this low temperature phase transition at $225 \mathrm{~K}[16,17]$. Pressure significantly affects the phase stability of many hydrogen storage compounds and enhanced hydrogen storage properties are also predicted by some theoretical calculations [18-20]. For instance, it has been reported that under high pressure $\mathrm{NH}_{3} \mathrm{BH}_{3}-\mathrm{H}_{2}$ compound can be formed which can store $8-12 \mathrm{wt} \%$ molecular hydrogen in addition to the chemically bound $\mathrm{H}_{2}$ in ammonia borane [21]. Ammonia borane also shows several kind of phase transitions which are induced by pressure. $14 \mathrm{~mm}$ to $\mathrm{Cmc2}_{1}$ (orthorhombic) phase transition at room temperature and high pressure is reported contradictorily. Two kinds of phase transitions at 0.5 and $1.5 \mathrm{GPa}$ is reported by Trudel and Gilson [22]. Although, Custelcean and Dreger reported that only one phase transition occurs at $0.8 \mathrm{GPa}$, with the delay of some mode splitting until $2.5 \mathrm{GPa}$ [23]. Lin et al. reported three possible phase transitions at 2, 5, and $12 \mathrm{GPa}$ [24]. Xie et al. reported Raman and Infrared (IR) study claiming four possible phase transitions at 2.4, 5.5, 8.5, and $10.5 \mathrm{GPa}$ [25]. Chen et al. reported first order phase transition (I4mm to $\left.C m c 2_{1}\right)$ at 1.3 GPa and second order phase transition at $5 \mathrm{GPa}$ based on x-ray diffraction study [26]. Kumar et al. has reported the $\mathrm{I} 4 \mathrm{~mm}$ to $\mathrm{Cmc} 2{ }_{1}$ phase transition occurring at $1.22 \mathrm{GPa}$ and 
$\mathrm{Cmc} 2{ }_{1}$ to $\mathrm{P} 1$ (monoclinic) phase transition occurring at $8 \mathrm{GPa}$ by combined X-ray, Neutron and theoretical investigation [30]. All of these phase transitions cause significant change in the lattice dynamics although the molecular structure of $\mathrm{NH}_{3} \mathrm{BH}_{3}$ is preserved $[27,28,30]$. At low temperature and high pressure, the formation of hydrogen clathrate hydrate, $\mathrm{H}_{2}\left(\mathrm{H}_{2} \mathrm{O}\right)_{2}$, which can store $5.3 \mathrm{wt} \% \mathrm{H}_{2}$ and can be preserved to ambient pressure at $77 \mathrm{~K}$ was reported [29]. So it is important to understand the details about the phase stability of ammonia borane at low temperature and high pressure region. The development of the methods to enhance the hydrogen discharge rate from ammonia borane requires a detailed study about the structural and dynamical properties that control the stability and the intermolecular interaction of this material. This study is motivated to investigate the stability of the existing phases and also to explore the existence of the possible new phases at the low temperature and high pressure region.

\subsection{Experimental}

Ammonia borane powder (with 97\% purity) purchased from Sigma Aldrich was used in the experiment without further purification as no additional Raman mode associated with impurity was observed in the Raman spectra at ambient condition. A symmetric diamond anvil cell (DAC) with two type-Ia diamonds (400 $\mu \mathrm{m}$ culet size) was used for the high pressure and low temperature experiments. A stainless steel gasket was pre-indented to $70 \mu \mathrm{m}$ thickness and then a hole of $180 \mu \mathrm{m}$ diameter was drilled in the center as a sample chamber. Ammonia borane powders, along with ruby chips for in situ pressure measurement, were loaded in the sample chamber. No pressure medium was used as the sample is sufficiently soft and no peak broadening was observed in the ruby fluorescence spectra at high pressure. 
After the pressure was applied to the sample in DAC, the cell was mounted in a cryostat (Cryo Industries of America, Inc.). Raman spectra of the sample and the ruby fluorescence spectra were collected at steps of $\sim 10$ Kelvin during cooling. Generally the pressure increases during cooling due to the thermal contraction of the system and it was not possible to keep the pressure constant. The sample pressure was calculated from the ruby fluorescence with the temperature correction [31-36]. Temperature was controlled within the range of $\pm 0.5 \mathrm{~K}$ by varying the flow of liquid nitrogen and by regulating the power to the electrical heater using Cryogenic Temperature Controller which has two Sidiode sensors. At every step of the data collection, the system was held for $\sim 15$ minutes to allow the system to reach thermal equilibrium. Raman spectroscopy was conducted by exciting Raman modes using a $514 \mathrm{~nm} \mathrm{Ar}^{+}$laser. After each cooling cycle, the cryostat was warmed up to the room temperature; the pressure was increased and then another cooling cycle was started. The cooling cycles were repeated at gradually higher pressures to cover the desired pressure-temperature region.

\subsection{Results and discussion}

\subsubsection{Raman mode assignment}

As discussed earlier, the body centered tetragonal phase of ammonia borane has the characteristic Raman spectra $(295 \mathrm{~K}, 0.7 \mathrm{GPa})$ as described in Figure 7.1a (bottom spectra), which is consistent with the result reported in the previous study [25].

The N-H asymmetric and symmetric stretching vibrations are observed at 3311 and $3245 \mathrm{~cm}^{-1}$ respectively and an additional peak due to the Fermi resonance mode (overtone of an $\mathrm{NH}_{3}$ deformation mode and $\mathrm{NH}_{3}$ stretching fundamental) has been

observed at $3173 \mathrm{~cm}^{-1}$. The $\mathrm{B}-\mathrm{H}$ stretching region shows two intense peaks at 2277 and 
$2375 \mathrm{~cm}^{-1}$ and a shoulder peak at $2329 \mathrm{~cm}^{-1}$. There has been debate over the symmetry assignment of peaks in this region. Lin et al., [24] has assigned the $2277 \mathrm{~cm}^{-1}$ peak to the symmetric B-H stretching mode and the $2375 \mathrm{~cm}^{-1}$ peak to the asymmetric B-H stretching mode depending on their observation that the peak at $2375 \mathrm{~cm}^{-1}$ split at high pressure whereas the 2277 and $2328 \mathrm{~cm}^{-1}$ peaks did not split. However, powder studies assigned the peak at $2277 \mathrm{~cm}^{-1}$ as the symmetric B-H stretch and the peak at $2328 \mathrm{~cm}^{-1}$ as the asymmetric B-H stretch $[37,38]$. Recent single crystal studies have assigned the $2277 \mathrm{~cm}^{-1}$ peak to the B-H symmetric stretch and the $2328 \mathrm{~cm}^{-1}$ to the $\mathrm{B}-\mathrm{H}$ asymmetric stretch according to the Raman polarization measurements [39] There are two $\mathrm{NH}_{3}$ deformation modes: the asymmetric mode at $1595 \mathrm{~cm}^{-1}$ (due to scissor like motion) and the symmetric mode at $1376 \mathrm{~cm}^{-1}$ (due to umbrella like motion). There is also an overtone mode at $1446 \mathrm{~cm}^{-1}$. The symmetric mode at $1376 \mathrm{~cm}^{-1}$ and the overtone mode at $1446 \mathrm{~cm}^{-1}$ are not discernible due to the appearance of the intense diamond peak there. The asymmetric $\mathrm{BH}_{3}$ deformation mode (due to umbrella like motion) at $1186 \mathrm{~cm}^{-1}$ and the symmetric $\mathrm{BH}_{3}$ deformation mode (due to scissor like motion) at $1160 \mathrm{~cm}^{-1}$ has been observed. The $\mathrm{N}-\mathrm{H}$ and $\mathrm{B}-\mathrm{H}$ rocking modes (due to the torsional motion of $\mathrm{H}$ atoms of $\mathrm{NH}_{3}$ and $\mathrm{BH}_{3}$ around the $\mathrm{BN}$ bond) are observed at the frequencies of 727 and 1055 $\mathrm{cm}^{-1}$, while the peak at $1055 \mathrm{~cm}^{-1}$ is very weak in intensity. The B-N stretching region shows two peaks: ${ }^{11} \mathrm{BN}$ mode at $783 \mathrm{~cm}^{-1}$ and ${ }^{10} \mathrm{BN}$ mode at $799 \mathrm{~cm}^{-1}$.

\subsubsection{Pressure induced transformation at room temperature}

Upon compression at room temperature, ammonia borane shows three different phase transitions at around $2.4,5.5$, and $8.5 \mathrm{GPa}$, which are evidenced by the change of the characteristic Raman spectra described by previous study [25]. Figure 7.1a, Figure 
7.1b, Figure 7.1c and Figure 7.1d represent the characteristic Raman spectra of mixed $I 4 m m+C m c 2_{1}, C m c 2_{1}$, phase III (as labeled by Xie et al. [25]) and $P 1$ (as determined by Kumar et al. [30]) respectively at the condition of (295 K, $1 \mathrm{GPa}),(295 \mathrm{~K}, 4.4 \mathrm{GPa}),(295$ K, $6 \mathrm{GPa})$ and (295 K, $9 \mathrm{GPa})$.

The $\mathrm{I} 4 \mathrm{~mm}$ to $\mathrm{Cmc} 2_{1}$ phase transition starts at $\sim 0.8 \mathrm{GPa}$ and completes at $\sim 2.4$ GPa. Mixed $\mathrm{I} 4 \mathrm{~mm}$ and $\mathrm{Cmc}_{1}$ phase is observed within $\sim 0.8$ to $\sim 2.4 \mathrm{GPa}$, which is associated with the immediate splitting of the $\mathrm{N}-\mathrm{H}$ asymmetric stretch, with the other modes becoming more intense. Figure 7.1a represents the spectra of the mixed $14 \mathrm{~mm}$ and $\mathrm{Cmc2}_{1}$ at the condition of $295 \mathrm{~K}$ and $1 \mathrm{GPa}$. The $\mathrm{I} 4 \mathrm{~mm}$ to $\mathrm{Cmc2}_{1}$ phase transition completes at $\sim 2.4 \mathrm{GPa}$ with the appearance of splitting of all the asymmetric modes and the $\mathrm{Cmc2}{ }_{1}$ phase is stable within the range of around 2.4 to $5.5 \mathrm{GPa}$. Figure $7.1 \mathrm{~b}$ describes the characteristic spectra of the $C m c 2_{1}$ phase at the condition of $295 \mathrm{~K}$ and $4.4 \mathrm{GPa}$. The $\mathrm{N}-\mathrm{H}$ asymmetric stretching mode, B-H asymmetric stretching mode, asymmetric $\mathrm{NH}_{3}$ deformation mode and asymmetric $\mathrm{BH}_{3}$ deformation mode split when this phase transition occurs (Figure 7.1a and Figure 7.1b). Low frequency NBH rocking mode also splits into two components. In the lattice region, the appearance of two lattice modes is considered as the characteristic of this phase. Upon further compression at room temperature, ammonia borane shows another phase transition at around 5.5 GPa. This high pressure phase (Phase III) is stable within the range of $\sim 5.5 \mathrm{GPa}$ to $\sim 8.5 \mathrm{GPa}$. The dominant feature of this phase transition $(295 \mathrm{~K}, 6 \mathrm{GPa})$ is the merging of the $\mathrm{NH}$ asymmetric doublet into singlet as described in Fig7.1b and Fig. 7.1c. The other asymmetric modes which splitted at $\sim 2.4 \mathrm{GPa}$ phase transition shows maximum splitting until $\sim 5.5 \mathrm{GPa}$ and beyond that pressure the splitted doublets start to come closer. The 
high frequency NBH rocking mode splits into three modes, while the low frequency NBH rocking mode doublet starts to come closer. The third phase transition appears at $\sim 8.5$ GPa (Pl phase). This phase transition $(295 \mathrm{~K}, 9 \mathrm{GPa})$ results in the merging of the asymmetric doublets with a markedly reduced intensity for most of the modes as described in Figure 7.1c and Figure 7.1d.

\subsubsection{Low temperature and high pressure induced phase transitions}

\subsubsection{Change of Raman modes during cooling down}

Upon cooling, the room temperature-high pressure phases transform into new phases, which can be identified from the change of the characteristic Raman modes as shown in Figure 7.1. Generally the sample pressure in the cell increases during cooling due to thermal contraction of the system. The sample pressure was calculated from the ruby fluorescence with the temperature correction [31-36]. The measured temperature and corresponding pressure of the system are listed in each spectrum. In the low temperature and high pressure region, we have observed four new phases which we have labeled as phases A, B, C, and D.

The mixed phase $\left(I 4 m m+C m c 2_{1}\right)$ at the condition of $(295 \mathrm{~K}, 1 \mathrm{GPa})$ was cooled continuously to $90 \mathrm{~K}$. As cooling progresses, the sample pressure increases as a result of thermal contraction of the system. At $160 \mathrm{~K}$, the pressure increases to $2.3 \mathrm{GPa}$ and the mixed $14 \mathrm{~mm}+\mathrm{Cmc2}_{1}$ phase changes to a new phase (Phase A) characterized by the distinct changes in Raman modes (Figure 7.1b). The asymmetric N-H stretching mode spiltting becomes more distinct and the intense asymmetric B-H stretching mode splits into two peaks. A new peak appears near the asymmetric $\mathrm{BH}_{3}$ deformation mode. Also, the splitted rocking mode of the mixed phase at around $1000 \mathrm{~cm}^{-1}$ split into three peaks 
with the appearance of the new phase A. Additionally, four sharp lattice modes at around $170,175,180$ and $186 \mathrm{~cm}^{-1}$ appear which indicates significant ordering of this new phase compared to both the tetragonal and orthorhombic phase.

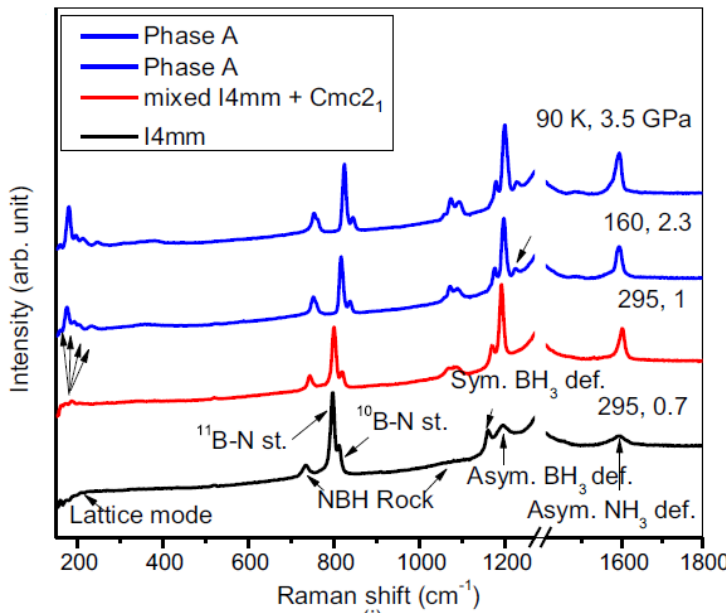

(i)

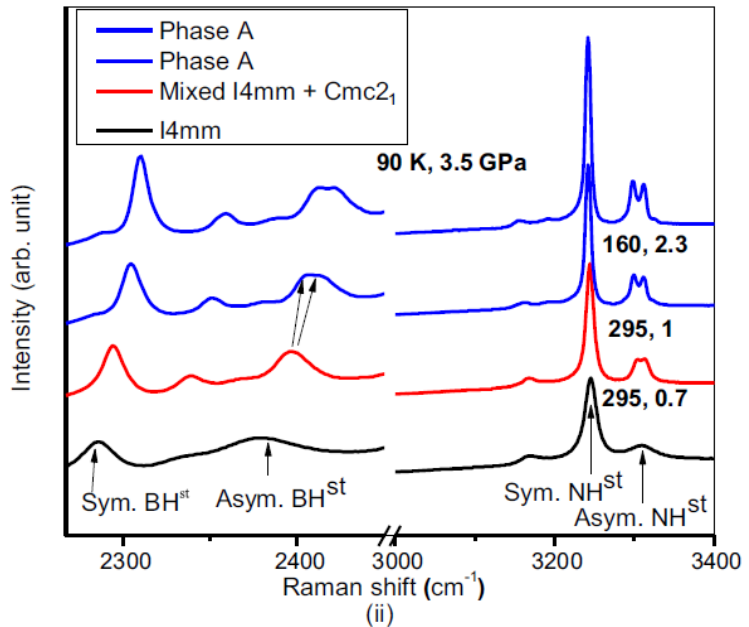

(a)

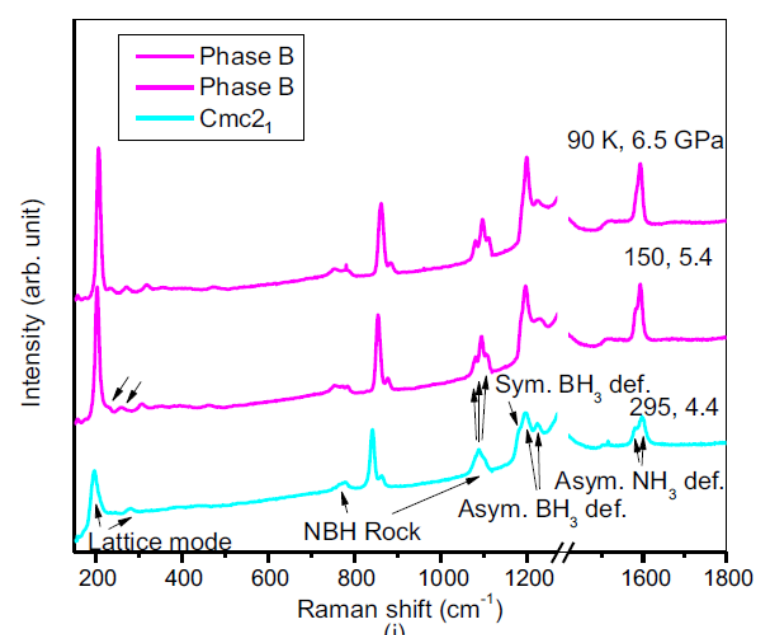

(i)

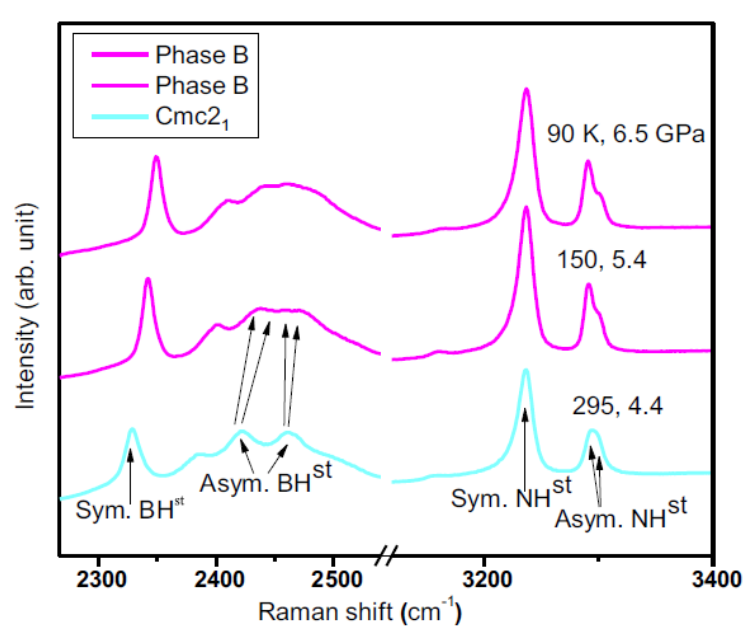

(ii)

(b) 

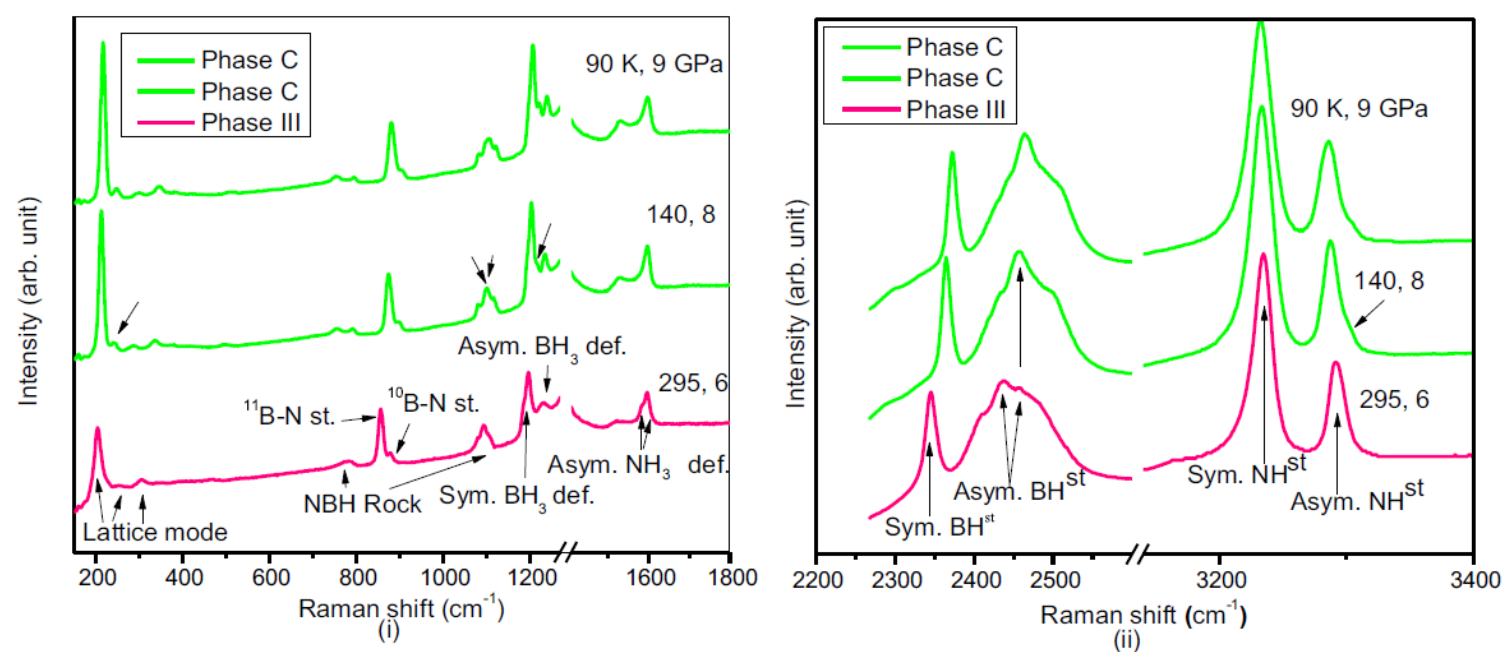

(ii)

(c)
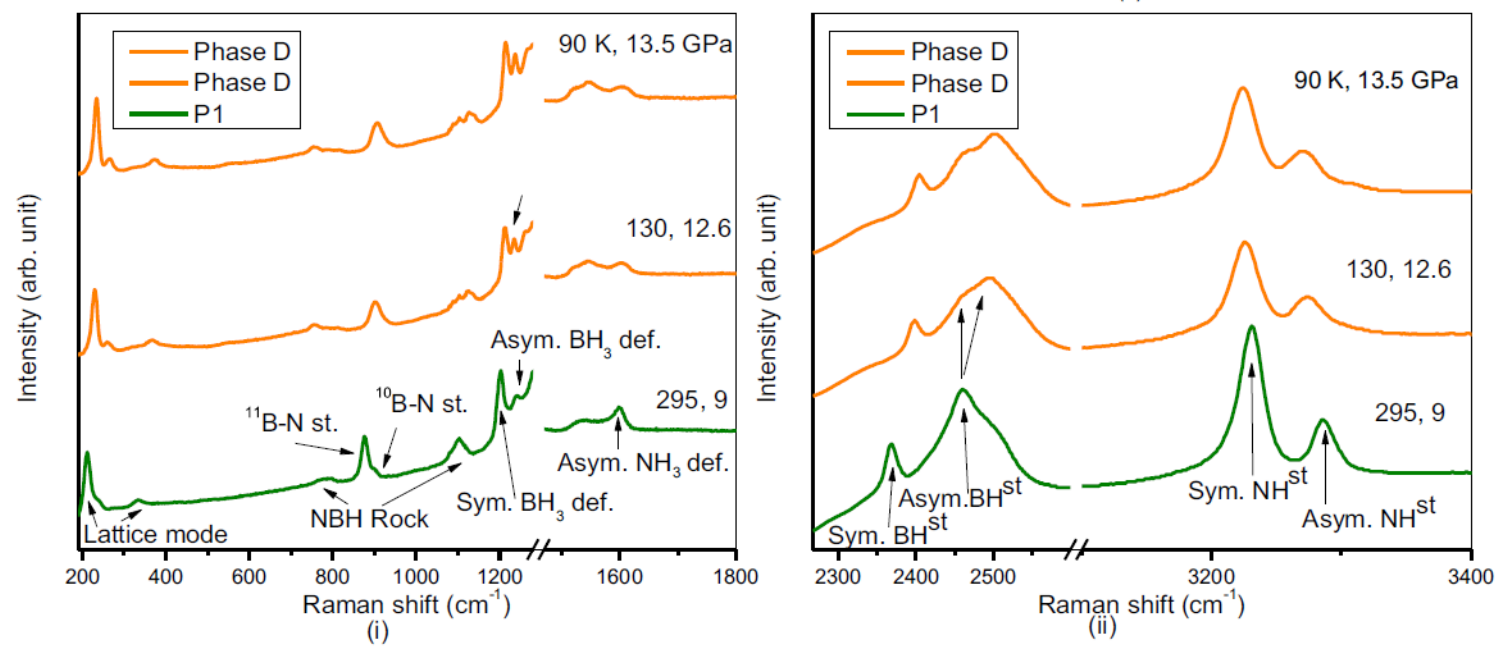

(d)

Figure 7.1 Raman spectra of $\mathrm{NH}_{3} \mathrm{BH}_{3}$ at different temperature and pressure in the spectral region of (i) $200-1800 \mathrm{~cm}^{-1}$ and (ii) $2260-3400 \mathrm{~cm}^{-1}$; (a) transition of mixed $14 \mathrm{~mm}+$ $\mathrm{Cmc} 2_{1}$ to phase A; (b) transition of $\mathrm{Cmc2} 2_{1}$ to phase B; (c) transition of Phase III to phase C; (d) transition of $P 1$ to phase D. The breaking in the region of $1250-1550 \mathrm{~cm}^{-1}$ and 
$2550-3120 \mathrm{~cm}^{-1}$ is due to Raman mode of diamond anvils. The corresponding temperature $(\mathrm{K})$ and pressure (GPa) are indicated in each spectrum.

The $I 4 m m$ to $C m c 2_{1}$ phase transition completes at around $2.4 \mathrm{GPa}$ and the $C m c 2_{1}$ phase is stable up to $5.5 \mathrm{GPa}$ at room temperature. The completely transformed $\mathrm{Cmc} 2_{1}$ phase at the condition of ( $295 \mathrm{~K}, 4.4 \mathrm{GPa}$ ) was cooled continuously to $90 \mathrm{~K}$. During cooling, it transforms to a new phase (Phase B) and this transition is associated with the change of the characteristic Raman spectra as shown in Figure 7.1b. The predominant change occurs in the asymmetric B-H stretching doublet which splits again into four modes. Also the intensity ratio of the $\mathrm{N}-\mathrm{H}$ asymmetric mode doublet increases, along with further separation of the doublet. Also, the asymmetric $\mathrm{NH}_{3}$ deformation doublet starts to come closer and becomes intense. The high frequency NBH rocking mode splits into three modes, while the low frequency NBH rocking mode splitting becomes sharply resolved. Also two additional new lattice modes appear along with the lattice mode I becoming more intense, which may indicate the structure becomes more ordered compared to $\mathrm{Cmc}_{1}$.

As phase III (which is stable between $\sim 5.5$ and $8.5 \mathrm{GPa}$ at room temperature) is cooled, another new phase (Phase C) appears at the condition of $140 \mathrm{~K}$ and $8 \mathrm{GPa}$ (Figure 7.1c). The BH asymmetric doublet of Phase III merges into singlet along with a low frequency shoulder peak. A shoulder peak also appears with the asymmetric N-H stretching mode. One new peak appears between the doublet of the asymmetric $\mathrm{BH}_{3}$ deformation mode, while $\mathrm{NH}_{3}$ deformation doublet merges into singlet. The symmetric $\mathrm{BH}_{3}$ deformation mode disappears. The medium frequency peak of the high frequency NBH rocking mode triplet starts to split. Low frequency NBH rocking mode splitting 
becomes more resolved. One additional lattice mode, in addition to three lattice modes (characteristic of Phase III) appears.

When phase $P 1$ is cooled, another new phase (phase D) appears at around $130 \mathrm{~K}$ and 12.6 GPa, with the change of the characteristic Raman modes (Figure 7.1d). The B$\mathrm{H}$ asymmetric stretch singlet which is characteristic of phase $P 1$, splits into two modes. The unassigned overtone mode at $\sim 1560 \mathrm{~cm}^{-1}$ also splits into two modes, which indicates the necessity of looking carefully for the assignment of this mode, which may provide more information about the bonding. One new peak appears in between the $\mathrm{BH}_{3}$ asymmetric deformation doublet and the symmetric $\mathrm{BH}_{3}$ deformation mode disappears. High frequency NBH rocking mode splits into complicated several modes. The ${ }^{10} \mathrm{~B}-\mathrm{N}$ stretching mode disappears. The low frequency NBH rocking mode splits into two modes of which one mode shows redshift with increasing pressure and lowering temperature, while another is very weak to resolve.

\subsubsection{Pressure Dependence of Raman Peak Wavenumber}

Although the appearance of the four new phase transitions are associated with the splitting and merging of the Raman peaks as well as with the appearance of new peaks in the spectra, changes in the pressure dependence slopes of the Raman shift are also observed at these phase transitions. It was difficult to conduct the experiment at constant pressure during cooling down. To observe the pressure effect on Raman shift, Raman spectra at different pressures (Figure 7.2) and Raman shift versus pressure (Figure 7.3) are plotted at a fixed temperature of $90 \mathrm{~K}$ of different cooling cycles. As shown in Figure 7.3, significant changes occur in the pressure dependence of the Raman shifts in the observed new phases (Phase A, B, C, and D), which enhances the evidence of phase 
transitions. Figure 7.2 and Figure 7.3 describe the approximate pressure ranges for the existence of these four new phases at the temperature of $90 \mathrm{~K}$, as evidenced by the change of the characteristic Raman spectra.

Throughout the whole pressure region, both the symmetric and the asymmetric N$\mathrm{H}$ stretching modes show redshift with pressure, which indicates the weakening of the N$\mathrm{H}$ bond (Figure 7.2ii and Figure 7.3a). This behavior indicates the presence of the dihydrogen bonding in this material at high pressure and low temperature region also. The four peaks of the asymmetric N-H stretching mode merges into two peaks (Pmn2 $2_{1}$ to phase A transition), one of which loses intensity and disappears completely as phase D appears. On the other hand, the B-H symmetric and asymmetric modes show blueshift with pressure, which indicates the strengthening of the B-H bond as like most of the bonds. The high frequency B-H stretching mode at around $2420 \mathrm{~cm}^{-1}$ splits into two peaks (transition of $\mathrm{Pmn} 2_{1}$ to phase A), two peaks again split into four peaks (transition of phase A to B), four peaks merge into one peak (transition of phase B to C) and one peak splits into two peaks (transition of phase $\mathrm{C}$ to D) (Figure 7.2ii and Figure 7.3b). The overtone mode at around $1550 \mathrm{~cm}^{-1}$ splits into two peaks as phase $\mathrm{C}$ to $\mathrm{D}$ transition occurs (Figure 7.2ii and Figure 7.3c). Also, ${ }^{10} \mathrm{~B}-\mathrm{N}$ stretching mode at around $920 \mathrm{~cm}^{-1}$ (Figure 7.2ii and Figure 7.3f) and one of the lattice modes (Figure 7.2ii and Figure 7.3g) at about $320 \mathrm{~cm}^{-1}$ disappear when phase $\mathrm{C}$ to $\mathrm{D}$ transition occurs. The high frequency asymmetric $\mathrm{BH}_{3}$ deformation mode at $\sim 1230 \mathrm{~cm}^{-1}$ shows sudden slope change as phase A (negative slope) to B (positive slope) transition occurs, a new peaks appears and the symmetric $\mathrm{BH}_{3}$ deformation mode disappears in this $\mathrm{BH}_{3}$ deformation region during phase $\mathrm{B}$ to $\mathrm{C}$ transition and (Figure 7.2 $\mathrm{i}$ and Figure 7.3d). The change of pressure 
dependence slopes of all the Raman modes does not follow any general trend (increase/decrease) throughout all the phase transitions. Rather some of the pressure dependence slopes increase and some of those slopes decreases as phase A to B to C to D transition occur. Also, all these phase transitions are reversible, which indicates the intramolecular structure of this complex remains intact, the rearrangement of intermolecular bonding characteristics only change to induce the phase transitions. 

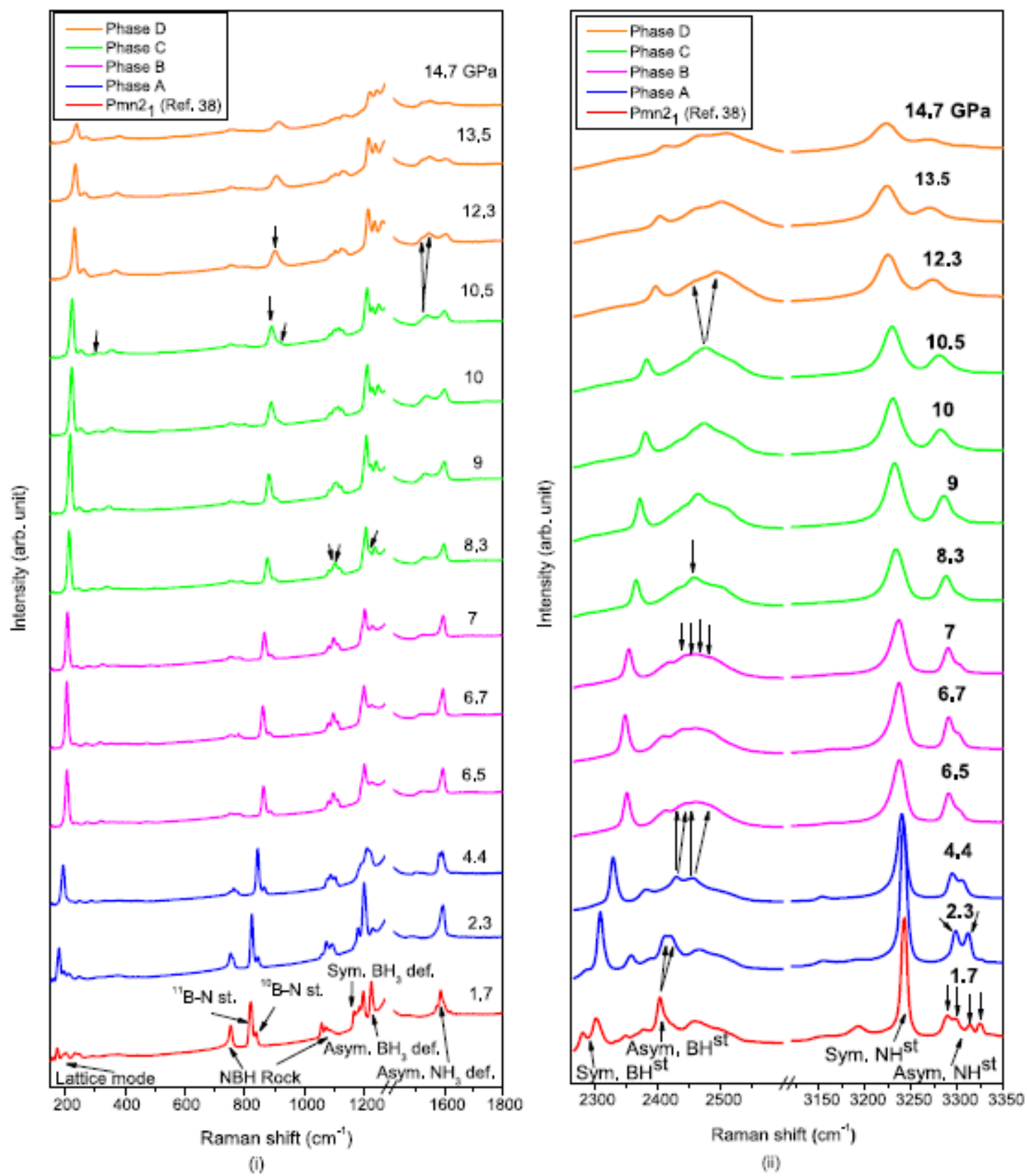

(ii)

Figure 7.2 Changes of Raman spectra of $\mathrm{NH}_{3} \mathrm{BH}_{3}$ with pressure at the temperature of 90 $\mathrm{K}$ temperature in the spectral region of (i) $160-1800 \mathrm{~cm}^{-1}$ and (ii) $2260-3350 \mathrm{~cm}^{-1}$. 


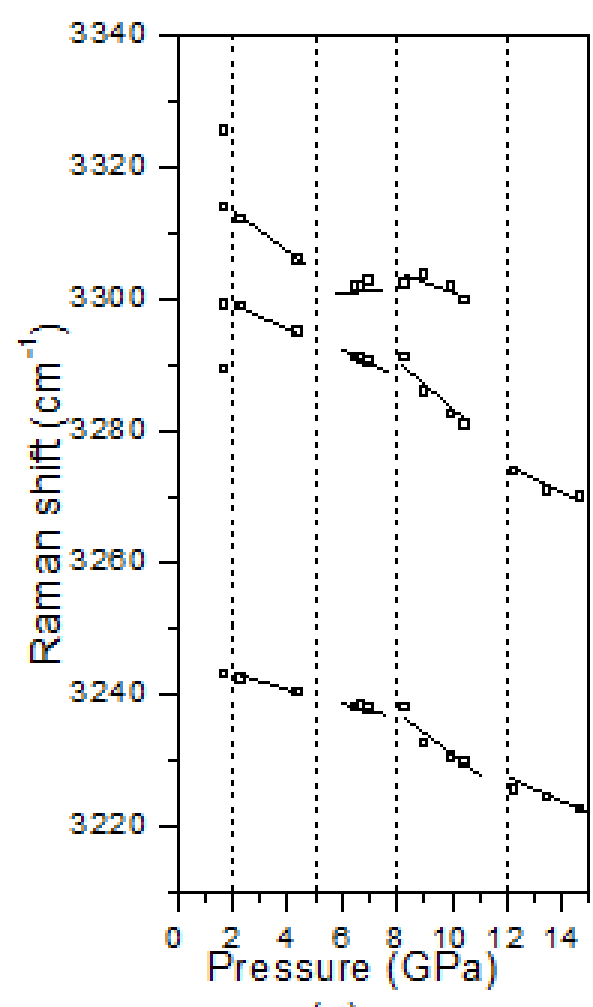

(a)

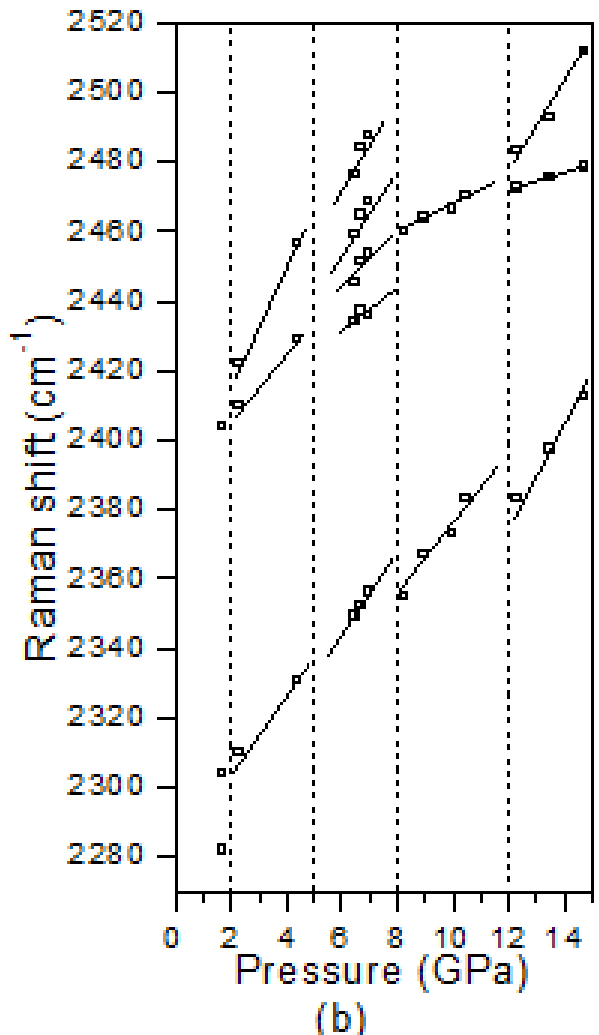

(b)

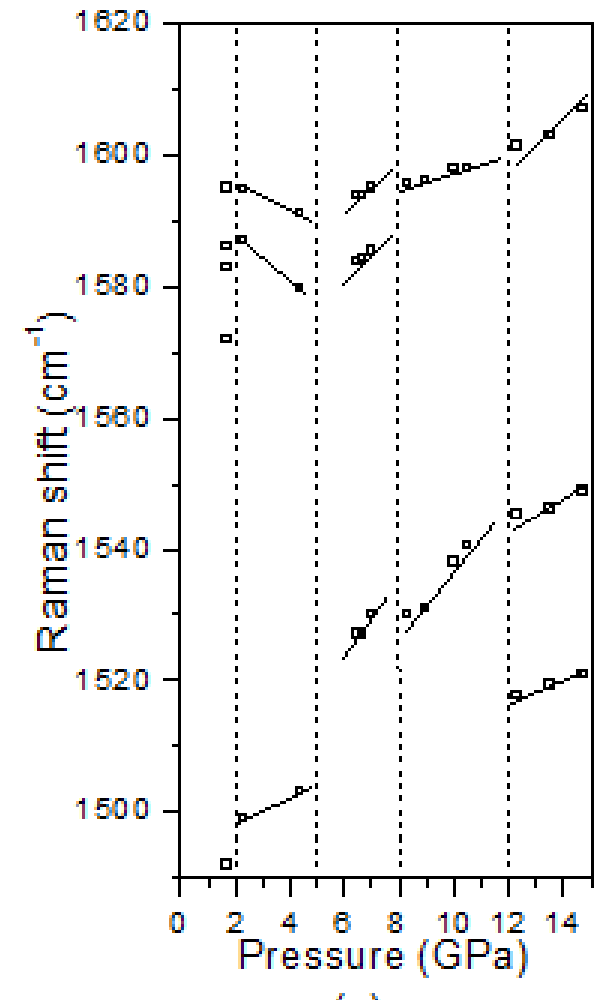

(c) 


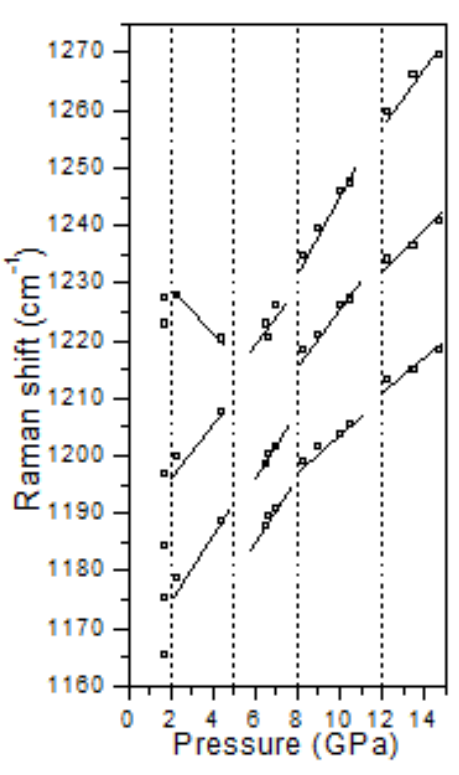

(d)

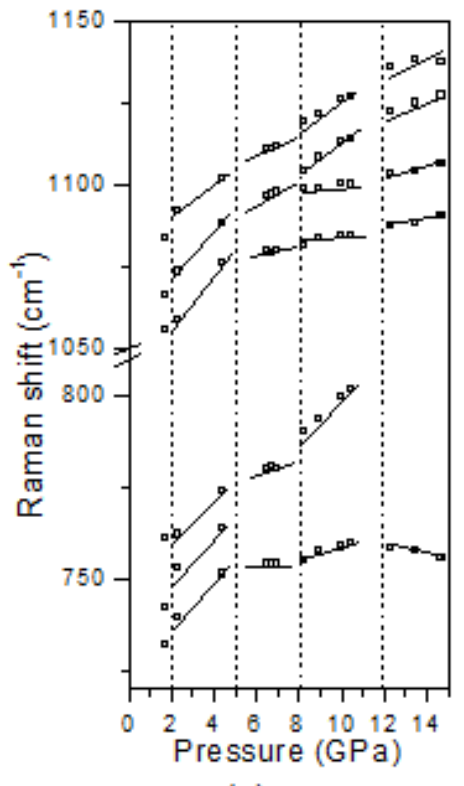

(e)

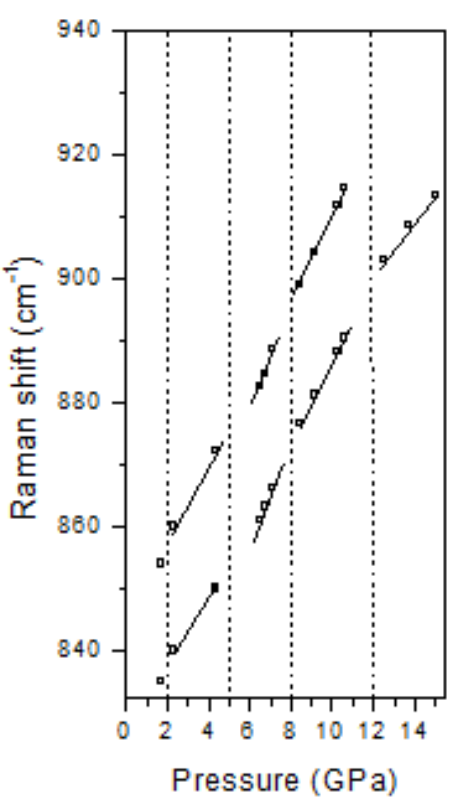

(f)

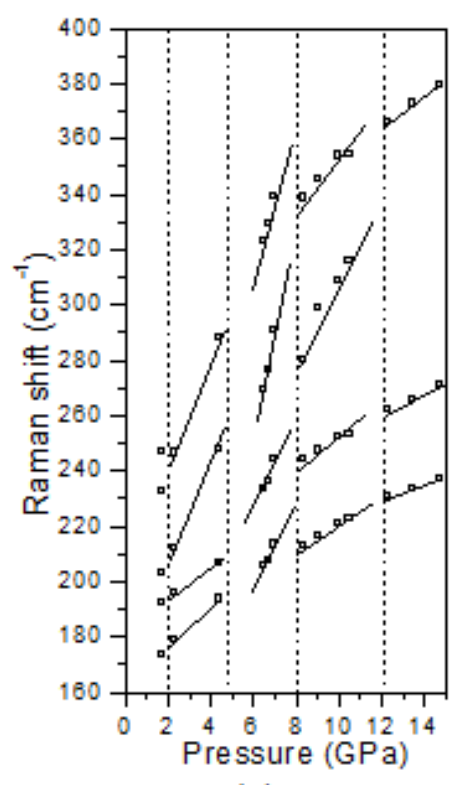

(g)

Figure 7.3 Raman shift of different modes of $\mathrm{NH}_{3} \mathrm{BH}_{3}$ with pressure at temperature of $90 \mathrm{~K}$ in the spectral region of (a) $\mathrm{N}-\mathrm{H}$ Stretching (b) B-H stretching (c) $\mathrm{NH}_{3}$ deformation (d) $\mathrm{BH}_{3}$ deformation (e) $\mathrm{NBH}$ rocking (high frequency and low frequency) (f) B-N stretching and 


\subsection{Phase diagram}

Schematic phase diagram including all of the observed phases at low temperature and high pressure region is plotted in Figure 7.4. During cooling, the mixed $14 \mathrm{~mm}+$ $\mathrm{Cmc}_{1}$ phase transforms to Phase A, which was predicted by Filinchuk et al. [27] and experimentally observed by Liu et al. [41]. Although, Anderson et al. [40] did not observe this phase transition as they did not continue their experiment at higher pressure and low temperature region where this new phase is stable. We also observed phase B which is quite evident from the change of Raman modes. This new phase has very narrow temperature and pressure range for stability. Liu et al. [41] did not observe phase B in their experiment, which may be because of the narrow pressure-temperature stability range of this phase.

$I 4 m m$ to $C m c 21$ phase transition has a negative slope which is in agreement with Chen et al. [26], although it is not in agreement with the observation of Anderson et al. [40]. $I 4 m m$ to $P m n 2_{1}$ transformation shows a very sharp positive Clapeyron slope. All the phase transitions from the mixed $I 4 m m+C m c 2_{1}$ phase to Phase A, Cmc2 ${ }_{1}$ to Phase B, phase III to Phase C and Pl to Phase D show positive Clapeyron slope, indicating that these phase transitions are of endothermic in nature.

Raman spectroscopy provides information about the atomic bonding of the structure even with the same or slightly different crystal structure and therefore these phase transitions investigated by Raman spectroscopy may be of second order which may not necessarily be observed in X-ray diffraction study. However, future X-ray diffraction 
study may be helpful to determine the crystal structure, if any of these new phase transitions are of first order in nature.

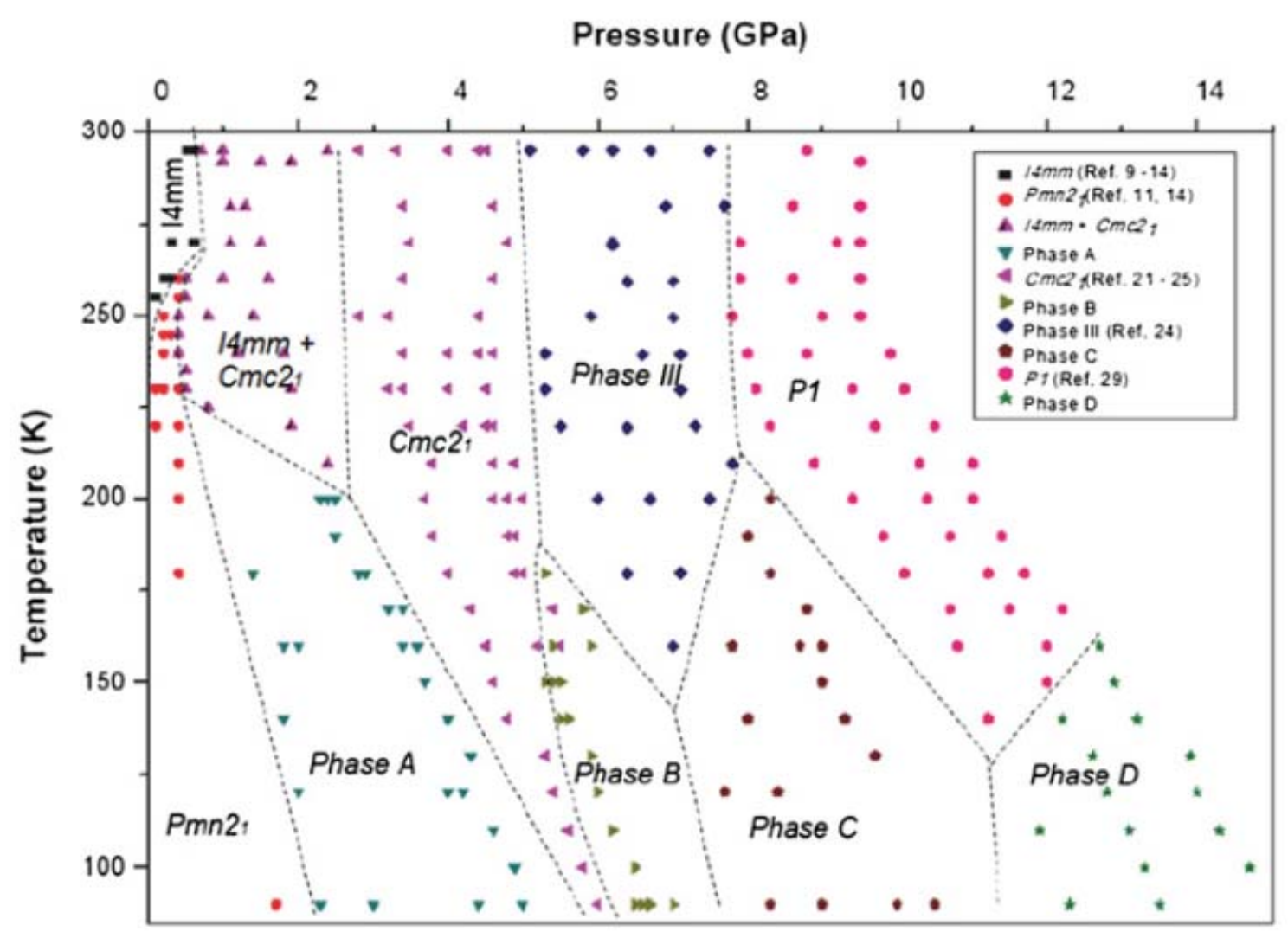

Figure 7.4 Schematic phase diagram of ammonia borane in the low temperature and high pressure region. 


\subsection{Conclusion}

The phase transformation behavior of ammonia borane at low temperature down to $90 \mathrm{~K}$ and high pressure up to $15 \mathrm{GPa}$ has been investigated using in situ Raman spectroscopy. Four new phases with distinct features in their Raman spectra were observed at this temperature and pressure region. The slope of the pressure dependence Raman shifts also enhances the evidence of these phase transformations. All these pressure-temperature induced phase transformations are reversible. Further work is needed for Raman mode assignment for these phases, and neutron / x-ray diffraction is required to investigate the structural details of these four new phases.

\subsection{References}

[1] M. Bowden, T. Autrey, I. Brown, and M. Ryan, Curr. Appl. Phys. 8, 498 (2008).

[2] G. Wolf, J. Baumann, F. Baitalow, and F. P. Hoffmann, Thermochim. Acta 343, 19 (2000)

[3] F. Baitalow, J. Baumann, G. Wolf, K. Jaenicke-Ro“ssler, and G. Leitner, Thermochim. Acta 391, 159 (2002).

[4] P. A. Storozhenko, R. A. Svitsyn, V. A. Ketsko, A. K. Buryak, and A. V. Ulyanov, Russ. J. Inorg. Chem. 50, 980 (2005).

[5] A. Gutowska, L. Li, Y. Shin, C. M. Wang, X. S. Li, J. C. Linehan, R. S. Smith, B. D. Kay, B. Schmid, W. Shaw, M. Gutowski, and T. Autrey, Angew. Chem., Int. Ed. 44, 3578 (2005).

[6] M. E. Bluhm, M. G. Bradley, R. Butterick, U. Kusari, and L. G. Sneddon, J. Am. Chem. Soc. 128, 7748 (2006).

[7] F. H. Stephens, R. T. Baker, M. H. Matus, D. J. Grant, and D. A. Dixon, Angew. Chem., Int. Ed. 46, 746 (2007).

[8] R.J. Keaton, J.M. Blacquiere, and R.T. Baker, J. Am. Chem. Soc.129, 1844 (2007). 
[9] C. A. Jaska, K. Temple, A. J. Lough, and I. Manners, J. Am. Chem. Soc. 125, 9424 (2003).

[10] M. C. Denney, V. Pons, T. J. Hebden, M. Heinekey, and K. I. Goldberg, J. Am. Chem. Soc. 128, 12048 (2006).

[11] M. E. Bowden, G. J. Gainsford, and W. T. Robinson, Aust. J. Chem. 60, 149 (2007).

[12] S. G. Shore and R. W. Parry, J. Am. Chem. Soc. 77, 6085 (1955).

[13] E. W. Hughes, J. Am. Chem. Soc. 78, 502 (1956).

[14] C. F. Hoon and E. C. Reynhardt, J. Phys. C 16, 6129 (1983).

[15] H. Kim, A. Karkamkar, T. Autrey, P. Chupas, and T. Proffen, J. Am. Chem. Soc. 131,13749 (2009).

[16] A. Paolone, O. Palumbo, P. Rispoli, R. Cantelli, T. Autrey, and A. Karkamkar, J. Phys. Chem. C 113, 10319 (2009).

[17] R.S. Kumar, E. Kim, and A. L. Cornelius Andrew, J. Phys. Chem. B 112, 8452 (2008).

[18] H.R. Wenk, L. Lutterottia, and S. Vogel, Nucl Instr Meth A 515, 575 (2003).

[19] R.S. Kumar, X. Ke, A.L. Cornelius, and C. Chen, Chem. Phys. Lett. 460, 442 (2008).

[20] Y. Lin, W.L. Mao, and H.K. Mao, PNAS 106, 8113 (2009).

[21] S. Trudel and D. F. R. Gilson, Inorg. Chem. 42, 2814 (2003).

[22] R. Custelcean and Z. A. Dreger, J. Phys. Chem. B 107, 9231(2003).

[23] Y. Lin, W. L. Mao, Vadym Drozd, J. Chen, and L. L. Daemen, J. Chem. Phys. 129, 234509 (2008).

[24] S. Xie, Y. Song, and Z. Liu, Can. J. Chem. 87, 1235 (2009).

[25] J. Chen, H. Couvy, H. Liu, Vadym Drozd, L. L. Daemen, Y. Zhao, C.-C. Kao, Int. J. Hydrogen Energy 35, 11064 (2010). 
[26] Y. Filinchuk, A.H. Nevidomskyy, D. Chernyshov, and V. Dmitriev, Phys. Rev. B 79, 214111 (2009).

[27] Y. Lin, H. Ma, W.M. Charles, K. Brian, S. Stanislav, T. Timo, et al. J. Phys. Chem. C 116, 2172 (2012).

[28] W.L. Mao, and H.K. Mao, Proc. Natl. Acad. Sci. 101, 708 (2004).

[29] R.S. Kumar, K. Xuezhi, J. Zhang, Z. Lin, S.C. Vogel, M. Hartl, et al. Chem. Phys. Lett. 495, 203 ( 2010).

[30] H.K. Mao, and P.M. Bell, J. Appl. Phys. 49, 3276 (1978).

[31] D.E. Mccumber, M.D. Sturge, J. Appl. Phys. 34, 1682 (1963).

[32] W.L. Vos, J.A. Schouten, J. Appl. Phys. 69, 6744 (1991).

[33] H.K. Mao, J. Xu, and P.M. Bell, J. Geophys. Res. 91, 4673 (1986).

[34] D. Schiferl, S. Buchsbaurn, R.L. Mills, J. Phys. Chem. 892324 (1985).

[35] S. Buchsbaum, R.L. Mills, D. Schiferl, J. Phys. Chem. 882522 (1984).

[36] J. Goubeau, and E. Ricker, Anorg. Z. Allg. Chem. 310123 (1961).

[37] W. Sawodny, J. Z. Goubeau, Phys. Chem. Neue. Folge. 44, 227 (1965).

[38] (a) N. J. Hess, M. E. Bowden, V. M. Parvanov, C. Mundy, S. M. Kathmann, G. K. Schenter, and T. Autrey, J. Chem. Phys. 128, 034508 (2008); (b) S. Najiba, J. Chen, V. Drozd, A. Durygin, and Y. Sun, J. Appl. Phys. 111, 112618 (2012).

[39] O. Anderson, Y. Filinchuk, V. Dmitriev, I. Quwar, A. V. Talyzin, and B. Sundqvist, Phys. Rev. B 84, 024115 (2011).

[40] A. Liu, and Y. Song, J. Phys. Chem. C 116, 2123 (2012). 


\section{SUMMARY AND FUTURE WORK}

\subsection{Summary}

This dissertation presents the investigation of ammonia borane in the high pressure and low temperature region, low temperature phase transition of nanoconfined ammonia borane, and high pressure study of lithium amidoborane. High pressure and low temperature phase transition of ammonia borane was investigated by Raman spectroscopy. The transition from disordered tetragonal $(14 \mathrm{~mm})$ structure to the ordered orthorhombic $\left(P m n 2_{1}\right)$ structure is found to be of exothermic in nature. The appearance of full factor group splitting of orthorhombic phase is not kinetic-controlled, rather it requires undercooling of around $\sim 15 \mathrm{~K}$ below the transition temperature. The Raman spectroscopic study of nanoconfined ammonia borane indicates the dependence of the physical properties of ammonia borane embedded in mesoporous silica on its pore size. Nanoconfinement of $\mathrm{NH}_{3} \mathrm{BH}_{3}$ depresses the structural phase transition observed in bulk $\mathrm{NH}_{3} \mathrm{BH}_{3}$. The occurrence of different electronic and lattice interactions in nanoscaffolded ammonia borane may be responsible for this change in the characteristic physical properties of ammonia borane. The nanoconfinement could provide an alternative approach to modify the physical characteristics of other bulk hydrogen storage materials to obtain enhanced dehydrogenation and rehydrogenation properties. The investigation of the phase transformation behavior of ammonia borane at low temperature down to $90 \mathrm{~K}$ and high pressure up to $15 \mathrm{GPa}$ using in situ Raman spectroscopy has revealed four new phases with distinct features in their Raman spectra. The slope of the pressure dependence Raman shifts also enhances the evidence of these phase transformations. All these pressure-temperature induced phase transformations are reversible. Raman 
spectroscopy was also used to investigate the bonding behavior of lithium amidoborane structure and the phase stability of lithium amidoborane at high pressure and room temperature. In the lithium amidoborane structure, the bonding behavior is significantly altered than its parent compound ammonia borane. The characteristic dihydrogen bonding of ammonia borane, is absent in lithium amidoborane. This phenomenon is evidenced by the blueshift of $\mathrm{N}-\mathrm{H}$ stretching frequency with pressure compared to its parent compound ammonia borane. B-H bonding becomes weaker in lithium amidoborane structure, which will show more reactivity in dehydrogenation. The different bonding characteristics are likely responsible for improved dehydrogenation behavior of lithium amidoborane. The Raman spectroscopy study and optical microscopy study identifies two phase transitions of lithium amidoborane at high pressure and room temperature. The first phase transition occurs at $3.9 \mathrm{GPa}$ and the second phase transition occurs at $12.7 \mathrm{GPa}$. These new phases are likely to have more volumetric hydrogen content. Synchrotron X-ray diffraction indicated only one phase transition occurring at 9.6 GPa. The first pahse transition observe at around 3.9 GPa through Raman spectroscopy may be an isostructural phase transition.

\subsection{Future Scope of this Work}

- Further work is needed for Raman mode assignment for the observed new phases of ammonia borane at low temperature and high pressure region. Neutron and $\mathrm{x}-$ ray diffraction can be carried out to investigate the structural details of these four new phases.

- Lithium amidoborane has significantly different bonding characteristics than its parent compound. Future Neutron diffraction study is required to further 
investigate the phase transition and the absence of dihydrogen bonding phenomenon.

- The reactivity of $\mathrm{N}-\mathrm{H}$ and/or B-H of lithium amidoborane can be tuned by substituting protonic and/or hydridic hydrogen by more electroposive and/or electronegative elements. If both of the $\mathrm{N}-\mathrm{H}$ and $\mathrm{B}-\mathrm{H}$ bonding can be made weaker by simultaneously substituting protonic and hydridic hydrogen, then dihydrogen bonding may appear in the structure, which may dehydrogenate more easily than lithium amidoboranes. It will open the opportunity for the design of new potential hydrogen storage material.

- Lithium amidoborane can be nanoconfined in mesoporous silica and the dehydrogenation study of nanoconfined lithium amidoborane can be carried out. It is expected that nanoconfined lithium amidoborane will exhibit improved dehydrogenation property than its parent coumpound ammonia borane, as lithium amidoborane has favorable bonding characteristics for dehydrogenation than the parent compound ammonia borane.

- The phase diagram of ammonia borane can be expanded to the high pressure and high temperature region also, which will provide a broadened view of all the possible phases of ammonia borane. Among all these phases, certain phases may have superior hydrogen storage property and those phases may be explored more to find a suitable hydrogen storage material.

- From the application point of view, the rehydrogenation is very important requirement for the hydrogen storage material and the rehydorgenation of ammonia borane and lithium amidoborane is yet to be explored. Further study can 
be carried out to explore the rehydrogenation behavior of these materials under high pressure. 


\section{APPENDIX}

\section{High-pressure study of lithium amidoborane using Raman spectroscopy and insight into dihydrogen bonding absence}

\begin{abstract}
Shah Najiba ${ }^{a+1}$ and Jiuhua Chen ${ }^{a b, 1}$
One of the major obstades to the use of hydrogen as an energy One of the major obstades to the use of hydrogen as an energy
carrier is the ladk of proper hydrogen storage material. Lithium amidoborane has attractud significant attention as hydrogen storsge material. It relesses $\sim 10.9$ wt $\%$ hydrogen, which is be. yond the Department of Energy target at remarkably low tempersture $\left(\sim 90^{\circ} \mathrm{C}\right)$ without borazine emission. It is essential to study the bonding behavior of this potential material to improve it de Iydrogenation behavior further and also to make mhydrogens. tion possible. We have studied the high-pressure behavior of lithlum amidobonne in a diamond anvil cell using in situ Raman spectroscopy. We have discovered that then is no dillydirogen bonding in this material, as the $\mathrm{N}-\mathrm{H}$ stretching modes do not show redk hift with pressure. The absence of the dilydrogen bond ing in this material is an intews sting phenomenon, as the difhydro. gen bonding is the dominant bonding feature in its pasent compound ammonis borane. This observation may provide guid. ance to the improvement of the hydrogen stonge propertes of this potential material and to design new material for hydrogen storage spplication. Also two phase transitions were found at high pressure at 3.9 and $12 \mathrm{~J} \mathrm{GPa}$, which are charactarized by sequen tial changes of Raman modes.
\end{abstract}

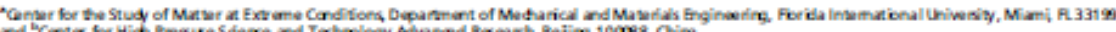

Hydrogen eoonomy has been considered as potentially effi Cient and envirummental friendly alternative energy solutic (1). However, one of the most important scientific and technical chelle safe and eccincmically viahle on bourd hydrogen starage for fuel cell applications, expedially to the tramportation sector. Am monia borane ( $\left.\mathrm{BH}_{3} \mathrm{NH}_{3}\right)$, a solid state hydrogen stor age material, posteses exceptionally high hydrogen content (19.6 wi and in particuar, it arntains a wrique an dimation of protcinie and hydridic hydrogen, and on this basis, offers new opportuni. ties for devekning a practical source for generating molecular dilydrogen (2-5). Steppisice relase of $\mathrm{H}_{2}$ takes place through thermolysis of ammonia borane, yolding one-third of its toth hydrogen content ( $6.5 \mathrm{wt} \%$ ) in each heating step, along with emixion of trvic borazine (6-8). Recently, reseanch interes ts are focusing on how to improve dixcharge of $\mathrm{H}_{2}$ from ammoria borane, induding kwering the dehydrogenation temperature and enhanaing hydrogen release rate wing different techniques, eg, nanoscaffolds (9), imic liquids (10), acid catalysis (11), hase metal atabyst (12), or transition metal catalyst $(13,14)$. More recently, significant atten bion is give $n$ to chemical modification of mmoria borane through substitution of cine of the protonic hydrogen atcims with an allali or allaline-earth element (15-21) Lithium amidoworane ( $\left.\mathrm{LNH}_{2} \mathrm{BH}_{2}\right)$ has bean sucessfully syn thesized by ball milling LiH with $\mathrm{NH}_{6} \mathrm{BH}_{3}(15-18)$. One of the driving forces suspested for the formation of $\mathrm{LiNH}_{2} \mathrm{BH}_{3}$ is the chemical potential of the protonic $\mathrm{H}^{\delta+}$ in $\mathrm{NH}_{3}$ and the lyydridie $\mathrm{H}^{\delta-}$ in alkali metal hydrides making them tond to combine, produding $\mathrm{H}_{2}+\mathrm{LiNH}_{2} \mathrm{BH}_{3}$. LiNH $\mathrm{BH}_{3}$ exhùit significanth different and inproved dehydrogenation characteristics from its

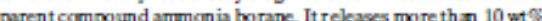
of hyctrogen at around $90^{\circ} \mathrm{C}$ without borazine emixion. $\mathrm{Akn}$, the

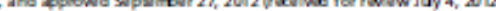

dehydrogenation process of lithium amidoborane is much less 然 $\left(\sim 3-5 \mathrm{kJmok}^{-1} \mathrm{H}_{2}\right)(15-17)$ than that of $\mathrm{NH}_{2} \mathrm{BH}_{3}$ $\left(\sim 22.5 \mathrm{kJmole}^{-1} \mathrm{H}_{2}\right)(6-8)$, which greatly en hances the search for sui tahle regeneration routes (prerequisite for a hydrogen starage material). Although the rationale behind the improwed dely. drogenation behwior is still undear, these improved property modicabom evidenty originate from the surstitution of one $\mathrm{H}$ in the $\mathrm{NH}_{3}$ group by the more electron donating $\mathrm{L}$, which exerts influences on the boinding characteristios, especially on the ditydrogen beinding, which is one of the character istic bonds of ammonia borane (15). So, it is essential to understand detaik ahout the bonding behwior of this potential material.

High-presure study of molecular aystak an provide unique insight into the intermolecular bonding forces, such as hydrogen bonding and phase stahility in hydrogen storage materiak and thus provides insight into the improvement of design $(22-30)$. For in stance, Raman spectroncopic study of ammonia borane at high pressure prowided insight about is phase tramition behwici and have investigated $\mathrm{LNNH}_{2} \mathrm{BH}_{3}$ at high pressure using $\mathrm{R}$ ampan spectrosoopy. We have found that, other than in $\mathrm{NH}_{3} \mathrm{BH}$, dity: drosen bonding is ahent in lithium amidoborane structure and $\mathrm{LiNH}_{2} \mathrm{BH}$ shows two phase transitions at high pressure.

\section{Results and Discussion}

We have used in situ Raman spectroscopy to characterize bonding changes in the sample. For collecting the Raman spectra at am hient condition, we have losded ammonia borane and lithium amidaborane samples into glass capillaries. Raman spetra (Fig.
1) of ammonia borane $(25-30)$ and lithium amidoborane (31) at ambient $\alpha$ nditicn have been well documented, and the major Raman modes can be described ty their molecular nature: $\mathrm{N}-\mathrm{H}$ strething, $\mathrm{B}-\mathrm{H}$ stretshing, and $\mathrm{B}-\mathrm{N}$ stretching modes. In the appear at lower wavenumbers compared with those of ammonia borane (Fig. 1), indicating that lithium amidchorane has weaker B-Hbond than ammonia borane. This observation is corkistent with the reportid $\mathrm{B}-\mathrm{H}$ bond strength by the previous $\mathrm{X}$-ray
studies $(15,18,31-34$. Likewise, both the $\mathrm{N}-\mathrm{H}$ and $\mathrm{B}-\mathrm{N}$ stucies $(15,18,31-34)$. Likewise, both the $\mathrm{N}-\mathrm{H}$ and $\mathrm{B}-\mathrm{N}$ stret hing mode in lithium amidoborane appear at higher wave-
numbers with respect to those in ammonia borane, ie, the $\mathrm{N}-\mathrm{H}$ and $\mathrm{B}-\mathrm{N}$ bonds beome stronger in lithium amidoborane, $\infty \mathrm{n}$ sistent with the prediction by Armstrong et al. regerding B-N bond strength $(35)$.

We have onducted diamond amil cell (DAC) experiments at room temperature on a lithium amidoborane sample from ambient presoure to $19 \mathrm{GPa}$. Two phase transformatiom are

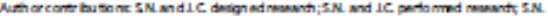

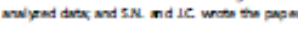

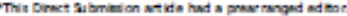

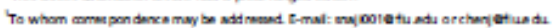
the presence of dilydrogen bonding in it structure (25-30). We Raman spectra, B-H stret.hing modes of lithium amidoborane

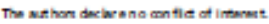




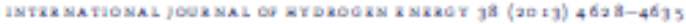

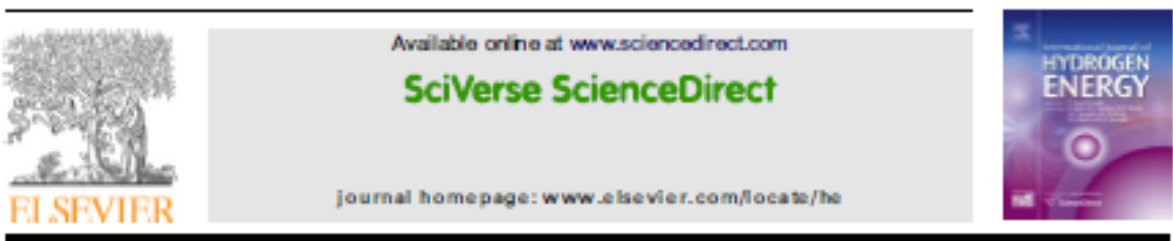

Ammonia borane at low temperature down to $90 \mathrm{~K}$ and high pressure up to $15 \mathrm{GPa}$

Shah Najiba*, Jiuhua Chen, Vadym Drozd, Andriy Durygin, Yongzhou Sun

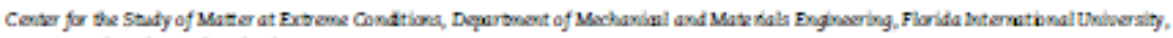
VH $14 Q$, Univerily Park, Miand, FL 33199, uSA

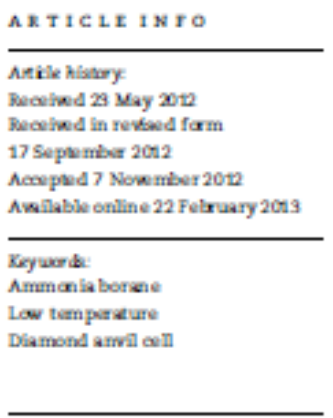

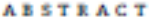

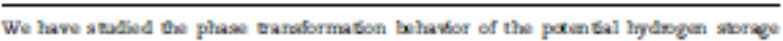
compound ammoni bonate at low wmpesature frrom room wmpesature down bo 90

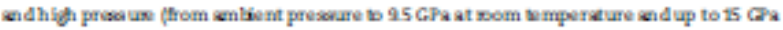

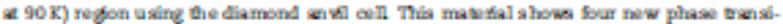

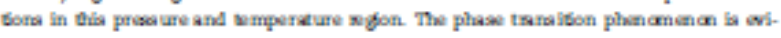

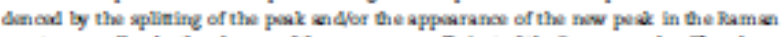

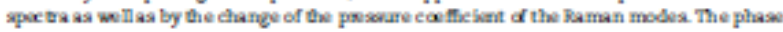
bamdeses betwen these phasen see abos establiahed from the data collorted during different colling geles. These results provide the information about the stabality of the

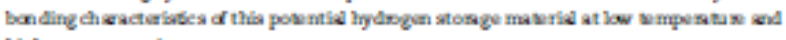
ligh prose use region.

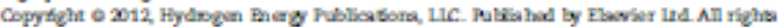

nowed.
\end{abstract}

1. Introduction

Ammorda borane (NH, $\mathrm{BH}$, ) has atractad sigrificant atrention as high potemtial hydrogen storze maverial due to its high gravimetric and wohumeric hydrogen density $[1-4\}$. Swpwise release of $\mathrm{H}_{2}$ takes place through thermolysia of ammonia borane, yleldingone third of its wtal hydrogen content $(6.5 \mathrm{wt}$ x) in ach heating step, along with the emiasion of toudic borazine $[2,3]$. Recently signifoant seserch interest be focusing on anmonia borane to lower the dehydrogenation temperature with an enhanced dehydrogenation rate using different techriques, eq. nancoscifolda [S, lonk liquida [6] and acid $[7,8]$ or transition metal catalys $t ; p, 10$. $A$ molecule of ammonda borane consis ts of protonic (NAH) and hydritic (RH) hydrogens bonded by the polarized dative bond. Thermal or catalyzed decomposition of ammonda borane requires brealing of the $\mathrm{N}-\mathrm{H}$ and the $\mathrm{B}-\mathrm{Hbonda}$. Til now, the detalad information about the bonding chancteriates of anmonia borane is not suffident to und ers tand detalls about it phases and structures.

At ambient condition, ammonia borane has the body cenved tetrgonal (14rmin) structure with dioorder in the position of $\mathrm{H}$ avoms $[9-14\}$. It tansforms from the diacrdered 14 mms tructure $v$ the ordernd orthorhombic $(P \operatorname{mon} 2)$ ) structure at the temperzure of $\sim 225 \mathrm{x} \mid 11,14]$. Recently, it has ben reportud that ammonis borrae embedded in mesoporous slica does not exhebit this bow wmperanure phase transition at $225 \mathrm{x} 115,16$. Presenure significantly affects the phrie stability of many hydrogen storage compounda and enhancad hydrogen storage propertes are also predicud by some theoredcal caloulationa $(17-19)$. For inatance, it has ben reported that under high presaure $\mathrm{NH}_{3} \mathrm{BH}_{3}-\mathrm{H}_{2}$ compound can be formed which can store 8-12 wox molecular hydrogen in additon to thechemically bound $\mathrm{H}_{2}$ in ammonia borane $[20)$.

\footnotetext{
- Cornoponding avehor.

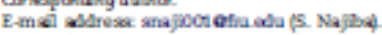

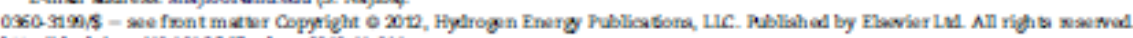

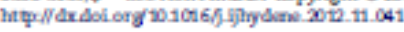


JOURNAL OF APFLIED PHYSKCS 111, 112618 (2012)

\title{
Tetragonal to orthorhombic phase transition of ammonia borane at low temperature and high pressure
}

\author{
Shah Najba, Jithua Chen, Vadym Drozd, Andrily Durygin, and Yongzhou Sun

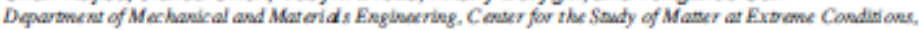

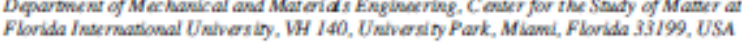 \\ (Received 27 A ugust 2011; accepted 5 Februry 2012; published online 15 June 2012)

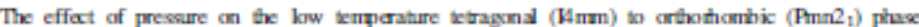 \\ tranition of a potential hydrogen stonge compound anmonia borne $\left(\mathrm{NH}_{3} \mathrm{BH}_{3}\right)$ was investigned in \\ diamond anvil cell using Raman spectroscopy. With applied pressure, the transition ocaus at higher \\ iemparature, which indicses that pressure ahances the andering of the structure. The positive Chapeyron \\ skpe of the transition was dedamined to be $\mathrm{dP} / \mathrm{dT}=\sim 25.7 \mathrm{MPa} / \mathrm{K}$, indicating the tras formation is of \\ exothermic. Appoarance of some of the charateristic Raman modes of arthothombic phase requires \\ undercooling of anound $\sim 15 \mathrm{~K}$ below the transition, indicating possible oxistence of $\mathbf{m}$ intemnediate \\ phase. $Q 2012$ American Instimuse of P hysics. [httq://dx.dai.arg/10.1063/1.4726236]
}

\section{INTRODUCTION}

Ammonix borane $\left(\mathrm{NH}_{3} \mathrm{BH}_{3}\right)$ has recently drawn great attertion as high potential hydrogen storage material due to high gravimetric and volumetric hydrogen density. ${ }^{1-4}$ How. ever, a fairly high temperature of $500^{\circ} \mathrm{C}$ is requiral to rekase all the hydrogen atoms. ${ }^{5}$ Recently, significant research effarts have been taken to kower the dehydrogens. fian temperature of $\mathrm{NH}_{3} \mathrm{BH}_{3}$ and to ahince the discharge rate of hydrogen using the nanoscaffolds," ioruic liquids," acid," and transition metal catalysts. ${ }^{9.10}$ In fact, the devdop. mert of methods to enhance hydrogen discharge rate foum ammonix borne requires a detailad study mout the struc. tural and dynamical properties that control the stahility and the intermolecular interations of this material.

Ammonia borane exhihits an unusual bonding system that is responsible for some unexpected physical properties. For example, its melting point $\left(104^{\circ} \mathrm{C}\right)$ is much higher than the isoelectronic $\mathrm{C}_{2} \mathrm{H}_{8}\left(-181^{\circ} \mathrm{C}\right)$. Part of this difference comes from the polarity of $\mathrm{NH}_{3} \mathrm{BH}$ (5.2 D). Howeva, the polar (1.8 D) $\mathrm{CH}_{3} \mathrm{~F}$ has a proparticnally much lower md ting point $\left(-140^{\circ} \mathrm{C}\right)$ elevation relative to ethane, so other factars might exist behind this unexpected property. One of the characteristic features of ammonis borane is tha due to the differing electronegativities of the $\mathrm{B}$ and $\mathrm{N}$ atoms, the hydrogen atoms have different charges. As nitrogen is strongly electronegative, the hydrogens bound to nitrogen are protoric $\left(\mathrm{H}^{\mathrm{S}}\right)$ in character; while borcn is less electronegative than hydrogen and thus the hydrogens bound to boron are hydridic $\left(\mathrm{H}^{3}\right)$ in character. These two hydrogen species form a network of $\mathrm{N}^{3} \mathrm{H}^{3+} \ldots{ }^{-s} \mathrm{H} \cdot \mathrm{B}$ dihydrogen bond and stahilizes the structure as solid due to umusually shart $\mathrm{H}$... H distance:

Pressure and temperature has a significart effect on the structural stahility of this molecular solid. At amhient condifion, ammonia borane crystallizes as body centered tetragorel $(14 \mathrm{~mm})$ structure, ${ }^{10-15}$ which transforms to the kow temperature orthorhombic $\left(\operatorname{Pmn} 2_{1}\right)$ phase at $\sim 218-225 K$ during cooling ${ }^{14,15}$ and to the high pressure orthorhombic phase $\left(\mathrm{Cmc} 2_{1}\right)$ at $\sim 1.3-2.4 \mathrm{GPa}$ during compression. ${ }^{10-3}$ These tmnsitions result in a significant change in the bitice dyramics although the molecular strudure of $\mathrm{NH}_{3} \mathrm{BH}_{3}$ mole. cule is preserved. In the $14 \mathrm{~mm}$ phase, the molecular axes ane aligned along the batice $\mathrm{c}$ axis, while the molecular aves become inclined rebative to the $\mathrm{c}$ axis in these two orthorhombic phases. The pressuretemperature phase boundery between the 1 amm phase and $\mathrm{Cmc} 2_{1}$ phase has been deter mined which has a negative Clapeyron skope indicafing the transfomnation is of endothermic. ${ }^{2}$ However, there is no study about the pressure-temperature phase boundary between the 1 Amm and low tampersure ortharhomhic Pmn?, phases. Rexndly, this transition atracts more attention because of the ahsence of this transition in ammoria borsne embedded in mesoporous silica which reduces dehydrogens. fion temperature significantly. ${ }^{21,22}$ Therefore, it is importart to understand details ahout this phase transition. Hare, we report a Raman spectrosocopic study of the 1 Amm to Pmn 2, phase tansformation at high pressures.

The paper is orgarized as follows. Finst, we give all nec. essary information on experimental techniques we used. Secand, we describe our experimental data to chancterize the room iemperature tetragomal phase and kow temperature arthorkmbic phese to compare with the previous stady about characteristic Raman modes of this material. Thixd, we describe the effect of annealing time at the onset trankition cempenture on the appearance of all charateristic Raman modes of artharhombic phase. Finally, we plotied the pressure-temperature data collected during different cooling cycles and describe the phase boundary between these two phases. The aim of this study is to obtain the phase boundery between $4 \mathrm{~mm}$ and $\mathrm{Pmn}_{1}$ phases. So, the pressure range studied in this experiment is kept well below the pressure at which the Cmc2 2 phase transition starts at room temperature.

\section{EXPERIMENTAL}

The experiment was carried out with ammoria borane powder purchased from Sigma Aldrich, with a purity greater 


\section{Raman Spectroscopy of Ammonia Borane at Low Temperature and High Pressure}

Maria D. Salazar-Villalpando, Neale R Neelameggham, Donna Post Guillen, Soobhankar Pati, Gregory K. Krumdick

Shah Najiba, Jiuhua Chen, Vadym

Drozd, Andriy Durygin, Yongzhou Sun

Published Online: 15 MAY 2012

DOI: $10.1002 / 9781118365038$.ch40

Copyright (9) 2012 The Minerals, Metals, \&

Book Title

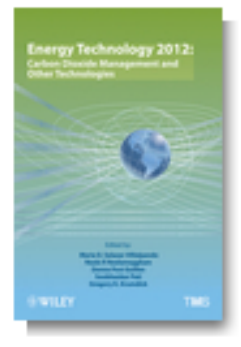

Energy Technology 2012:

Carbon Dioxide Management and Other Technologies

Additional Information (Show All)

How to Cite | Publication History | ISBN Information

\section{Summary Chapter References}

\section{Keywords:}

ammonia borane,

diamond anvil cell;

high pressure;

low temperature

phase transition

Summary

This chapter contains sections titled:

Introduction

Experimental

Results and Discussions

Conclusion 
VITA

SHAH NAJIBA

$2002-2007:$

B. Sc. in Materials \& Metallurgical Engineering Bangladesh University of Engineering \& Technology Dhaka, Bangladesh

2007 - 2009:

M. Sc. in Materials \& Metallurgical Engineering Bangladesh University of Engineering \& Technology Dhaka, Bangladesh

2009 - 2014:

Doctoral Candidate in Materials Science \& Engineering Florida International University

Miami, USA

AWARDS, HONORS AND VOLUNTEERING ACTIVITIES

1) UGS Provost Award for Outstanding Manuscript, GSAW 2013, Florida International University.

2) Dissertation Year Fellowship (May 2013- December 2013) awarded by Florida International University.

3) Doctoral Evidence Acquisition Fellowship (January 2013-April 2013) awarded by Florida International University.

4) Won travel grant award to attend the MS\&T 2012 conference.

5) Won travel grant award to attend the COMPRES 2011 meeting.

6) Won travel grant award to attend the COMPRES 2012 meeting.

7) Won travel grant award to attend the National School on Neutron and X-ray Scattering 2012, organized by Argonne National Lab. and Oak Ridge National Lab., August 12-25, 2012.

8) Acted as the President for the organization "Material Advantage at FIU", January 2012- July 2013.

9) Acted as the Treasurer for the organization "Material Advantage at FIU", May 2011December 2011. 
10) Acted as the President for the organization "Bangladeshi Student Organization", August 2011- August 2012.

11) Organized the SMEC Meeting 2011 and SMEC Meeting 2013

\section{PUBLICATIONS}

1) High pressure study of lithium amidoborane using Raman spectroscopy and insight of dihydrogen bonding absence, Shah Najiba, Jiuhua Chen, the Proceedings of the National Academy of Sciences (PNAS), 109, 19140-19144 (2012).

2) Tetragonal to orthorhombic phase transition of ammonia borane at low temperature and high pressure, Shah Najiba, Jiuhua Chen, Vadym Drozd, Andriy Durygin, Yongzhou Sun, the Journal of Applied Physics 111, 112618 (2012).

3) Ammonia borane at low temperature down to $90 \mathrm{~K}$ and high pressure up to $15 \mathrm{GPa}$, Shah Najiba, Jiuhua Chen, Vadym Drozd, Andriy Durygin, Yongzhou Sun, the International Journal of Hydrogen Energy 38, 4628 (2013).

4) Raman spectroscopy of ammonia borane at low temperature and high pressure, $\underline{\text { Shah }}$ Najiba, Jiuhua Chen, Vadym Drozd, Andriy Durygin, Yongzhou Sun, , in Energy Technology 2012: Carbon Dioxide Management and Other Technologies, Edited by Maria D. Salazar-Villalpando, Neale R Neelameggham, Donna Post Guillen, Soobhankar Pati, and Gregory K. Krumdick, TMS (The Minerals, Metals \& Materials Society), 2012, pp 339-346.

5) $\mathrm{I} 4 \mathrm{~mm}$ to $\mathrm{Cmc}_{1}$ Phase Boundary of Ammonia Borane at Elevated Temperature by Raman Study, Yongzhou Sun, Jiuhua Chen, Vadym Drozd, Andriy Durigin, Shah Najiba, Xiaoyang Liu, (in the publication press of the International Journal of Hydrogen Energy). 